\title{
SEX ALLOCATION, DIET, AND SMALL POPULATION MANAGEMENT OF AFRICAN RHINOCEROS
}

By

Elizabeth Victoria Berkeley

\begin{abstract}
A thesis
submitted to the Victoria University of Wellington in fulfillment of the requirements for the degree of

Doctor of Philosophy in Biological Sciences
\end{abstract}

Victoria University of Wellington

2011 


\section{Dissertation Abstract}

The application of sex allocation theory can provide useful insight into endangered rhinoceros biology to improve in situ and ex situ conservation efforts by understanding the factors that cause a female to produce one sex of calf. By decreasing the birth sex ratio (number of males born per number of females born) in a population it may be possible to increase population growth rates. The first aim was to determine if an environmentally cued sex allocation response occurred in black rhinos. By examining rainfall and calf sex records in a wild black rhino population, I identified that birth sex ratios increase in rainy seasons and rainy years. Mothers were more likely to be observed with male calves if they conceived during the wet season $(57.3 \%$ male) than during the dry season ( $42.9 \%$ male). Mothers were more likely to raise male calves if they conceived during wet years $(60.2 \%$ male) than during dry years ( $46.1 \%$ male). Next, I examined whether pulsatile or random variation in sex ratios of different magnitudes, as might occur under changes in climate patterns, would be detrimental to rhinoceros population growth. Results demonstrated that while random increases in the magnitude of birth sex ratio variation, in either direction, increased population survival probability up to 0.907 , sequential pulsed years of birth sex ratio bias had the opposite effect on population performance down to a survival probability of 0.619 . Furthermore, for both scenarios, populations of less than 50 animals are particularly vulnerable to extinction. Since the sex biases observed in the captive rhinoceros population were attributed to several factors, I used an information theoretic approach to evaluate the relative importance of different hypotheses for birth sex bias for predicting calf sex. The results demonstrated that none of the models tested were greatly predictive of 
calf sex. Suspecting that the mechanisms that were cueing calf sex occur close to the time of conception and were nutritionally cued, in the final experiment, I measured changes in blood glucose in white rhinos after they ate different meals. At 90 minutes, serum glucose levels in rhinos eating the $10 \%$ lucerne hay diet were significantly lower than the $5 \%$ glucose and $10 \%$ glucose diets but not the $10 \%$ pellet nor $10 \%$ grass hay diets. This is the first time such an experiment has been published in a wildlife species and not only demonstrates the feasibility of training rhinos for successive blood draws but also that captive diets are low glycemic for white rhinos. Overall, my research confirmed that an environmentally cued sex allocation response does occur in African rhinos, and changes in the duration and magnitude of sex ratio patterns can decrease population growth and increase potential for extinction. Additionally, none of the previous hypotheses for the suspected male-sex bias in captive born rhinos were influential on calf sex, which shifts the focus of sex allocation research in rhinos to more acute signals around the time of conception, such as changes in diet and body condition. 


\section{Acknowledgements}

I would like to gratefully acknowledge my advisor Wayne Linklater, for providing me with this opportunity and all the guidance through these past several years. Ellen Dierenfeld, my co-author on Chapter 6, for her speedy emails, no matter what time zone, and her advice on all things nutritional.

There are a number of Hluhluwe-Imfolozi Park personnel, in South Africa, who contributed to the rhinoceros observations over the years. Thanks to Ezemvelo KwaZulu-Natal Wildlife, in particular Sue van Rensburg, Lulama Falayo and Craig Reid. Thank you to CBSG for providing the Vortex program used in this study and to Kathy Traylor-Holzer for feedback on the model specifications. Renco Corporation provided the A-mode ultrasound and the recalibrations, Ben Farmer for the limited edition rhino height stick. Samantha Kudeweh for her constant support and opening doors for getting me access to rhinos in Australia and New Zealand, Veterinarians Mike Goold, Andrew Gore, Brenna Barber, Monique Tydens and other Massey vet students, Nat Sullivan, John Potter, keepers at Auckland Zoo, Hamilton Zoo, Western Plains Zoo, Monarto Zoo, Werribee Zoo, Cleveland Zoo, Columbus Zoo, Cincinnati Zoo, Ray Ball for performing the B-mode ultrasounds and Derek Weatherford at Busch Gardens; Vickie Steele and Scott Citino at White Oak Conservation Center. Kind regards to the registrars, studbook keepers, ISIS, and keepers worldwide who diligently collated the data used for this study. The Rhino Resource Center provided access to so many journal articles and hard to find 'gray' literature. It's been great working with members of The International Rhino Keepers Association on this project and I look forward to continued collaborations on their goal of maintaining healthy captive rhinos of all species. 
All the folks at the School of Biological Sciences, particularly the Admin Ladies: Lesley, Mary, Sandra, Patricia, Delwyn and the Admin Man Paul, for assistance and endless laughs. Faculty from the School of Biological Sciences including Phil Lester, Ben Bell, Ken McNatty, Paul Teesdale-Spittle and all the rest for their support and collegiality.

Students of the School for Biological Sciences, including the best German officemates ever, Peter and Nicolai, and my previous officemates, Wan, Nik and Gaius. The other early members of Wayne's group: Jay, Monica, Roz, Barnaby, Roan, Jennifer, Ray, and Ian for their support and intellectual insight throughout this PhD process. All the other SBS students, too many to list, but particularly Elizabeth Heeg, Heidy Kikillus and especially Catherine Duthie, for her unwavering friendship. I look forward to our future collaborations!

This dissertation research was supported by a Victoria University of Wellington PhD Scholarship and PhD Submission Scholarship, with additional support from the School of Biological Sciences. Funding for this project was provided by the International Rhino Foundation through a grant to Wayne Linklater.

A special thanks to the VUW Information Technology Services Department: Janet, Ruth, Jan, Bruce, Vincent, Craig and all the other folks for the perfect parttime job and the stellar computer support. Special gratitude to Lynn Phillips for her calming influence through the final year of writing.

My families, both Berkeley and Reynolds for their unwavering support, financial and emotional, and particularly my Mom for her constant cheerleading.

This $\mathrm{PhD}$ research has been a lot of fun to do and $\mathrm{I}$ hope it is of some use to my fellow biologists and to the rhinos. 
Table of Contents

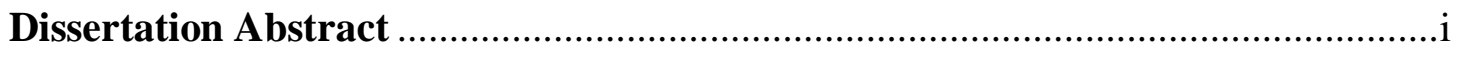

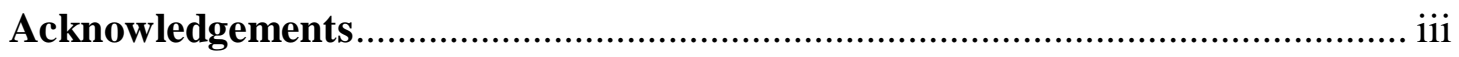

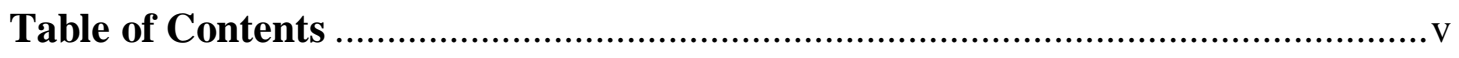

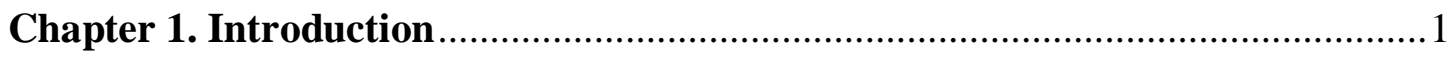

1.1. Biased sex ratios are observed in captive rhinos .......................................... 1

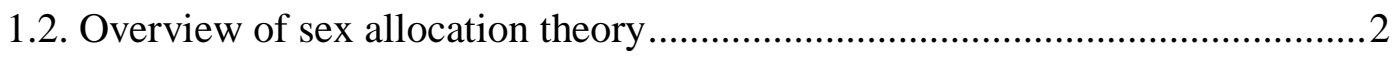

1.3. The problem of biased sex ratios in small populations ...................................5

1.4. A description of rhinoceros species and their population status .....................6 6

1.5. Description of experimental approach..................................................... 7

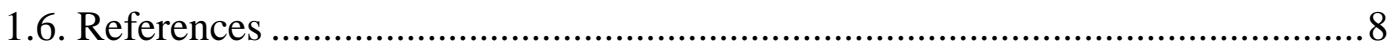

Chapter 2. Annual and seasonal variation in rainfall may influence progeny sex ratio in the black rhinoceros (Diceros bicornis) ................................................... 14

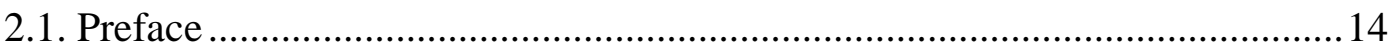

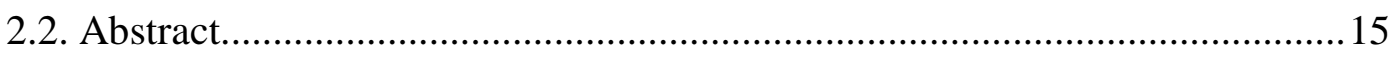

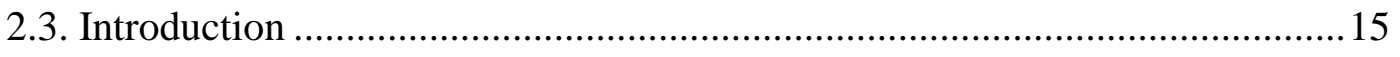

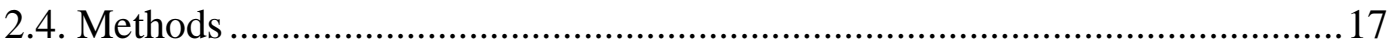

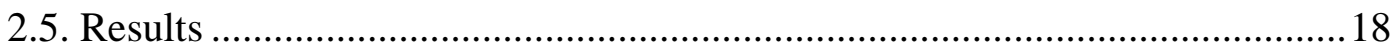

Figure 2.5.1. Monthly rainfall $(\mathrm{mm})$ in Hluhluwe-iMfolozi Park in South Africa from 1989 to 2004. Monthly rainfall (mm) from 1989 to 2004 at the northern (wet, $\bullet$ ) and southern (dry, ○) rainfall stations of Hluhluwe-iMfolozi Park (Research Station and Makhamisa Station, respectively). The black portion ( $\square$ ) of the horizontal axis indicates our classifications of the rainy season and the clear portion $(\square)$ the dry season.

Figure 2.5.2. Annual rainfall $(\mathrm{mm})$ in Hluhluwe-iMfolozi Park in South Africa from 1990 to 2004. Annual (October to September) variation in mean ( $\pm 1 \mathrm{SE}$ ) rainfall from 1990 to 2004. The horizontal line indicates average annual rainfall over all years. Years with rainfall higher and lower than the average were classified as wet and dry years, respectively. ..................................................220

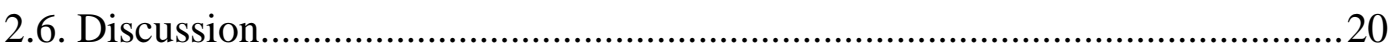

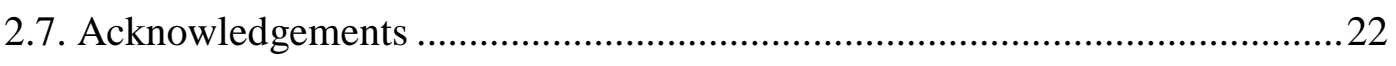

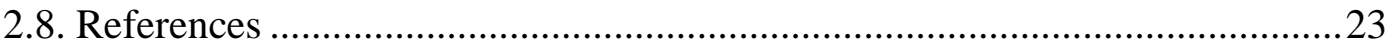

Chapter 3. Changes in rhinoceros birth sex ratio periodicity can increase

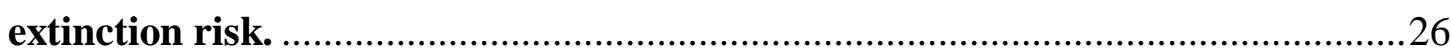


Figure 3.1.1 White rhino mother and calf, Hluhluwe-Imfolozi Park, South Africa (photo credit: Roan Plotz)...............................................................2

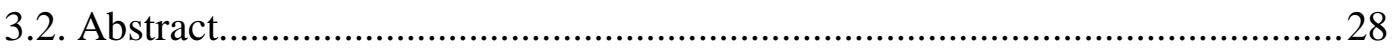

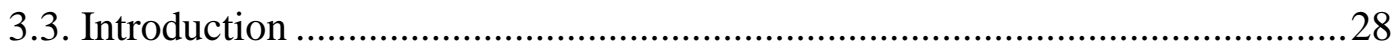

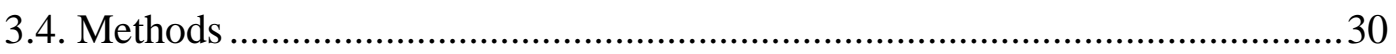

Table 3.4.1. List of parameters and variables used for all scenarios in this study.

3.5. Results .35

Table 3.5.1 Survival probabilities of populations with randomized birth sex ratios (+/- $0,0.5$, and 1.0 standard deviations).

Table 3.5.2 Survival probabilities of populations with randomized birth sex ratios (+/- 2.0 standard deviations).

Table 3.5.3 Survival probabilities of populations with five year pulsed birth sex ratios (+/- $0,0.5$, and 1.0 standard deviations).

Table 3.5.4 Survival probabilities of populations with five year pulsed birth sex ratios (+/- 2.0 standard deviations).

3.6. Discussion

3.7. References

\section{Chapter 4. An information theoretic multi-model analysis of long-term} studbook records to test hypotheses for birth sex bias.

4.1. Preface 48

4.2. Abstract. .49

4.3. Introduction 49

4.4. Methods

Table 4.4.1. A list of the models using in this study, the predictors they contain, and their supporting literature. .53

4.5. Results .56

Table 4.5.1. Summary of the 14 candidate models for influences on black rhino calf sex $(n=464$ calves). The models are in descending order indicating the most to least supported based on the change in the deviance information criteria $(\triangle \mathrm{DIC}), \mathrm{pD}=$ estimated number of parameters in the model, $*=$ these models include data at multiple levels.

Table 4.5.2. Summary of the 13 candidate models for influences on white rhino calf sex ( $n=693$ calves). The models are in descending order indicating the most to least supported based on the change in the deviance information criteria 
$(\triangle \mathrm{DIC}), \mathrm{pD}=$ estimated number of parameters in the model, $*=$ these models include data at multiple levels.

Figure 4.5.1.(On previous two pages) Parameter estimates from posterior densities and scaled effect size of coefficients for each predictor in the leading models. For black (A) and white (B) rhinoceros calf sex (female 0, male 1) that received some support (i.e., $\Delta \mathrm{DIC} \leq 2$, Tables 4.5.1 and 4.5.2). The open circle (O) represents mean parameter (coefficient) estimate and the horizontal lines represent their credible intervals. A value of zero indicates that the predictor had no influence on calf sex. A positive value indicates a positive relationship between the predictor and calf sex. To calcualate effect size, coefficients were scaled by multiplying each by two standard deviations of the corresponding predictor and converting to absolute values for comparison of their relative effect size.

4.6. Discussion

4.7. References

Chapter 5. Dietary impact on circulating glucose profiles in the white rhinoceros.

5.1. Preface

Figure 5.1.1. Hand held glucose meter and blood glucose results from a white rhino female in a restraining chute at the Hamilton Zoo, Hamilton, New Zealand.

5.2. Abstract. .72

5.3. Introduction .73

5.4. Materials and Methods .76

Table 5.4.1. Nutritional constituents of meals used in this study. .78

5.5 Results: 80

Figure 5.5.1. Zeroed changes in blood glucose values in white rhinos fed meals varying in digestible energy ( $\%$ of total daily DE intake) $\circ=10 \% \mathrm{DE}$ lucerne hay, $\bullet=10 \%$ DE glucose, $\square=5 \%$ DE glucose, $\bullet=10 \%$ DE pellets, $\square=10 \%$ DE grass hay ( $\mathrm{n}=6 ; \pm$ s.e.m.). For each meal, an additional $5 \mathrm{~kg}$ of grass hay was provided ad libitum.

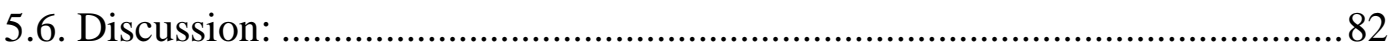

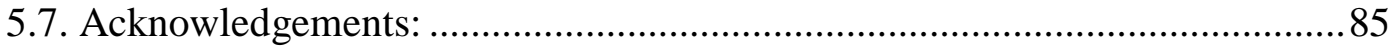

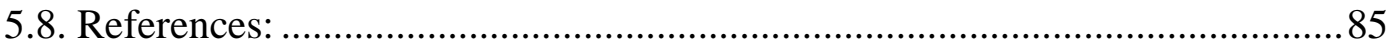

Chapter 6. Synopsis. Understanding the role of sex allocation theory explains biased sex ratios in rhinos and improves small population management.

6.1 Summary 


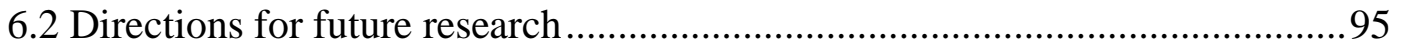

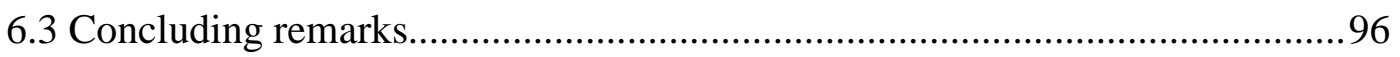

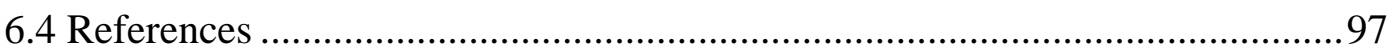

Appendix A. Quantification of black rhino and white rhino body condition by visual assessment, ultrasound, and morphometrics...........................................99

A.1 Preface .99

Figure A.1.1. Determining the suitability of a young male black rhino for blood collection, Western Plains Zoo, Dubbo, Australia. .99

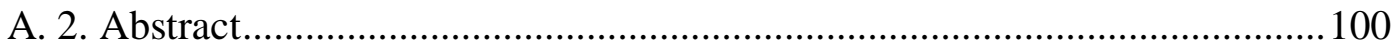

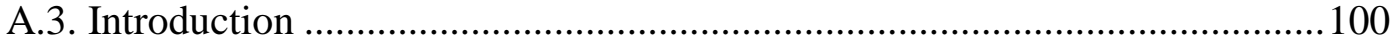

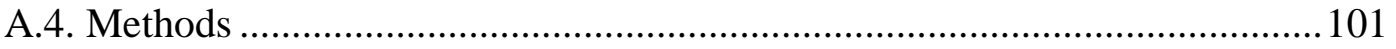

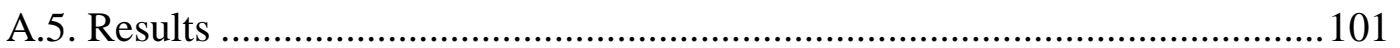

Table A.5.1. List of Research Trips, December, 2006-September, 2008......... 102

Table A.5.2 Body condition scores (BCS) from black rhinos and white rhinos.

Figure A.5.1. Weights and body condition scores .........................................104

Figure A.5. 2. Weight versus height correlation for white rhinos .................... 104

Figure A.5.3. Examples of black rhino B-mode transdermal ultrasound. ........ 105

Table A.5.3. Transdermal A-mode ultrasound results from white rhinos. ........105

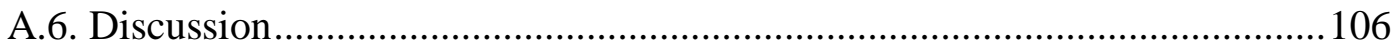

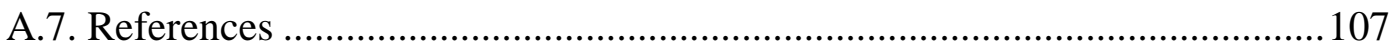

Appendix B. Changes in circulating glucose after oral glucose administration: a

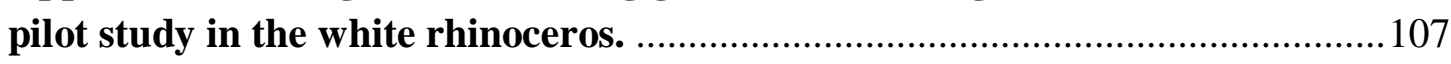

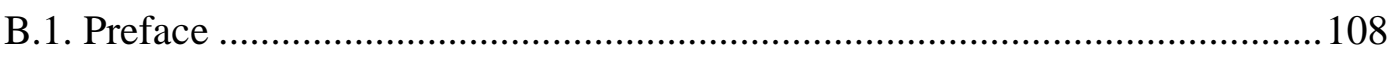

Figure B.1.1: Collecting blood from an unrestrained male white rhino at the Auckland Zoo, Auckland, New Zealand. ......................................................108

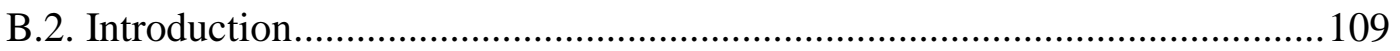

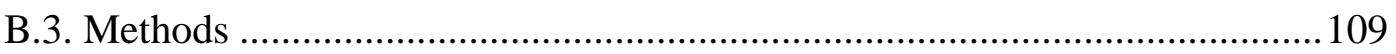

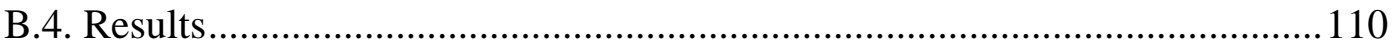

Figure B.4.1. Change in white rhino blood glucose values after eating 5\%

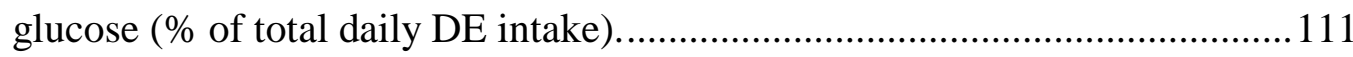

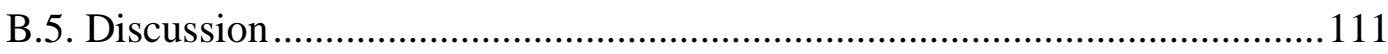

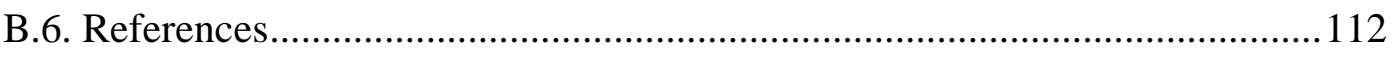

Appendix C. Conference presentations.............................................................113 
C.1. Berkeley, E.V. and W. L. Linklater: The Effects of Changes in Body Condition on Rhinoceros Birth Sex Ratios: Initiation of a Worldwide Zoo Research Study. In: Proceedings of the 2007 Australasian Regional Association of Zoos and Aquariums, Wellington, New Zealand.

C.2. Berkeley, E.V. and W. L. Linklater: Effects of Diet on Glucose Levels and Subsequent Birth Sex Ratios in Rhino Species, Rhino Keeper Association 5th International Meeting, Melbourne, Australia, May, 2007.

C.3. Berkeley, E. V. and W. L. Linklater. Assessing Body Condition in Rhinos. Crissey Zoo Nutrition Symposium, Raleigh, North Carolina, December, 2007 .. 114 C.4. Berkeley, E.V. and W. L. Linklater. The Effect of Elevated Body Condition on Birth Sex Ratios in Rhinos. Crissey Zoo Nutrition Symposium, Raleigh, North Carolina, December, 2007.

C.5. Berkeley, E. V. and W. L. Linklater. Blood glucose profiles in response to different diets in white rhinoceros (Ceratotherium simum). In: Proceedings of the 7th International Conference on Behaviour, Physiology and Genetics of Wildlife, Berlin Germany, September 2009. 


\section{Chapter 1. Introduction}

\subsection{Biased sex ratios are observed in captive rhinos}

The application of sex allocation theory to explain biased sex ratios can provide useful insight into endangered rhinoceros biology and improve in situ and ex situ conservation efforts. The ratio of males to females influences population growth and by increasing the number of females born, the generation doubling time is decreased. In the 1990's a pattern was observed in the captive African rhinoceros (Diceros bicornis: Perissodactyla, Linnaeus, 1758; Ceratotherium simum simum: Perissodactyla, Burchell, 1817) population in North America - a perceived excess of male rhinos were being born. Too many males are a problem for captive rhino managers. Rhinos are polygynous, where one male breeds many females.

Additionally, rhinos compete for access to females, with the fittest male holding off his competitors and breeding many females. Since one male is sufficient to breed many females, having an excessive number of males in a captive or reserve setting adds to an institution's financial and logistical burden. What are the factors in rhinoceros' innate biology that are driving the production of excess male calves? This research attempts to elucidate the factors that select male calves and suggest strategies for normalizing birth sex ratios in captivity and in small populations in the wild. This chapter introduces sex allocation theory and its application in small population management of endangered species, particularly rhinos, and rhinoceros biology and conservation. 


\subsection{Overview of sex allocation theory}

Sex allocation theory explains that a mother will partition resources to the offspring sex that offers her greatest fitness gain. Sex allocation, though briefly mentioned by Charles Darwin (1871) as an issue of some concern for evolutionary theory, was not further explored until Fisher (1930). Fisher identified that there will always be equilibrium between the sexes within a population in a frequency dependent manner. As one sex becomes rarer in the population, the mother that has the greatest reproductive variance of producing the rarer sex will have greater reproductive fitness and her offspring will be most successful. As the rarer offspring sex becomes the most frequent offspring sex, the pendulum will shift towards selecting mothers that produce the now rarer sex in the population. Thus a balance is maintained of the sex ratio in the population. Hamilton expanded on Fisher's model by applying mathematical modelling and empirical testing of sex allocation theory (Hamilton, 1967).

Numerous hypotheses have been proposed to explain sex allocation in vertebrates with $\mathrm{XY}$ chromosomal sex determination and why offspring sex ratio biases in both directions occur. Currently, chief among these for polygynous mammals is the Trivers-Willard hypothesis (TWH; 1973), closely followed by the local resource competition hypothesis (LRC; Clark, 1978; Silk, 1983). In polygynous mammals, where males compete for access to females for breeding, there is a fitness advantage to produce more competitive males, as they have the potential to outcompete their peers, thus resulting in higher reproductive success. Many mammals and birds fall into this grouping. In species with a large degree of parental investment, females in relatively good condition will tend to produce male offspring 
(Trivers and Willard, 1973). The TWH states that parents in good condition will invest in the sex of offspring that give the greatest reproductive benefit. In contrast the LRC states that where parents compete with their offspring for local resources, the parent in good condition will invest in the less competing/more likely to disperse sex (or invest in the more supportive/less likely to disperse sex).

As offshoots of these theories, numerous factors have been identified as influencing birth sex ratios in different species. A mother's ability to invest in the sex of her offspring has been correlated to her previous amount of investment in ungulates and other mammals (Drickamer, 1990; Robert, 2010), either as a consequence of her previous energetic investment in producing and raising progeny or as a reflection of her genetic fitness. Environmental cues can act to modify body condition, leading to production of the more costly sex during favourable times (Blanchard, 2005; Garroway and Broders, 2007). However it has also been observed that climatic cues such as rainfall and winter severity cause a female to invest more heavily in one sex apparently independently of the benefit to a dam's reproductive fitness (Post et al., 1999; Forchhammer, 2000). Individual characteristics such as age have been identified as an important predictor of offspring sex ratio in ungulates such as the Asiatic wild ass and reindeer (Saltz 2001, 2003; Weladji, 2003), though not in all species (Hewison et al., 2002). From this large body of research, it appears that multiple cues may work in tandem to influence calf sex and it is only recently that the specific physiological mechanisms have been suggested (i.e. Cameron, 2004; Rosenfield, 2004).

In several mammalian species, age has a demonstrated effect on birth sex in either a linear or polynomial relationship (Saltz and Kotler, 2003). Saltz (2001) reported a bell-shaped curve for the relationship in the Asiatic wild ass: younger and 
older females produce more females than mothers of prime breeding age (and inferred superior condition). The terminal investment hypothesis, a correlate to the TWH, states that females will increase production of the more costly offspring sex as they age (Clutton-Brock, 1984). Captive Nile lechwe (Kobus megaceros), a strongly sexually dimorphic polygynous ungulate, have a significant male birth sex ratio bias correlated with dam's age (Bercovitch et al., 2009). In contrast, Veeroja et al. (2010) found that moose in Estonia were more likely to produce male calves when they were yearlings and subadults but not as adults.

Stress has an apparent role in selection of offspring sex. Heifers that were superovulated, artificially inseminated and repeatedly stressed by frequent handling, blood collection and transrectal palpation, had a significantly higher number of female embryos than an unstressed control group (Ideta et al., 2009). In rhinos, Linklater (2007) found evidence that at least two different mechanisms may be driving birth sex ratio biases observed in rhinos stressed by translocation, depending on the time of the stress relative to conception. Other factors such as a female's reproductive history have been suggested to influence calf sex. For example, Monard (1997) identified in horses, that the sex of the previous calf was correlated to the following calf sex.

Other research that has focused specifically on rhinos has identified the following factors as important: subspecies, husbandry, captivity (Atkinson, 2002; Dennis, et al, 2007; Faust and Thompson, 2000). These papers used the rhinoceros studbooks as a data source, but were not explicitly testing hypotheses; rather they measured correlations which may have led to spurious results. 
1.3. The problem of biased sex ratios in small populations

Few papers have closely examined the roles of biased birth sex ratios for population performance in mammals, though many have acknowledged its important role in population growth (Ferrer et al., 2009; Wedekind, 2002). As the secondary sex ratio of a population increases (defined as the proportion of males to females at birth), the 'doubling time' of the generation increases, as fewer females are available to breed. A reproductive skew in small population can also cause a reduction in genetic fitness (i.e. in tuatara: Miller et al., 2009). Furthermore, the relationship between adult and progeny sex ratios, while understood in theory, is not well quantified in wild populations. While sex ratios at birth or juvenile sex ratios may be known, the consequences of early mortality, dispersal, and mating success on operative adult sex ratios are difficult to measure (Donald, 2007). The majority of reports of birth sex biases in captive populations are male-biased (Faust and Thompson, 2000), though there is a previous report of a female birth sex ratio bias in captive pygmy hippopotamuses (Zschokke, 2002).

Finally, there is the possibility of manipulating birth sex ratios as an aid in small population management. This strategy has been tested successfully in several species of birds: the Lesser Kestrel (Lenz et al., 2007), and kakapo (Robertson et al., 2006). But, to my knowledge, no one has applied this theory to mammals. If we can design strategies for shifting birth sex purposely in one direction or the other, that could aid in increasing the rate of population growth and improve conservation efficacy. If we can select for females as needed, we can shorten generation doubling times. 
1.4. A description of rhinoceros species and their population status

Five species of rhinos are extant and all species are considered threatened or endangered (IUCN, 2010). Three of the species are in Asia: the Javan Rhino (Rhinoceros sondaicus: Perissodactyla, Desmarest, 1822), Sumatran Rhino (Dicerorhinus sumatrensis: Perissodactyla, G. Fischer, 1814) and Greater OneHorned Rhino (Rhinoceros unicornis: Perissodactyla, Linnaeus 1758), and two are in Africa: the Black Rhino (Diceros bicornis: Perissodactyla, Linnaeus 1758) and the White Rhino (Ceratotherium simum simum: Perissodactyla, Burchell, 1817). White rhinos have the largest population size of the five extant species, with an estimated 17,475 wild rhino in Africa and 760 in captivity (Emslie, 2008, Milliken, 2009). There are an estimated 4230 black rhinos living in the wild in Africa and an additional 240 in captive breeding situations around the world (Emslie, 2008, Milliken, 2009). The Asian rhinos have far fewer animals left. The greater onehorned rhinos are an estimated population of 2800 in the wild and approximately 160 in captivity (Milliken, 2009). The Sumatran rhinos' population numbers are not well known, estimates range from 160 to 300 individuals with another 10 in captivity (Milliken, 2009). The Javan rhinos are almost extinct, with only 38-44 animals estimated in the wild and none in captivity. The main threats to the five rhino species continued existence, habitat loss and poaching for rhino horns. Currently, the best approach for rhino conservation involves keeping rhinos in most of their historic range states in numerous small reserves, parks with rhino protection units for guarding rhinos against the threat of poaching. 


\subsection{Description of experimental approach}

The overall goal of this thesis was to evaluate what factors drive birth sex ratio biases and how this information can be used to improve rhinoceros population growth both in captivity and in the wild. My $\mathrm{PhD}$ research is designed to have retrospective, prospective and experimental components, and is constructed of four individual but conceptually linked chapters. Because it is difficult to gather the types of data necessary on long-lived and small populations of endangered species, the combination of using long-term historical data and more influential experimental work is most likely to advance the field. All work in this dissertation is my own original research and those who contributed technical, veterinary, and logistical support were acknowledged in the general Acknowledgements section or specifically in the published chapters. Two of the chapters have been published, with co-authors Wayne Linklater on Chapter 2, and Ellen Dierenfeld and Wayne Linklater on Chapter 5, and the other two will be submitted for publication in the near future.

Chapter 2, "Annual and seasonal variation in rainfall may influence progeny sex ratio in the black rhinoceros (Diceros bicornis)" is a retrospective analysis of the relationship between rainfall levels, inferred available nutrition and black rhino birth sex ratios in the wild to determine a potential cue for sex allocation as has been observed in other large polygynous species (Berkeley and Linklater, 2010). In Chapter 3, "Population viability modelling of black rhinos birth sex ratios", I explored if hypothetical changes in the magnitude of the variations in birth sex ratios would increase the probability of population extinction rates. Chapter 4, "Hierarchical models of long-term studbook records to test hypotheses for birth sex bias" is another retrospective study using the historical information to test several 
hypotheses for birth sex bias in captive rhinos. Chapter 5, "Dietary impact on circulating glucose profiles in the white rhinoceros" is a series of feeding trials designed to validate that blood glucose variations in response to different diets can be measured in white rhinos (Berkeley, et al., 2010). Chapter 6 is a synopsis and synthesis of the body of research and contains suggestions for future avenues of research. The appendices contain results from several ongoing projects that have been started during this $\mathrm{PhD}$ period for assessing body size and condition in rhinos, the pilot dietary glucose study, and copies of abstracts from presentations I gave at the four conferences I attended during this degree.

\subsection{References}

Atkinson S. 1997. Possible determinants of skewed natal sex ratios in captive black and Indian rhinoceros in North America. International Rhinoceros Foundation. $81 \mathrm{p}$.

Bercovitch FB, Loomis CP, Rieches RG. 2009. Age-specific changes in reproductive effort and terminal investment in female Nile lechwe. Journal of Mammalogy 90(1):40-46.

Berkeley EV, Linklater WL. 2010. Annual and seasonal rainfall may influence progeny sex ratio in the black rhinoceros. South African Journal of Wildlife Research 40(1):53-57.

Berkeley, EV, Linklater, WL, and ES Dierenfeld. 2010. Dietary impact on circulating glucose profiles in the white rhinoceros. Journal of Animal 
Physiology and Animal Nutrition (Early View Access: DOI: 10.1111/j.14390396.2010.01047.x).

Blanchard P, Festa-Bianchet M, Gaillard J-M, Jorgenson JT. 2005. Maternal condition and offspring sex ratio in polygynous ungulates: a case study of bighorn sheep. Behavioral Ecology 16(1):274-279.

Cameron EZ. 2004. Facultative adjustment of mammalian sex ratios in support of the Trivers-Willard hypothesis: evidence for a mechanism. Proceedings of the Royal Society of London Series B-Biological Sciences 271(1549):1723-1728.

Clark AB. 1978. Sex ratio and local resource competition in a prosimian primate. Science 201(4351):163-165.

Clutton-Brock TH. 1984. Reproductive effort and terminal investment in iteroparous animals. American Naturalist 123(2):212-229.

Darwin C. 1871. The Descent of Man and Selection in Relation to Sex. London: Murray.

Dennis PM, Rajala-Schultz PJ, Funk JA, Blumer ES, Miller RE, Wittum TE, William JA. 2007. Risk factors associated with a skewed natal sex ratio in captive black rhinoceroses (Diceros bicornis) in the United States. Journal of Zoo and Wildlife Medicine 38(4):533-539.

Donald PF. 2007. Adult sex ratios in wild bird populations. Ibis 149(4):671-692.

Drickamer LC. 1990. Seasonal-variation in fertility, fecundity and litter sex-ration in laboratory and wild stocks of house mice (Mus domesticus). Laboratory Animal Science 40(3):284-288.

Emslie RH. 2008. Rhino population sizes and trends. Pachyderm 44(1):88-95. 
Faust LJ, Thompson SD. 2000. Birth sex ratio in captive mammals: Patterns, biases, and the implications for management and conservation. Zoo Biology 19(1):11-25.

Ferrer M, Newton I, Pandolfi M. 2009. Small populations and offspring sex-ratio deviations in eagles. Conservation Biology 23(4):1017-1025.

Fisher RA. 1930. The genetical theory of natural selection. Oxford Univ. Press. 272 p.

Forchhammer MC. 2000. Timing of foetal growth spurts can explain sex ratio variation in polygynous mammals. Ecology Letters 3(1):1-4.

Garroway CJ, Broders HG. 2007. Adjustment of reproductive investment and offspring sex ratio in white-tailed deer (Odocoileus virginianus) in relation to winter severity. Journal of Mammalogy 88:1305-1311.

Gerber LR. 2006. Including behavioral data in demographic models improves estimates of population viability. Frontiers in Ecology and the Environment 4(8):419-427.

Green M, Hunter M, Mann G. 2005. Relationships between maternal hormone secretion and embryo development on day 5 of pregnancy in dairy cows. Animal Reproduction Science 88:179-189.

Hamilton WD. 1967. Extraordinary sex ratios. Science 156(3774):477-488.

Hewison AJM, Gaillard JM, Blanchard P, Festa-Bianchet M. 2002. Maternal age is not a predominant determinant of progeny sex ratio variation in ungulates. Oikos 98(2):334-339.

Ideta A, Hayama K, Kawashima C, Urakawa M, Miyamoto A, Aoyagi Y. 2009. Subjecting Holstein heifers to stress during the follicular phase following 
superovulatory treatment may increase the female sex ratio of embryos. The Journal of Reproduction and Development 55(5):529-533.

IUCN. 2010. IUCN Red List of Threatened Species. <http://www.iucnredlist.org >

Lenz TL, Jacob A, Wedekind C. 2007. Manipulating sex ratio to increase population growth: the example of the Lesser Kestrel. Animal Conservation 10(2):236244.

Linklater WL. 2007. Translocation reverses birth sex ratio bias depending on its timing during gestation: evidence for the action of two sex-allocation mechanisms. Reproduction Fertility and Development 19(7):831-839.

Miller KA, Nelson NJ, Smith HG, Moore JA. 2009. How do reproductive skew and founder group size affect genetic diversity in reintroduced populations? Molecular Ecology 18(18):3792-3802.

Milliken T, Emslie RH, Talukdar B. 2009. African and Asian rhinoceroses: A report from the IUCN Species Survival Commission (IUCN/SSC) African and Asian Rhino Specialist Groups and TRAFFIC to the CITES Secretariat pursuant to Resolution Conf. 9.14 (Rev. CoP14) and Decision 14.89. Doha: IUCN. 1-18 p.

Monard AM, Duncan P, Fritz H, Feh C. 1997. Variations in the birth sex ratio and neonatal mortality in a natural herd of horses. Behavioral Ecology and Sociobiology 41(4):243-249.

Post E, Forchhammer MC, Stenseth NC, Langvatn R. 1999. Extrinsic modification of vertebrate sex ratios by climatic variation. American Naturalist 154(2):194-204. 
Robert KA, Schwanz LE, Mills HR. 2010. Offspring sex varies with maternal investment ability: empirical demonstration based on cross-fostering. Biology Letters 6(2):242-245.

Robertson BC, Elliott GP, Eason DK, Clout MN, Gemmell NJ. 2006. Sex allocation theory aids species conservation. Biology Letters 2(2):229-231.

Saalfeld ST, Ditchkoff SS, Ozoga JJ, Mitchell MS. 2007. Seasonal variation in sex ratios provides developmental advantages in white-tailed deer, Odocoileus virginianus. Canadian Field-Naturalist 121(4):412-419.

Saltz D. 2001. Progeny sex ratio variation in ungulates: maternal age meets environmental perturbation of demograpgy. Oikos 94(2):377-384.

Saltz D, Kotler BP. 2003. Maternal age is a predominant determinant of progeny sex ratio variation in ungulates: a reply to Hewison et al. Oikos 101(3):646-648.

Sheldon BC, West SA. 2004. Maternal dominance, maternal condition, and offspring sex ratio in ungulate mammals. American Naturalist 163(1):40-54.

Silk JB. 1983. Local resource competition and facultative adjustment of sex ratios in relation to competitive abilities. American Naturalist 121(1):56-66.

Trivers R, Willard D. 1973. Natural selection of parental ability to vary the sex ratio of offspring. Science 179:90-92.

Veeroja R, Kirk A, Tilgar V, Sade S, Kreitsberg M, Tonisson J. 2010. Conception date affects litter type and foetal sex ratio in female moose in Estonia. Journal of Animal Ecology 79(1):169-175.

Wedekind C. 2002. Manipulating sex ratios for conservation: short-term risks and long-term benefits. Animal Conservation 5:13-20. 
Weladji RB, Holand O, Yoccoz NG, Lenvik D. 2003. Maternal age and offspring sex ratio variation in reindeer (Rangifer tarandus). Annales Zoologici Fennici 40(4):357-363.

Zschokke S. 2002. Distorted sex ratio at birth in the captive pygmy hippopotamus, Hexaprotodon liberiensis. Journal of Mammalogy 83(3):674-681. 


\section{Chapter 2. Annual and seasonal variation in rainfall may influence progeny sex ratio in the black rhinoceros (Diceros bicornis).}

\subsection{Preface}

In order to understand the factors responsible for biased sex ratios observed in captive rhinos, I examined wild rhino biology. Sex allocation, or a mother's investment in one sex of offspring or the other, is known to occur in many animal species. Evidence in other ungulates, such as wild horses, suggests that the cues for differential sex investment are environmentally linked. With this in mind, I conducted a retrospective field-based analysis of the relationship between rainfall levels, inferred available nutrition and black rhino birth sex ratios.

This chapter was previously published as:

Berkeley, E. V. and W. L. Linklater. Annual and seasonal variation in rainfall may influence progeny sex ratio in the black rhinoceros. South African Journal of Wildlife Research 40:53-57, 2010.

Subsequent changes for inclusion in this dissertation are enclosed between brackets: [ ]. 


\subsection{Abstract}

Facultative sex allocation theories predict that animals will bias their offspring's sex in response to environmental cues. Biased sex ratios can be a problem when managing small populations in the wild or captivity. Using rainfall and calving records [from black rhinos (Diceros bicornis minor: Perissodactyla, Linnaeus, 1758)] in Hluhluwe-iMfolozi Park in South Africa, we compared seasonal and annual rainfall with calving rates and sex of the calves. Between 1989 and 2004, 159 calves were sighted soon enough after birth to reliably attribute their conception to a particular season and year. Conceptions were strongly seasonal, with most (73.6\%) occurring during rainy seasons and the remainder during dry seasons. Overall progeny sex ratio for the period 1989-2004 was 53.1\% male. Mothers were more likely to be observed with male calves if they conceived during the wet season (57.3\% male) than during the dry season (42.9\% male) in accordance with the Trivers-Willard hypothesis. Similar numbers of conceptions that resulted in calves occurred during wet and dry years (52.2\% of conceptions occurred during wet years). Mothers were more likely to raise male calves if they conceived during wet years $(60.2 \%$ male) than during dry years ( $46.1 \%$ male). Removal of males from small populations might be particularly important after a sequence of wet years to facilitate greater population growth.

\subsection{Introduction}

Sex allocation theory and empirical tests suggest that maternal energy balance around or soon after conception influences birth sex (Clout et al. 2002; Roche et al. 2006; Cameron \& Linklater 2007). Many species demonstrate changes 
in the birth sex ratio of their offspring in response to variation in food availability in accordance with predictions of sex allocation theory (Trivers \& Willard 1973; Silk 1983). Shifts in birth sex ratios have important implications for wildlife managers since they can limit population growth by reducing effective population size, especially in small and fragmented populations (Wedekind 2002). By better understanding the mechanisms and environmental cues that influence birth sex ratios, we can develop strategies for managing animals both in captivity and in small reserves.

Hluhluwe-iMfolozi Park (HiP), South Africa, has the largest endemic population of the black rhinoceros Diceros bicornis var. minor and one of the few original populations remaining in Africa. This population is of strategic importance as a source for the managed rhino metapopulation (Emslie \& Brooks 1999). Black rhinos in HiP show large variation in adult sex ratios across the park, though it is not clear whether this is due to management (i.e. selected removal of individuals for translocation) or a variation between the sexes in habitat preference (Reid et al. 2007). In African savannah habitats like those in HiP, range condition and the resources available to rhinoceros are closely related to rainfall because the availability of water strongly constrains plant growth (Emslie \& Adcock 1994; Fritz \& Duncan 1994). Previously, it was observed that birth sex ratios were positively correlated with rainfall in a small introduced population of black rhinos (Hrabar \& Du Toit 2005). Our aim, therefore, was to establish if progeny sex ratios in black rhinoceros responded positively to rainfall modifications of the environment as has been reported in other ungulate species (Kruuk et al. 1999a; Garroway \& Broders 2007). We expect wetter years and the wet season to correspond with the conception 
of more male calves. To this end, we obtained permission to use Ezemvelo KZN Wildlife's long-term database on rainfall and black rhinoceros calf sightings by field ranger patrols in HiP to investigate the influence of seasonal and annual differences in range condition on conception rates and subsequent birth sex ratios.

\subsection{Methods}

Data were collected in Hluhluwe-iMfolozi Park which is an approximately 90 000 ha park located between S 28.0000-28.43000, E 31.7160-32.0150 (Waldram et al. 2008). Annual rainfall is highly variable and seasonal, with wet warm summers and cool dry winters (Balfour \& Howison 2002; Waldram et al. 2008). Monthly rainfall (mm) from 1989-2004 was characterised from records made at two weather stations that represent the Park's wetter north and drier south. Annual rainfall was averaged for the 14 years beginning with the onset of the rainy season in October. Years were classified as wet or dry if they were above or below the calculated average, respectively.

By the end of the study period (1989-2004), HiP had an estimated 235 black rhinos (Clinning et al. 2009). Records of calves sighted with marked mothers by field rangers and the calf's sex and size-age class when first sighted were used to place the calf's conception into a year and season based on the 15.3 month gestation of black rhinoceros. By using this subset of calves we have assumed that there is not a sex bias in the detectability of male and female calves after birth. Although black rhinoceros mothers are known to hide their calves during the first months postpartum, there is no evidence that one sex is better hidden than the other (Berger 
1993). We compared conception rates and progeny sex ratios for calves conceived during wet and dry years and seasons. Progeny sex ratio results are reported as percent male and Fisher's exact tests used for all comparisons.

\subsection{Results}

Rainfall was strongly seasonal in Hluhluwe-iMfolozi Park (Figure 2.5.1). Annual rainfall ranged from 465.7 to $1164.4 \mathrm{~mm}$, and averaged $832.6 \mathrm{~mm}$ such that nine years were classified as wet years and six as dry years (Figure 2.5.2).

Between 1989 and 2004, 159 calves were sighted soon enough after birth to reliably attribute their conception to a particular season and year. Overall progeny sex ratio for the period $1984-2004$ was $53.1 \%$ male. Similar numbers of observed calves were conceived during wet and dry years $(52.2 \%$ of conceptions occurred during wet years). Conceptions were, however, strongly seasonal, with most (73.6\%) occurring during rainy seasons.

Mothers were more likely to be observed with male calves if they conceived during the wet season ( $57.3 \%$ male) than during the dry season ( $42.9 \%$ male) but the difference was only approaching significance (Fisher's exact test: $P=0.077, n=$ 159). Mothers were also more likely to raise male calves if they conceived during wet years (60.2\% male) than during dry years ( $46.1 \%$ male), although these results were also only approaching statistical significance (Fisher's exact test: $P=0.051, n$ $=159$ ). 


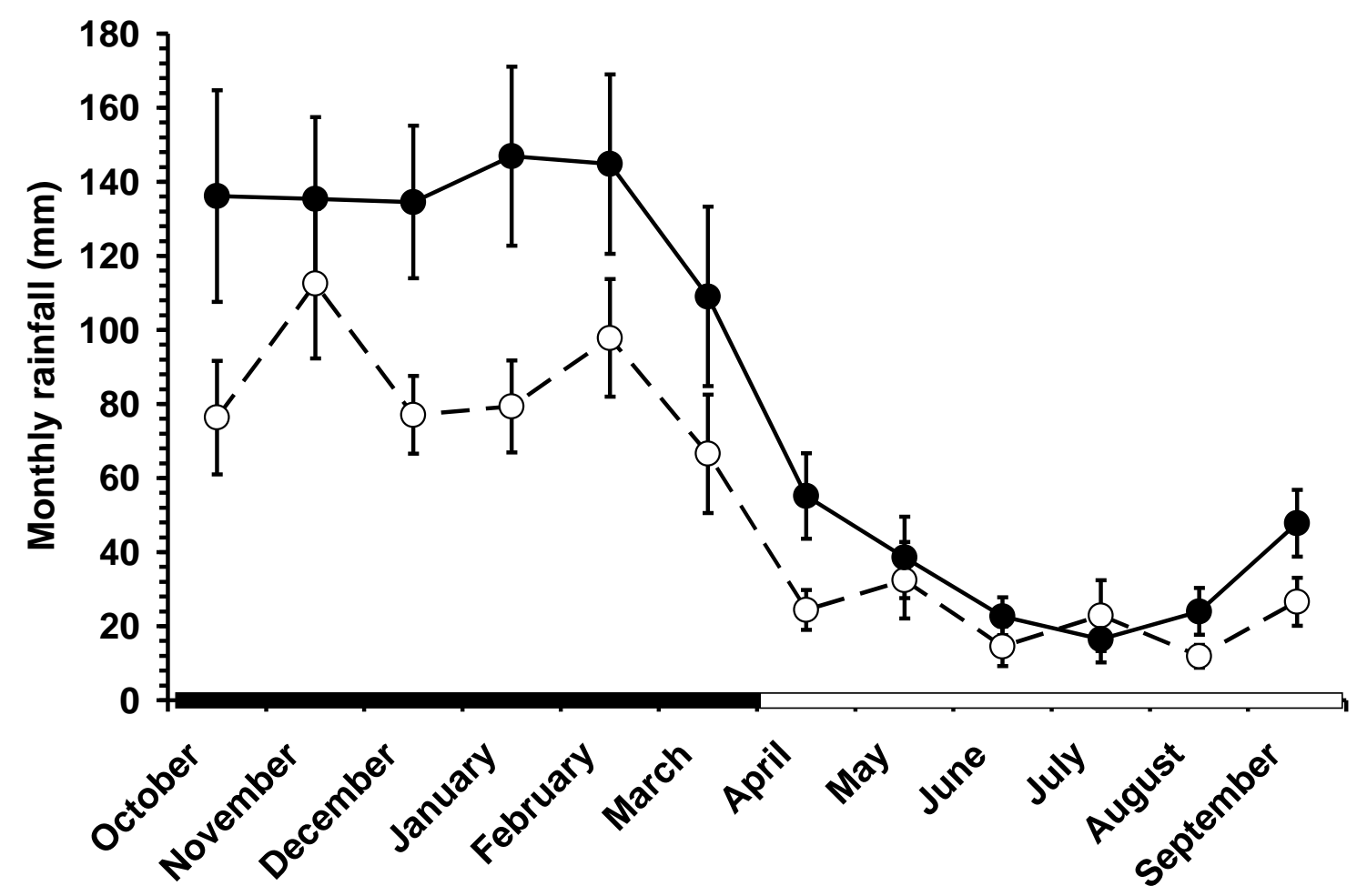

Figure 2.5.1. Monthly rainfall (mm) in Hluhluwe-iMfolozi Park in South Africa from 1989 to 2004. Monthly rainfall (mm) from 1989 to 2004 at the northern (wet, •) and southern (dry, ○) rainfall stations of Hluhluwe-iMfolozi Park (Research Station and Makhamisa Station, respectively). The black portion ( $\square$ ) of the horizontal axis indicates our classifications of the rainy season and the clear portion $(\square)$ the dry season. 


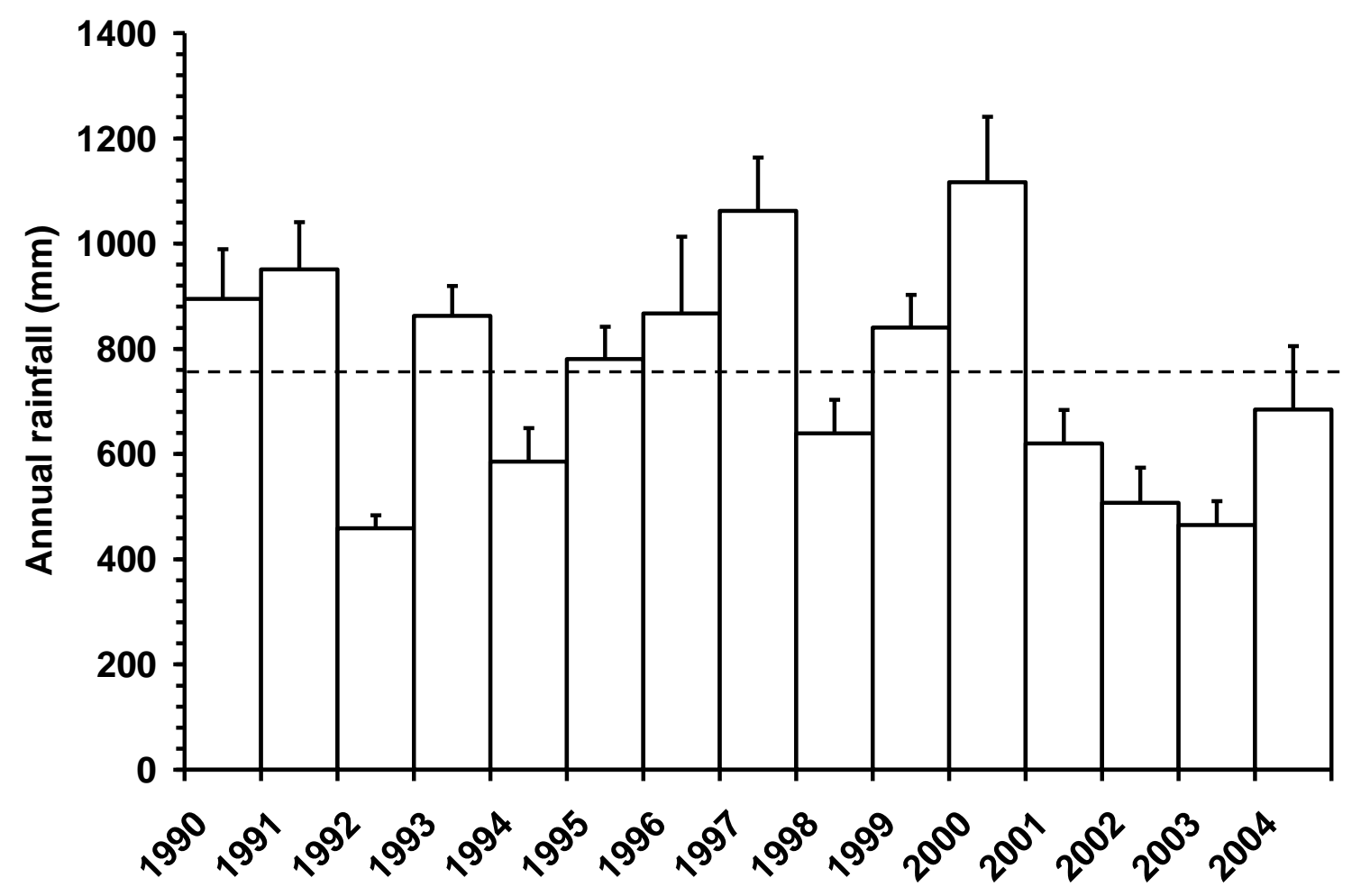

Figure 2.5.2. Annual rainfall $(\mathrm{mm})$ in Hluhluwe-iMfolozi Park in South Africa from 1990 to 2004. Annual (October to September) variation in mean ( \pm 1 SE) rainfall from 1990 to 2004. The horizontal line indicates average annual rainfall over all years. Years with rainfall higher and lower than the average were classified as wet and dry years, respectively.

\subsection{Discussion}

Evidence from HiP, one of the few large, wild and endemic populations of black rhinoceros, indicates that rainfall and, therefore, range conditions around conception influence seasonal conception rates and seasonal and annual progeny sex ratios. This result is similar to findings from other polygynous Perissodactyla (Monard et al. 1997). Higher birth rates were associated with conception periods 
during wetter seasons and corresponded with a statistically weak, but nonetheless relatively large, male bias in progeny sex ratios. Similar results were reported from black rhinos in the reintroduced population in Pilanesberg National Park (Hrabar \& Du Toit 2005).

This study is limited to sightings of wild black rhinoceros calves whose exact birthdates are unknown. Progeny sex ratios, therefore, might be different from birth sex or even foetal sex ratios, since there may be sex-differentiated foetal and neonatal loss. The seasonal difference in progeny sex ratios might have been stronger if we had been able to observe birth or foetal sex ratios. In particular, it is known that male foetuses are vulnerable to poor maternal resources during mid- to late-gestation (Kruuk et al. 1999b; Linklater 2007 in rhinoceros; Stopher et al. 2008). Since the black rhino gestation is 15.3 months long, a calf conceived during the wet season is gestated through the dry season, whereas a calf conceived in the dry season is in late gestation during the wet season. Thus, for the larger number of conceptions during the wet season, there might be male-biased foetal loss that reduces an early postconception male bias at parturition. Mid-gestation foetal loss during the wet season, however, is less likely to be male biased.

A better understanding of how range and climate conditions influence sex ratio dynamics may enable managers to identify appropriate rhinos from the source population for translocation. Reid et al. (2007) suggest that selecting specific animals for removal is important to maintain balanced social structures. After wet years, there may be a pulse of male recruitment so it may be advisable to schedule the removal of more males four to five years after a wet period when they become sexually mature and begin competing for mates. Heightened male-male competition 
for mates increases death rates and may impact female fitness (Linklater et al. 1999). Managers might remove old bulls that have already contributed progeny to provide space for the next generation or remove young males to contribute to new populations. Such a management strategy might be particularly important in small confined populations where male-male conflict is the leading cause of death among males and young females reproducing for the first time (Brett 1998).

Our results provide support in the wild for the influence of maternal condition at conception on birth sex in black rhinoceros, as in several other large ungulates (Flint et al. 1997; Roche et al. 2006; Cameron \& Linklater 2007), assuming that maternal condition for most prospective mothers correlates seasonally and annually with rainfall. In particular, our results support the contention that birth sex ratios amongst captive black rhinoceros might be lowered by reducing female body condition and restricting the diet of breeding mothers such that they are temporarily in neutral to negative energy balance for a period around and soon after conception (Atkinson 1997; Dennis et al. 2007).

\subsection{Acknowledgements}

The authors gratefully acknowledge the HiP personnel who contributed to the rainfall data collection and rhinoceros observations over many years. Thanks to Ezemvelo KZN Wildlife for long-term birth data, in particular Sue van Rensburg, Lulama Falayo and Craig Reid for facilitating our studies there. Funding for this project was provided by the International Rhino Foundation. EVB was supported by a Victoria University of Wellington PhD Scholarship. WLL was supported by grants 
from USFWS (grant agreement numbers 98210-2-G363, 98210-4-G920, and 98210-

6-G102). Thanks also to two anonymous reviewers of this manuscript.

\subsection{References}

Atkinson S. 1997. Possible determinants of skewed natal sex ratios in captive black and Indian rhinoceros in North America. International Rhinoceros Foundation. 81 p.

Balfour DA, Howison OE. 2002. Spatial and temporal variation in a mesic savanna fire regime: Responses to variation in annual rainfall. African Journal of Range and Forage Science 19(1):45-53.

Berger J. 1993. Disassociations between black rhinoceros mothers and young calves: Ecologically variable or, as yet, undetected behaviour? African Journal of Ecology 31(3):261-264.

Brett RA. 1998. Mortality factors and breeding performance of translocated black rhinos in Kenya: 1984-1995. Pachyderm 26:69-82.

Cameron EZ, Linklater WL. 2007. Extreme sex ratio variation in relation to change in condition around conception. Biology Letters 3(4):395-397.

Clinning G, Druce D, Robertson D, Bird J, Nxele B. 2009. Black rhino in HluhluweiMfolozi Park: Historical records, status of current population and monitoring and future management recommendations. South Africa. 9 p.

Clout MN, Elliott GP, Robertson BC. 2002. Effects of supplementary feeding on the offspring sex ratio of kakapo: a dilemma for the conservation of a polygynous parrot. Biological Conservation 107(1):13-18.

Dennis PM, Rajala-Schultz PJ, Funk JA, Blumer ES, Miller RE, Wittum TE, William JA. 2007. Risk factors associated with a skewed natal sex ratio in 
captive black rhinoceroses (Diceros bicornis) in the United States. Journal of Zoo and Wildlife Medicine 38(4):533-539.

Emslie, R.H. \& Adcock, K. 1994. Feeding ecology of black rhinos. In: B.L.

Penzhorn \& N.P.J. Kriek (eds.), Proceedings of the South African Veterinary Association Symposium on Rhinos as Game Ranch Animals (pp. 65-81), Onderstepoort.

Emslie, R. \& Brooks, M. 1999. African Rhino: Status Survey and Conservation Action Plan., pp. i-x, 1-92. IUCN/SSC African Rhino Specialist Group, Gland and Cambridge.

Flint A., Albon S. \& Jafar S. 1997. Blastocyst development and conceptus sex selection in red deer Cervus elaphus: Studies of a free-living population on the Isle of Rum. Gen Comp Endocrinol 106:374 - 383.

Fritz, H. \& Duncan, P. 1994. On the carrying capacity for large ungulates of African savanna ecosystems. Proc. R. Soc. Lond. B 256: 77-82.

Garroway, C.J. \& Broders, H.G. 2007. Adjustment of reproductive investment and offspring sex ratio in white-tailed deer (Odocoileus virginianus) in relation to winter severity. J. Mammal. 88: 1305-1311.

Hrabar, H. \& Du Toit, J.T. 2005. Dynamics of a protected black rhino Diceros bicornis population: Pilanesberg National Park, South Africa. Anim. Conserv. 8: 259-267.

Kruuk LEB, Clutton-Brock TH, Albon SD, Pemberton JM, Guinness FE. 1999a. Population density affects sex ratio variation in red deer. Nature 399(6735):459-461.

Kruuk LEB, Clutton-Brock TH, Rose KE, Guinness FE. 1999b. Early determinants of lifetime reproductive success differ between the sexes in red deer. Proceedings of the Royal Society of London Series B: Biological Sciences 266(1429):1655-1661. 
Linklater, W.L. 2007. Translocation reverses birth sex ratio bias depending on its timing during gestation: evidence for the action of two sex-allocation mechanisms. Reprod. Fertil. Develop. 19: 831-839.

Linklater WL, Cameron EZ, Minot EO, Stafford KJ. 1999. Stallion harassment and the mating system of horses. Animal Behaviour 58:295-306.

Monard, A.M., Duncan, P., Fritz, H. \& Feh, C. 1997. Variations in the birth sex ratio and neonatal mortality in a natural herd of horses. Behav. Ecol. Sociobiol. 41: 243-249.

Reid C, Slotow R, Howison O, Balfour D. 2007. Habitat changes reduce the carrying capacity of Hluhluwe-Umfolozi Park, South Africa, for critically endangered black rhinoceros Diceros bicornis. Oryx 41(2):247-254.

Roche JR, Lee JM, Berry DP. 2006. Pre-conception energy balance and secondary sex ratio - Partial support for the Trivers-Willard hypothesis in dairy cows. Journal of Dairy Science 89(6):2119-2125.

Silk, J.B. 1983. Local resource competition and facultative adjustment of sex ratios in relation to competitive abilities. American Naturalist 121: 56-66.

Stopher KV, Pemberton JM, Clutton-Brock TH, Coulson T. 2008. Individual differences, density dependence and offspring birth traits in a population of red deer. Proceedings of the Royal Society B-Biological Sciences 275(1647):2137-2145.

Trivers, R.L. \& Willard, D.E. 1973. Natural selection of parental ability to vary the sex ratio of offspring. Science 179: 90-92.

Waldram MS, Bond WJ, Stock WD. 2008. Ecological engineering by a mega-grazer: white rhino impacts on a South African savanna. Ecosystems 11(1):101-112.

Wedekind, C. 2002. Sexual selection and life-history decisions: Implications for supportive breeding and the management of captive populations. Conservation Biology 16: 1204-1211. 


\title{
Chapter 3. Changes in rhinoceros birth sex ratio periodicity can increase extinction risk.
}

\author{
3.1. Preface
}

In Chapter 2, I demonstrated that environmentally cued sex allocation does occur in rhinos. Rainfall patterns were correlated to calf sex, greater annual and seasonal rainfall resulted in a higher percentage of male calves. With this in mind, I wanted to explore if hypothetical changes in the patterns of calf sex ratio, as would occur due to changes in the duration of rainy years, would increase the probability of extinction rates. Since rhinos are kept in small fragmented populations under constant threat of poaching and/or habitat loss, managing them for optimal growth is a priority (Fig. 3.1.1). Increasing our understanding of the ecological influences on reproduction would improve our ability to increase population numbers. 


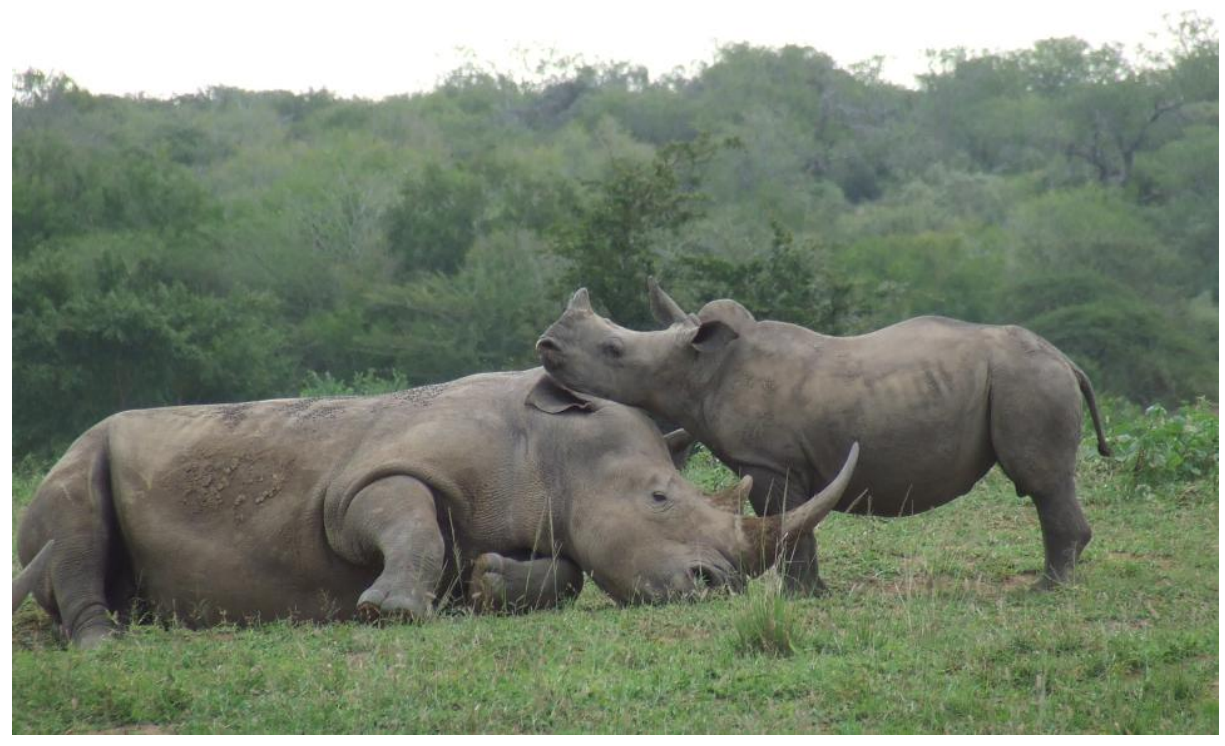

Figure 3.1.1 White rhino mother and calf, Hluhluwe-Imfolozi Park, South Africa (photo credit: Roan Plotz) 


\subsection{Abstract}

A population viability analysis on the influence of biased sex ratios on black rhinoceros (Diceros bicornis minor: Perissodactyla, Linnaeus, 1758) small population survival was modeled using population parameters primarily from the Hluhluwe-Imfolozi Park in South Africa. Black rhinos were known to have an environmentally-cued sex allocation response, positively linked to annual and seasonal changes in rainfall. I wanted to examine how the magnitude of birth sex ratio variation, both random and pulsed, would affect population survival. I modeled the influence of variation in birth sex ratios on extinction probabilities over 200 years. At 53\% BSR the survival probabilities reached a plateau at the 20/50 (initial/surviving) population size and remaining elevated for the larger population sizes. Results demonstrated that while random increases in the magnitude of birth sex ratio variation, in either direction, increased population survival probability up to 0.907 at $53 \% \pm 2.0 \mathrm{s.d}$ for the $20 / 332$ initial/final population, sequential pulsed years of birth sex ratio bias had the opposite effect on population performance with a survival probability of 0.619 for the $53 \% \pm 2.0 \mathrm{~s} . \mathrm{d}$ for the $20 / 50 \mathrm{initial} / \mathrm{final}$ population. Furthermore, for both scenarios, populations of less than 50 animals are particularly vulnerable to extinction. Climate models predicted changes in the variation and frequency of rainy seasons and years in the region. I suggested that that current population viability models may underestimate future population performance unless they include birth sex ratio variation.

\subsection{Introduction}


Sex ratio variation is known to have an effect on effective population size (Wedekind, 2002). In polygynous animals, females are the limiting sex to population growth since females can produce only one litter or offspring per breeding, while a male can breed many times during that same time period. Theoretically, female mammals have the ability to adjust the sex of their offspring in order to increase their reproductive fitness (Trivers and Willard, 1973). In polygynous, sexually dimorphic species this translates to mothers producing male offspring when environmental cues are favorable as a better quality male stands a better chance of outcompeting his peers for controlling access to females. Empirical observations have confirmed this theory in polygynous ungulates such as red deer (Post et al., 1999), horses (Cameron et al., 1999), and other species (Sheldon and West, 2004). Though the mechanisms controlling this process are poorly understood, increasing or decreasing levels of available nutrition appear to be an important physiological influence (Cameron, 2004; Cameron and Linklater, 2007).

Black rhinoceros (Diceros bicornis: Perissodactyla, Linnaeus, 1758) should be good candidates for TWH-type sex allocation, as they are a polygynous, moderately sexually dimorphic species that live in an environment with highly seasonal rainfall resulting in highly seasonal available nutrition. As would be predicted by the TWH, I previously demonstrated that black rhinoceros birth sex ratios vary according to available rainfall, with increased number of males conceived during the rainy seasons, and increased number of females during the dry season (Berkeley and Linklater, 2010; also see Hrabar and Du Toit, 2005).

The population viability analysis (PVA) process estimates the probability of a population's extinction over time, through input of various demographic parameters into computer simulation models (Brook et al., 1999). More than 150 PVAs have 
been performed using the Vortex computer software provided by the Conservation Breeding Specialist Group of the International Union for Conservation of Nature (Miller and Lacy, 2005). As with all models, the value of the resulting information is highly dependent upon the quality of data entered into the program (Chapman et al., 2001).

I wanted to evaluate under what conditions of population size and birth sex ratio bias, hypothetically due to several sequential dry or rainy years, would increase that population's extinction risk. This information can be useful to wildlife managers for developing guidelines for translocation, population monitoring, and setting up new reserves. In particular, I was interested in whether increasing random or cyclic variability in biased sex ratios would decrease population success and increase mean time to extinction, using black rhinos as a model species.

\subsection{Methods}

Scenarios for this study were constructed in the population viability analysis program Vortex, version 9.98 (Lacy et al., 2009, available at www.vortex9.org). All scenarios were based on data from Hluhluwe-iMfolozi Park (HiP), primarily the black rhino status report compiled by Clinning et al. (2009) and Berkeley and Linklater (2010). HiP is a 90,000 ha park located between S28.0000-28.430000 and E31.7160-32.0150, in KwaZulu-Natal, South Africa (Waldram et al., 2008). I chose the HiP data since it was a discreet data-set, though the values reported may not be reflective of other population's performance. If data from HiP was not available, I reviewed the literature and chose values that best represented the data available for black rhinoceros from other reserves. Variables and parameters used for each 
scenario are described below and/or listed in Table 3.4.1. Models were run for 1000 iterations and for 200 years (Miller and Lacy, 2005). Extinction was defined as the loss of one sex. Mean final population size for successful cases and mean time to first extinction were rounded to whole numbers. Environmental variation was modeled.

Table 3.4.1. List of parameters and variables used for all scenarios in this study.

\begin{tabular}{|c|c|c|}
\hline Parameter/variable & Value & Reference \\
\hline Extinction definition & one sex remains & \\
\hline Inbreeding depression & no & \\
\hline Reproductive system & polygynous & Owen-Smith, 1988 \\
\hline Age at first offspring for females & 9 & Clinning, 2009 \\
\hline Age at first offspring for males & 7 & $\begin{array}{l}\text { Owen-Smith, } 1988 \text { (for } \\
\text { Hluhluwe) }\end{array}$ \\
\hline Maximum age of reproduction & 30 & Clinning, 2009 \\
\hline Maximum number of broods/year & 1 & Owen-Smith, 1988 \\
\hline Maximum number of progeny/brood & 1 & Owen-Smith, 1988 \\
\hline Sex ratio at birth (\% male) & $53 \%$ & Berkeley, 2010 \\
\hline Annual reproductive rates & $3.39 \%$ & Clinning, 2009 \\
\hline$\%$ adult females breeding & 31.7 & $\begin{array}{l}\text { See text for details, } \\
\text { Clinning, } 2009\end{array}$ \\
\hline Distribution of broods/year & $0=0,1=100$ & \\
\hline $\begin{array}{l}\text { Specify the distribution of } \\
\text { offspring/brood }\end{array}$ & $\begin{array}{l}\text { normal, mean }=1 \text {, } \\
\text { sd. }=0\end{array}$ & \\
\hline Distribution of offspring & $1=100$ & \\
\hline$\%$ mortality between ages 0 and 3 & 16 & Owen-Smith, 1988 \\
\hline$\%$ mortality after age 3 & 3.22 & KZN 2005 \\
\hline$\%$ adult males in the breeding pool & 100 & \\
\hline$\%$ males successfully siring offspring & 27.1 & calculated by Vortex \\
\hline Mean \# mates/successful sire & 1.2 & calculated by Vortex \\
\hline Initially at stable age distribution & yes & \\
\hline
\end{tabular}

Inbreeding depression: No evidence of inbreeding depression has been identified in South African black rhinos (Swart et al., 1994). In addition, Nielsen concluded that black rhino in South Africa still maintain a moderate degree of 
heterozygosity (2008). Therefore, I did not factor inbreeding depression into my models.

Reproduction: For females, 9 years was set as the age of first offspring (Clinning, 2009). Age of first reproduction for males was set at 7 years based on earlier observations at Hluhluwe (Owen-Smith, 1988). Maximum age of reproduction was set at 30 years old based on Clinning (2009). While aborted twins have been recorded in the captive black rhino studbooks (Ochs, 2005), they are rarely observed in the wild, so maximum number per brood was set at one.

Sex ratio at birth (\% male): Sequences of dry years (defined as less than 833 mm rainfall/year, 1990-2004) can last up to four years in HIP (Berkeley and Linklater, 2010). Overall percent male offspring ranged from 42.9 to $60.2 \%$ under known annual rainfall variation during the years 1990 to 2004 (Berkeley and Linklater, 2010). The population's birth sex ratio was 53.1\% (approximately $=53$ ), which would not be statistically different than a 50:50 sex ratio for smaller populations, therefore $53 \%$ male calves was used as the baseline for all models. The standard deviation from the birth sex ratio was $15.9 \%$ (approximately $=16$ ) for the calving data used in the rainfall paper (Berkeley and Linklater, 2010). In horses, birth sex can vary from 3 to $81 \%$ male according to changes in individual body condition (Cameron and Linklater, 2007), therefore I included up to two standard deviations of percent male offspring in the different scenarios.

Reproductive rates: Annual reproductive rate was 3.39\% (Clinning, 2009). Estimates of historical population sizes in HIP were significantly modified in the most recent KZN report (Clinning, 2009), which may be a factor for the lower annual reproduction rates reported. The percent of adult females (31.7\%) was based on observations in HIP rhinos, where known intercalf intervals were observed to be 
3.15 years. This was supported by the observation that $79 \%$ of the females are with calves annually. If a calf stays with its dam for two or more years and gestation is around 16 months, and there is some degree of calf mortality, this number accords with (1/3.15 years) x 100, where 3.15 years is the inter-calf interval in HIP rhinos reported in Clinning (2009)). Percent breeding was kept constant for all years. No data is available on what percentage of males are actual sires in wild populations. For the purpose of this study, variation in the number of males breeding should not influence the outcome, therefore, $27.1 \%$ is assumed for all scenarios, based on rates automatically calculated by Vortex (Lacey, 2009).

Initial population sizes: I selected a range of important population sizes to model, from 10 to 350 rhinos, based on Emslie's (2008) report of recent average reserve population sizes. Emslie (2008) categorized the existing rhino populations into four 'Key' population sizes of 29, 62, 219 and 332 individuals. These sizes were also used as the carrying capacities for the models.

Mortality rates: Mortality rates for rhinos may be different between the sexes. Berger and Cunningham (1995) found females outlive males in Namibia but Kiwia (1989) found a consistent $8 \%$ mortality rate in both sexes in Tanzania. I used a mortality rate of $3.22 \%$ after age three based on data from Fanayo et al., (2005).

Percent mortality between ages 0 and 3: Calf predation mortality is potentially an underreported driver of reproductive success in black rhinos (Plotz and Linklater, 2009). Owen-Smith (1988) stated 69\% calf loss at Hluhluwe but only 9\% at Umfolozi (but these values include barren females and calf losses) and $16 \%$ in Tsavo. Amiyo (2003) reported 7 deaths out of 20 calves observed from 1990-2003. For this model I selected $16 \%$ calf mortality between ages 0 and three, and no annual variation in calf loss. 
Scenario Selection: For all models, all values are kept the same except for sex ratio.

Scenariol: Sex ratio is varied in a random manner in both positive and negative directions. The equation is sex ratio $=x+\left(z^{*}\left(\operatorname{SNRAND}\left(\mathrm{Y}+\left(\mathrm{R}^{*} 100\right)\right)\right)\right)$, where $x=\%$ annual sex ratio, $z=$ the $\%$ standard deviation, SNRAND $=$ a 'seeded' random normal deviate, $\mathrm{Y}=$ year, and $\mathrm{R}=$ run (simulation iteration) (Miller and Lacy, 2005). For all our models we used $53 \%$ as the annual average sex ratio (Berkeley and Linklater, 2010). For example, for the ' $53 \pm 0.5 *$ (s.d.)' simulation, the equation is sex ratio $=53+(8 *(\operatorname{SNRAND}(\mathrm{Y}+(\mathrm{R} * 100))))$

Scenario 2: Since sequences of dry years (defined as less than $833 \mathrm{~mm}$ rainfall/year,1990-2004) can last up to four years in HIP, I pulsed sequential years of birth sex bias every five years, purposefully increasing the number of years to increase the possibility of detecting an influence) (Berkeley and Linklater, 2010). The sex ratio is varied in five year pulses both positive and negative around the mean. The equation is sex ratio $=x+\left(z^{*} \operatorname{SIN}\left(\left(\mathrm{PI}^{*} \mathrm{Y}\right) / 5\right)\right)$, where $x=\%$ annual sex ratio, $z=$ the $\%$ standard deviation, $\mathrm{SIN}=$ Sine, $\mathrm{PI}=3.1415927, \mathrm{Y}=$ year, $\mathrm{R}=$ run (simulation iteration) (Miller and Lacy, 2005). For example, the equation for the '53 $\pm 1.0 *($ s.d. $) '$ simulation is sex ratio $=53+(16 * \operatorname{SIN}((\mathrm{PI} * \mathrm{Y}) / 5))$

Models were run for 14 population sizes (initial/final): 7/7, 7/10, 10/20, 20/29, 20/40, 20/50, 20/62, 20/100, 20/150, 20/219, 20/300, 20/332, 20/350. These values were based on recommendations of initial population sizes for new reserves of at least 6 animals by Emslie (2009) and based on average key population sizes in Africa (Emslie, 2008). 


\subsection{Results}

Scenario 1 - Random variation in birth sex ratios: The survival probabilities ranged from 0.001 to 0.907 for all simulations. At 53\% BSR, the survival probability reached 0.841 at 20/50 (initial/surviving) and remained elevated for the larger population sizes (Figure 3.5.1). Increasing the standard deviation of random variation of the birth sex ratio caused a small increase in population survival, reaching a peak survival probability at $53 \% \pm 2.0$ s.d. BSR of 0.907 for the $20 / 332$ initial/final population simulation (Figure 3.5.1).

Scenario 2 - 5-year pulsed variation: Five year pulsed survival probabilities (Figure 3.5.2) were overall lower than the randomized simulations, but showed a similar pattern of increasing until reaching a survival probability of 0.841 for the 53\% BSR simulation and 20/50 population and remaining elevated above 0.841 for the larger population sizes. In contrast to the previous scenario, increasing the standard deviation of the five year pulsed variation in birth sex ratios caused a decrease in population survival: for the $53 \% \pm 2.0 \mathrm{BSR}$ simulation, the $20 / 50$ population had a survival probability of 0.619 (Figure 3.5.2). 
Table 3.5.1 Survival probabilities of populations with randomized birth sex ratios (+/- $0,0.5$, and 1.0 standard deviations).

\begin{tabular}{|c|c|c|c|c|c|c|c|}
\hline $\begin{array}{c}\text { initial } \\
\text { population } \\
\text { size }\end{array}$ & $\begin{array}{c}\text { final } \\
\text { population } \\
\text { size }^{*}\end{array}$ & $\begin{array}{c}\text { sex ratio } \\
\text { percentage } \\
(+/- \\
\text { standard } \\
\text { deviation) }\end{array}$ & $\begin{array}{l}\text { Number of } \\
\text { surviving } \\
\text { populations }\end{array}$ & $\begin{array}{c}\text { mean } \\
\text { time to } \\
\text { first } \\
\text { extinction } \\
\text { (years) }\end{array}$ & $\begin{array}{l}\text { mean final } \\
\text { population } \\
\text { size for } \\
\text { successful } \\
\text { cases }\end{array}$ & $\begin{array}{c}\text { extinction } \\
\text { probability }\end{array}$ & $\begin{array}{c}\text { survival } \\
\text { probability }\end{array}$ \\
\hline 7 & 7 & 53 & 6 & 36 & 6 & 0.994 & 0.006 \\
\hline 7 & 10 & 53 & 62 & 64 & 7.32 & 0.938 & 0.062 \\
\hline 10 & 20 & 53 & 394 & 156 & 13.95 & 0.606 & 0.394 \\
\hline 20 & 29 & 53 & 749 & 118 & 21 & 0.251 & 0.749 \\
\hline 20 & 40 & 53 & 809 & 111.8 & 30.53 & 0.191 & 0.807 \\
\hline 20 & 50 & 53 & 841 & 106.7 & 32.12 & 0.159 & 0.841 \\
\hline 20 & 62 & 53 & 834 & 102.5 & 48.09 & 0.166 & 0.834 \\
\hline 20 & 100 & 53 & 828 & 104.44 & 71.95 & 0.172 & 0.828 \\
\hline 20 & 150 & 53 & 851 & 103.8 & 88.6 & 0.149 & 0.851 \\
\hline 20 & 200 & 53 & 833 & 105.38 & 104.49 & 0.167 & 0.833 \\
\hline 20 & 219 & 53 & 846 & 101.33 & 91.16 & 0.154 & 0.846 \\
\hline 20 & 300 & 53 & 837 & 102.39 & 97.24 & 0.163 & 0.837 \\
\hline 20 & 332 & 53 & 807 & 98.09 & 93.98 & 0.193 & 0.807 \\
\hline 20 & 350 & 53 & 853 & 97.66 & 116.29 & 0.147 & 0.853 \\
\hline 7 & 7 & $53+/-0.5$ & 1 & 42.04 & 6 & 0.999 & 0.001 \\
\hline 7 & 10 & $53+/-0.5$ & 20 & 61.66 & 6.7 & 0.98 & 0.02 \\
\hline 10 & 20 & $53+/-0.5$ & 372 & 88.55 & 14.34 & 0.628 & 0.372 \\
\hline 20 & 29 & $53+/-0.5$ & 747 & 120.84 & 21.84 & 0.253 & 0.747 \\
\hline 20 & 40 & $53+/-0.5$ & 807 & 117.19 & 31.18 & 0.193 & 0.807 \\
\hline 20 & 50 & $53+/-0.5$ & 845 & 108.28 & 39.55 & 0.155 & 0.845 \\
\hline 20 & 62 & $53+/-0.5$ & 841 & 99.56 & 49.53 & 0.159 & 0.841 \\
\hline 20 & 100 & $53+/-0.5$ & 866 & 98.02 & 74.88 & 0.134 & 0.866 \\
\hline 20 & 150 & $53+/-0.5$ & 874 & 103.71 & 99.16 & 0.126 & 0.874 \\
\hline 20 & 200 & $53+/-0.5$ & 850 & 104.39 & 109.6 & 0.15 & 0.85 \\
\hline 20 & 219 & $53+/-0.5$ & 846 & 99.1 & 115.6 & 0.154 & 0.846 \\
\hline 20 & 300 & $53+/-0.5$ & 881 & 101.34 & 118.65 & 0.119 & 0.881 \\
\hline 20 & 332 & $53+/-0.5$ & 843 & 102.08 & 118.6 & 0.157 & 0.843 \\
\hline 20 & 350 & $53+/-0.5$ & 877 & 97 & 127.25 & 0.123 & 0.877 \\
\hline 7 & 7 & $53+/-1$ & 1 & 41.48 & 3 & 0.999 & 0.001 \\
\hline 7 & 10 & $53+/-1$ & 27 & 67.81 & 6.74 & 0.973 & 0.027 \\
\hline 10 & 20 & $53+/-1$ & 430 & 96.59 & 14.59 & 0.57 & 0.43 \\
\hline 20 & 29 & $53+/-1$ & 717 & 125.3 & 21.24 & 0.283 & 0.717 \\
\hline 20 & 40 & $53+/-1$ & 846 & 105.38 & 30.7 & 0.154 & 0.846 \\
\hline 20 & 50 & $53+/-1$ & 856 & 102.31 & 39.43 & 0.144 & 0.856 \\
\hline 20 & 62 & $53+/-1$ & 855 & 108.86 & 49 & 0.145 & 0.855 \\
\hline 20 & 100 & $53+/-1$ & 864 & 102.14 & 74.87 & 0.136 & 0.864 \\
\hline 20 & 150 & $53+/-1$ & 864 & 104.74 & 98.62 & 0.136 & 0.864 \\
\hline 20 & 200 & $53+/-1$ & 870 & 101.49 & 114.01 & 0.13 & 0.87 \\
\hline 20 & 219 & $53+/-1$ & 863 & 98.86 & 110.98 & 0.137 & 0.863 \\
\hline 20 & 300 & $53+/-1$ & 867 & 102.74 & 119.79 & 0.133 & 0.867 \\
\hline 20 & 332 & $53+/-1$ & 869 & 105.24 & 122.96 & 0.131 & 0.869 \\
\hline 20 & 350 & $53+/-1$ & 869 & 107.56 & 123.75 & 0.131 & 0.869 \\
\hline
\end{tabular}


Table 3.5.2 Survival probabilities of populations with randomized birth sex ratios (+/- 2.0 standard deviations).

\begin{tabular}{cccccccc}
$\begin{array}{c}\text { initial } \\
\text { population } \\
\text { size }\end{array}$ & $\begin{array}{c}\text { final } \\
\text { population } \\
\text { size* }\end{array}$ & $\begin{array}{c}\text { sex ratio } \\
\text { percentage } \\
\text { (+/- } \\
\text { standard } \\
\text { deviation) }\end{array}$ & $\begin{array}{c}\text { Number of } \\
\text { surviving } \\
\text { populations }\end{array}$ & $\begin{array}{c}\text { mean } \\
\text { time to } \\
\text { first } \\
\text { extinction } \\
\text { (years) }\end{array}$ & $\begin{array}{c}\text { mean final } \\
\text { population } \\
\text { size for } \\
\text { successful } \\
\text { cases }\end{array}$ & $\begin{array}{c}\text { extinction } \\
\text { probability }\end{array}$ & $\begin{array}{c}\text { survival } \\
\text { probability }\end{array}$ \\
\hline 7 & 7 & $53+/-2$ & 4 & 45.85 & 4.25 & 0.996 & 0.004 \\
7 & 10 & $53+/-2$ & 47 & 69.57 & 6.62 & 0.953 & 0.047 \\
10 & 20 & $53+/-2$ & 478 & 106.03 & 14.22 & 0.522 & 0.478 \\
20 & 29 & $53+/-2$ & 777 & 129.31 & 29.47 & 0.223 & 0.777 \\
20 & 40 & $53+/-2$ & 870 & 115.26 & 30.21 & 0.13 & 0.87 \\
20 & 50 & $53+/-2$ & 895 & 117.33 & 35.08 & 0.105 & 0.895 \\
20 & 62 & $53+/-2$ & 891 & 115.95 & 49.44 & 0.109 & 0.891 \\
20 & 100 & $53+/-2$ & 890 & 112.33 & 76.65 & 0.11 & 0.89 \\
20 & 150 & $53+/-2$ & 901 & 111.43 & 103.69 & 0.099 & 0.901 \\
20 & 200 & $53+/-2$ & 899 & 115.04 & 118.52 & 0.101 & 0.899 \\
20 & 219 & $53+/-2$ & 901 & 107.61 & 117.56 & 0.099 & 0.901 \\
20 & 300 & $53+/-2$ & 894 & 101.65 & 134.28 & 0.106 & 0.894 \\
20 & 332 & $53+/-2$ & 907 & 110.53 & 131.11 & 0.093 & 0.907 \\
20 & 350 & $53+/-2$ & 902 & 122.08 & 135.33 & 0.098 & 0.902 \\
\hline
\end{tabular}


Table 3.5.3 Survival probabilities of populations with five year pulsed birth sex ratios (+/- $0,0.5$, and 1.0 standard deviations).

\begin{tabular}{|c|c|c|c|c|c|c|c|}
\hline $\begin{array}{c}\text { initial } \\
\text { population } \\
\text { size }\end{array}$ & $\begin{array}{c}\text { final } \\
\text { population } \\
\text { size* }^{*}\end{array}$ & $\begin{array}{c}\text { sex ratio } \\
\text { percentage } \\
(+/- \\
\text { standard } \\
\text { deviation) }\end{array}$ & $\begin{array}{l}\text { Number of } \\
\text { surviving } \\
\text { populations }\end{array}$ & $\begin{array}{c}\text { mean } \\
\text { time to } \\
\text { first } \\
\text { extinction } \\
\text { (years) }\end{array}$ & $\begin{array}{c}\text { mean final } \\
\text { population } \\
\text { size for } \\
\text { successful } \\
\text { cases }\end{array}$ & $\begin{array}{l}\text { extinction } \\
\text { probability }\end{array}$ & $\begin{array}{c}\text { survival } \\
\text { probability }\end{array}$ \\
\hline 7 & 7 & 53 & 6 & 36 & 6 & 0.994 & 0.006 \\
\hline 7 & 10 & 53 & 62 & 64 & 7.32 & 0.938 & 0.062 \\
\hline 10 & 20 & 53 & 394 & 156 & 13.95 & 0.606 & 0.394 \\
\hline 20 & 29 & 53 & 749 & 118 & 21 & 0.251 & 0.749 \\
\hline 20 & 40 & 53 & 809 & 111.8 & 30.53 & 0.191 & 0.807 \\
\hline 20 & 50 & 53 & 841 & 106.7 & 32.12 & 0.159 & 0.841 \\
\hline 20 & 62 & 53 & 834 & 102.5 & 48.09 & 0.166 & 0.834 \\
\hline 20 & 100 & 53 & 828 & 104.44 & 71.95 & 0.172 & 0.828 \\
\hline 20 & 150 & 53 & 851 & 103.8 & 88.6 & 0.149 & 0.851 \\
\hline 20 & 200 & 53 & 833 & 105.38 & 104.49 & 0.167 & 0.833 \\
\hline 20 & 219 & 53 & 846 & 101.33 & 91.16 & 0.154 & 0.846 \\
\hline 20 & 300 & 53 & 837 & 102.39 & 97.24 & 0.163 & 0.837 \\
\hline 20 & 332 & 53 & 807 & 98.09 & 93.98 & 0.193 & 0.807 \\
\hline 20 & 350 & 53 & 853 & 97.66 & 116.29 & 0.147 & 0.853 \\
\hline 7 & 7 & $53+/-0.5$ & 11 & 42.29 & 5.18 & 0.989 & 0.011 \\
\hline 7 & 10 & $53+/-0.5$ & 57 & 63.66 & 6.84 & 0.943 & 0.057 \\
\hline 10 & 20 & $53+/-0.5$ & 366 & 82.29 & 13.69 & 0.634 & 0.366 \\
\hline 20 & 29 & $53+/-0.5$ & 704 & 108.58 & 20.62 & 0.296 & 0.704 \\
\hline 20 & 40 & $53+/-0.5$ & 787 & 104.39 & 29.88 & 0.283 & 0.787 \\
\hline 20 & 50 & $53+/-0.5$ & 780 & 100.62 & 38.41 & 0.22 & 0.78 \\
\hline 20 & 62 & $53+/-0.5$ & 798 & 99.51 & 38.72 & 0.202 & 0.798 \\
\hline 20 & 100 & $53+/-0.5$ & 804 & 95.83 & 56.48 & 0.196 & 0.804 \\
\hline 20 & 150 & $53+/-0.5$ & 780 & 96.34 & 67.97 & 0.22 & 0.78 \\
\hline 20 & 200 & $53+/-0.5$ & 789 & 96.1 & 96.69 & 0.211 & 0.789 \\
\hline 20 & 219 & $53+/-0.5$ & 785 & 101.61 & 103.43 & 0.215 & 0.785 \\
\hline 20 & 300 & $53+/-0.5$ & 785 & 97.3 & 111.2 & 0.215 & 0.785 \\
\hline 20 & 332 & $53+/-0.5$ & 796 & 91.92 & 112.38 & 0.204 & 0.796 \\
\hline 20 & 350 & $53+/-0.5$ & 805 & 95.33 & 110.17 & 0.195 & 0.805 \\
\hline 7 & 7 & $53+/-1$ & 3 & 41.87 & 6.67 & 0.997 & 0.003 \\
\hline 7 & 10 & $53+/-1$ & 59 & 61.12 & 7.12 & 0.941 & 0.059 \\
\hline 10 & 20 & $53+/-1$ & 335 & 79.85 & 14.07 & 0.665 & 0.335 \\
\hline 20 & 29 & $53+/-1$ & 304 & 106.76 & 20.74 & 0.696 & 0.304 \\
\hline 20 & 40 & $53+/-1$ & 753 & 96.19 & 22.58 & 0.247 & 0.753 \\
\hline 20 & 50 & $53+/-1$ & 741 & 90.08 & 38.08 & 0.259 & 0.741 \\
\hline 20 & 62 & $53+/-1$ & 747 & 87.64 & 46.26 & 0.253 & 0.747 \\
\hline 20 & 100 & $53+/-1$ & 767 & 94.45 & 69.69 & 0.233 & 0.767 \\
\hline 20 & 150 & $53+/-1$ & 762 & 94.65 & 85.4 & 0.238 & 0.762 \\
\hline 20 & 200 & $53+/-1$ & 758 & 86.1 & 97.86 & 0.242 & 0.758 \\
\hline 20 & 219 & $53+/-1$ & 732 & 93.51 & 100.48 & 0.268 & 0.732 \\
\hline 20 & 300 & $53+/-1$ & 764 & 94.14 & 103.91 & 0.246 & 0.764 \\
\hline 20 & 332 & $53+/-1$ & 756 & 96.1 & 107.29 & 0.244 & 0.756 \\
\hline 20 & 350 & $53+/-1$ & 746 & 91.21 & 104.86 & 0.254 & 0.746 \\
\hline
\end{tabular}


Table 3.5.4 Survival probabilities of populations with five year pulsed birth sex ratios (+/- 2.0 standard deviations).

\begin{tabular}{cccccccc}
$\begin{array}{c}\text { initial } \\
\text { population } \\
\text { size }\end{array}$ & $\begin{array}{c}\text { final } \\
\text { population } \\
\text { size* }\end{array}$ & $\begin{array}{c}\text { sex ratio } \\
\text { percentage } \\
\text { (+/- } \\
\text { standard } \\
\text { deviation) }\end{array}$ & $\begin{array}{c}\text { Number of } \\
\text { surviving } \\
\text { populations }\end{array}$ & $\begin{array}{c}\text { mean } \\
\text { time to } \\
\text { first } \\
\text { extinction } \\
\text { (years) }\end{array}$ & $\begin{array}{c}\text { mean final } \\
\text { population } \\
\text { size for } \\
\text { successful } \\
\text { cases }\end{array}$ & $\begin{array}{c}\text { extinction } \\
\text { probability }\end{array}$ & $\begin{array}{c}\text { survival } \\
\text { probability }\end{array}$ \\
\hline 7 & 7 & $53+/-2$ & 3 & 37.58 & 3.33 & 0.997 & 0.003 \\
7 & 10 & $53+/-2$ & 49 & 54.4 & 6.43 & 0.951 & 0.049 \\
10 & 20 & $53+/-2$ & 276 & 55.66 & 14.47 & 0.724 & 0.276 \\
20 & 29 & $53+/-2$ & 607 & 83.83 & 21.57 & 0.393 & 0.607 \\
20 & 40 & $53+/-2$ & 605 & 75.19 & 30.51 & 0.395 & 0.605 \\
20 & 50 & $53+/-2$ & 619 & 73.35 & 37.58 & 0.381 & 0.619 \\
20 & 62 & $53+/-2$ & 627 & 78.17 & 46.3 & 0.373 & 0.627 \\
20 & 100 & $53+/-2$ & 612 & 74.5 & 68.36 & 0.388 & 0.612 \\
20 & 150 & $53+/-2$ & 617 & 70.74 & 84.22 & 0.383 & 0.617 \\
20 & 200 & $53+/-2$ & 629 & 72.54 & 92.38 & 0.371 & 0.629 \\
20 & 219 & $53+/-2$ & 617 & 71.14 & 97.28 & 0.383 & 0.617 \\
20 & 300 & $53+/-2$ & 612 & 74.75 & 101.58 & 0.388 & 0.612 \\
20 & 332 & $53+/-2$ & 606 & 71.42 & 101.77 & 0.394 & 0.606 \\
20 & 350 & $53+/-2$ & 599 & 76.48 & 104.91 & 0.401 & 0.599 \\
\hline
\end{tabular}




\subsection{Discussion}

Several population viability analyses have been performed on black rhinos (for examples, see: Foose, 1987; Moehlman et al., 1996; Swart et al., 1990). Other models have been developed to predict population growth for Hluhluwe-Imfolozi Park (HIP) black rhinos (Adcock, 2001; Cromsigt et al., 2002). As these authors suggest, I added additional quantifiable variables to the body of knowledge of black rhino population dynamics to improve the quality of existing population viability models. In agreement with previous reports, these results support the idea that managers should focus on establishing larger populations, ideally greater than 40 black rhinos (Brett, 1998; Emslie et al., 2009; Linklater and Swaisgood, 2008). In particular, my findings agreed with the suggestions put forth in the Species Survival Commission guidelines for a carrying capacity of at least 50 rhinos (Emslie et al., 2009) because the smaller populations were much more vulnerable to perturbations in birth sex ratio.

If there are several sequential years where a male bias occurs, these male biased cohorts will limit population growth as they reach breeding age. Fewer females available for breeding will result in fewer calves born. A female bias, however, will not impair population growth in polygynous species such as rhinos as only a few males are needed to breed. Genetic diversity, however, may be reduced as fewer males would do a greater proportion of the breeding.

We know in other species that annual and seasonal variation in rainfall has an effect on reproductive function, presumably through changes in available nutrition and resulting body condition. Craine et al. (2009) found that body condition shifted significantly in a North American megaherbivore, the bison (Bison bison), as rainfall 
availability changed the quality and quantity of the available food biomass. However, the effect depended on the time of year that the precipitation change occurred, with increasing mid-summer precipitation decreasing weight gain, while late-summer increasing precipitation increased weight gain.

The results from this study describe one way that population viability may be impacted by pulses in resources due to seasonal and annual rainfall variation. Only one study has measured the potential implications of climate change on black rhino habitat availability and this was in Kenya (Saffery, 2009). The author identified that decreased precipitation and ensuing drought would be the factors that have the largest impact on black rhinos. This study does not measure changes in density dependent reproduction, which has been observed in white rhinos (Rachlow and Berger, 1998). Okita-Ouma (2009) found female-biased sex ratios may contribute to increased growth rates in Kenyan black rhinos. If South African black rhinos have a similar response, survival rates could be even lower than my models predict.

Bioclimatic model projections indicate that temperatures will rise over the whole of South Africa and summer rainfall will decrease by between $5 \%$ in the northern regions and 25\% in the eastern and southern Cape (Rutherford et al., 1999). More recent reports indicate that rainfall will increase overall in the eastern parts of South Africa but the duration and frequency will be more variable (Lumsden et al., 2009; Wadge, 2007). While the future climate models often produce apparently conflicting results, all agree that changes in rainfall pattern are likely (Fauchereau et al., 2003; Post et al., 1999). Annual and seasonal changes in progeny sex ratios correlated with rainfall have been observed in black rhino habitat (Berkeley and Linklater, 2010). These biases can be male-biased as may occur when small numbers of rhinos are released in areas with large amounts of available food and low 
numbers, and females will presumably be increasing body condition as a result of lower competition for resources. Based on the results of the current study, increased variation in rainfall annual cycles could reduce black rhino population growth, regardless of the direction of sex bias.

These results demonstrate that birth sex ratio variability needs to be considered in greater detail when constructing PVAs. Models of adaptive sex determination suggest long-lived organisms are likely to produce biased sex ratios under directional environmental change in the short-term, as I observed in this model and in the previous retrospective analysis of black rhino progeny sex ratios (Berkeley and Linklater, 2010; Schwanz et al., 2010). Specific models of rainfall change compared with previous population performance could predict if any biologically consequent changes in birth sex ratio may occur in black rhinos. Whether rhinos have the phenotypic plasticity to adapt to rapid climate change remains unresolved. Further information on the projected duration and magnitude of interannual variation in precipitation, changes in habitat structure and population demographics is needed to more precisely model the potential effect of climate change on black rhinos.

\subsection{References}

Adcock K. 2001. RMG Black Rhino Carrying Capacity Model. SADC Regional Programme for Rhino Conservation. Harare, Zimbabwe: SADC Regional Programme Coordinator, IUCN-ROSA. p 64.

Amiyo A. 2003. Ngorongoro black rhino: current status and problems. Nairobi: African Wildlife Foundation, Frankfurt Zoological Society and Ngorongoro Conservation Area Authority. 10-11 p. 
Berger J, Cunningham C. 1995. Predation, sensitivity, and sex: why female black rhinoceroses outlive males. Behavioral Ecology 6(1):57-64.

Berkeley EV, Linklater WL. 2010. Annual and seasonal rainfall may influence progeny sex ratio in the black rhinoceros. South African Journal of Wildlife Research 40(1):53-57.

Brett RA. 1998. Mortality factors and breeding performance of translocated black rhinos in Kenya: 1984-1995. Pachyderm 26:69-82.

Brook BW, Akcakaya HR, Keith DA, Mace GM, Pearson RG, Araujo MB. 2009. Integrating bioclimate with population models to improve forecasts of species extinctions under climate change. Biology Letters 5(6):723-725.

Brook BW, Cannon JR, Lacy RC, Mirande C, Frankham R. 1999. Comparison of the population viability analysis packages GAPPS, INMAT, RAMAS and VORTEX for the whooping crane (Grus americana). Animal Conservation 2(1):23-31 .

Cameron EZ. 2004. Facultative adjustment of mammalian sex ratios in support of the Trivers-Willard hypothesis: evidence for a mechanism. Proceedings of the Royal Society of London Series B-Biological Sciences 271(1549):1723-1728.

Cameron EZ, Linklater WL. 2007. Extreme sex ratio variation in relation to change in condition around conception. Biology Letters 3(4):395-397.

Cameron EZ, Linklater WL, Stafford KJ, Veltman CJ. 1999. Birth sex ratios relate to mare condition at conception in Kaimanawa horses. Behavioral Ecology $10(5): 472-475$.

Chapman AP, Brook BW, Clutton-Brock TH, Grenfell BT, Frankham R. 2001. Population viability analyses on a cycling population: a cautionary tale. Biological Conservation 97(1):61-69. 
Clinning G, Druce, D., Robertson, D., Bird, J. \& Nxele, B. 2009. Black rhino in Hluhluwe-iMfolozi Park: Historical records, status of current population and monitoring and future management recommendations. South Africa. 9 p.

Craine JM, Towne EG, Joern A, Hamilton RG. 2009. Consequences of climate variability for the performance of bison in tallgrass prairie. Global Change Biology 15(3):772-779.

Cromsigt JPGM, Hearne J, Heitkönig IMA, Prins HHT. 2002. Using models in the management of Black rhino populations. Ecological Modelling 149(1-2):203211.

Emslie RH. 2008. Rhino population sizes and trends. Pachyderm 44(1):88-95.

Emslie RH, Amin R, Kock R. 2009. Guidelines for the in situ reintroduction and translocation of African and Asian rhinoceros. Occasional Paper of the IUCN Species Survival Commission 39:i-v, 1-115.

Fanayo L, Van Rensburg S, Emslie RH, Ngobese J. 2005. KZN black rhino status report. Hluhluwe: Ezemvelo KZN Wildlife. 56 p.

Fauchereau N, Trzaska S, Rouault M, Richard Y. 2003. Rainfall variability and changes in Southern Africa during the 20th century in the global warming context. Natural Hazards 29(2):139-154.

Foose TJ. 1987. Small population management of black rhino. Pachyderm 9:31-34.

Hrabar H, Du Toit JT. 2005. Dynamics of a protected black rhino Diceros bicornis population: Pilanesberg National Park, South Africa. Animal Conservation $8(3): 259-267$.

Kiwia HD. 1989. Black rhinoceros (Diceros bicornis (L.)): population size and structure in Ngorongoro Crater, Tanzania. African Journal of Ecology 27(1):1-6. 
Lacy RC, Borbat M, Pollak JP. 2009. Vortex: A Stochastic Simulation of the Extinction Process. Version 9.95. Brookfield, IL: Chicago Zoological Society.

Linklater WL, Swaisgood RR. 2008. Reserve size, conspecific density, and translocation success for black rhinoceros. Journal of Wildlife Management 72(5):1059-1068.

Lumsden T, Schulze R, Hewitson B. 2009. Evaluation of potential changes in hydrologically relevant statistics of rainfall in Southern Africa under conditions of climate change. Water SA 35(5):649-656.

Miller PS, Lacy RC. 2005. Vortex: A Stochastic Simulation of the Extinction Process. Version 9.50 User's Manual. Apple Valley, MN: Conservation Breeding Specialist Group (SSC/IUCN). 149 p.

Moehlman PD, Amato G, Runyoro V. 1996. Genetic and demographic threats to the black rhinoceros population in the Ngorongoro Crater. Conservation Biology 10(4):1107-1114.

Nielsen L, Meehan-Meola D, Kilbourn A, Alcivar-Warren A. 2008. Characterization of microsatellite loci in the black rhinoceros (Diceros bicornis) and white rhinoceros (Ceratotherium simum): their use for cross-species amplification and differentiation between the two species. Conservation Genetics 9(1):239242.

Ochs A. 2005. International studbook for the black rhinoceros, Diceros bicornis (Linne 1758). Berlin AG: Zoologischer Garten Berlin AG. Report nr Volume 10. $233 \mathrm{p}$.

Okita-Ouma B, Amin R, van Langevelde F, Leader-Williams N. 2009. Density dependence and population dynamics of black rhinos (Diceros bicornis 
michaeli) in Kenya's rhino sanctuaries. African Journal of Ecology 48(3):791-799.

Owen-Smith N. 1988. Megaherbivores: The influence of very large body size on ecology. 1st ed. Cambridge: Cambridge University Press.

Plotz RD, Linklater WL. 2009. Black rhinoceros (Diceros bicornis) calf succumbs after lion predation attempt: implications for conservation management. African Zoology 44(2):283-287.

Post E, Forchhammer MC, Stenseth NC, Langvatn R. 1999. Extrinsic modification of vertebrate sex ratios by climatic variation. American Naturalist 154(2):194-204.

Rachlow JL, Berger J. 1998. Reproduction and population density: trade-offs for the conservation of rhinos in situ. Animal Conservation 1:101-106.

Rutherford MC, Powrie LW, Schulze RE. 1999. Climate change in conservation areas of South Africa and its potential impact on floristic composition: A first assessment. Diversity and Distributions 5(6):253-262.

Saffery J. 2009. Assessing the potential effects of climate change on two species of rhinoceros, Diceros bicornis and Rhinoceros unicornis, using species distribution modelling. London: Imperial College London. 64 p.

Schwanz LE, Janzen FJ, Proulx SR. 2010. Sex allocation based on relative and absolute condition. Evolution 64(5):1331-1345.

Sheldon BC, West SA. 2004. Maternal dominance, maternal condition, and offspring sex ratio in ungulate mammals. American Naturalist 163(1):40-54.

Swart J, Hearne JW, Goodman PS. 1990. A conservation model for the black rhino. System Dynamics 1:1128-1136. 
Swart MKJ, Ferguson JWH, Du Toit R, Flamand JRB. 1994. Substantial genetic variation in Southern African black rhinoceros (Diceros bicornis). Journal of Heredity 85(4):261-266.

Trivers R, Willard D. 1973. Natural selection of parental ability to vary the sex ratio of offspring. Science 179:90-92.

Wadge MJH. 2007. A vulnerability analysis of Hluhluwe Imfolozi Park for the period 1980 to 2000. Johannesburg: University of Witwatersrand. 159 p.

Waldram MS, Bond WJ, Stock WD. 2008. Ecological engineering by a mega-grazer: white rhino impacts on a South African savanna. Ecosystems 11(1):101-112.

Wedekind C. 2002. Manipulating sex ratios for conservation: short-term risks and long-term benefits. Animal Conservation 5:13-20. 


\section{Chapter 4. An information theoretic multi-model analysis of long-term studbook records to test hypotheses for birth sex bias.}

\subsection{Preface}

The central problems addressed in this dissertation are whether birth sex ratios are biased in intensively managed rhino populations and, if so, how can we ameliorate this problem. In Chapters 2 and 3, I demonstrated that environmentally cued sex allocation does occur in wild rhinos and that increased variation in birth sex ratios can increase probability of extinction rates, especially in populations with less than 50 animals. Because the environmental influences are greatly different in captivity than in the wild, I wanted to know the consequences of the captive environment on birth sex ratios. In ex situ situations, rhinos have access to an almost constant food supply, and are housed in environments that greatly limit activity. There are additional stressors such as being moved from one zoo to another for breeding, and being on public display. In this chapter, I used a retrospective dataset of over 60 years of data from the world studbooks of black and white rhinoceroses to test the relative importance of several hypothetical factors regulating birth sex ratios in captive and wild rhinos. 


\subsection{Abstract}

Excessive numbers of male calves are a potential problem for African rhinoceros species (black rhinos: Diceros bicornis: Perissodactyla, Linnaeus, 1758; white rhinos: Ceratotherium simum simum: Perissodactyla, Burchell, 1817) held in captivity and in small reserves in the wild. Several papers have proposed hypotheses to explain what is causing a perceived male calf production bias in captive rhino populations. Zoo studbooks are fortuitous datasets providing demographic and historical information on captive populations. In the present study, data was collated from the international zoo studbooks for 464 calves over 64 years for black rhinos and 693 calves over 39 years for white rhinos. We used a multi-model information theoretic approach to test 14 hierarchical models for birth sex in the historical captive white rhino and black rhino populations. The model that had the most support for predicting calf sex for black rhinos was geographical region and the dam's age had the most support for white rhinos. However, in either species, no model was greatly supported relative to the others for predicting calf sex.

Furthermore, the credible intervals all overlapped zero and no predictor had a strong effect size, suggesting that none of the models tested were good predictors of calf sex. We conclude that the broad-scale and population level data that we analyzed are not useful predictors of calf sex.

\subsection{Introduction}

Extreme secondary (birth) sex ratios are occasionally observed within ex situ populations (e.g., Faust and Thompson, 2000) and simulate considerable interest and 
concern (Glatston, 1997). Male biases in ungulates are a particular problem: females are the limiting factor in population growth and excess males are difficult to maintain. Males either have to be selectively culled, kept alone and isolated, or in bachelor herds, which can lead to inter-male aggression and injury (Cassinello and Pieters, 2000; Veasey, 2006). Increasing our understanding of the factors that influence calf sex could lead to protocols for pre-breeding calf sex selection. Birth sex ratio variation has been attributed to facultative sex allocation in response to unusual captive environments, diets and stressors (Clout 2002; Cockburn et al., 2002; Linklater 2007). Some bias, however, may occur with Mendelian assortment of sex chromosomes in small populations.

Nowhere is the need for calf sex selection greater than in the large charismatic ungulates that are expensive to maintain in captivity and potentially dangerous to handle, particularly elephants and rhinos (Atkinson, 1997; Saragusty et al., 2009). Previous papers have attempted to explain the role of sex allocation theory in biased sex ratios observed in captive rhinoceros and elephants by using the large amount of data available in the international studbooks (Atkinson, 1997; Dennis et al., 2007; Faust and Thompson, 2000; Saragusty et al., 2009). These papers were limited as they searched for correlation between variables and drew conclusions from these relationships, rather than explicitly tested hypotheses. There is a drawback to this approach: the results observed may merely be spurious, not causal, as the critical variables may not actually be in the studbook dataset.

In this paper, we elected to use an information theoretic multi-model approach, which has the advantage of being able to test multiple hypotheses simultaneously, as well as ranking their ability to fit to the variability in the data (Burnham and Anderson, 1998). 
Previous analyses have proposed several environmental, physiological and sociological factors that have influenced calf sex. The models in this study are based partially on these suggested factors, as far as can be calculated from the data available in the studbooks. For example, Atkinson (1997) identified a significant difference in calf sex depending on what region of the world the institution was that the calf was born in. Furthermore, she identified maternal age as a factor, with older females tending to have more female births, which has previously been suggested by other researchers in rhinos and other polygynous species (Atkinson, 1997; CluttonBrock et al., 1984; Owen-Smith, 1988; Saltz, 2001). The prior reproductive history of the dam has been suggested to influence calf sex, perhaps via body condition or endocrine milieu (Dennis et al., 2007; Faust and Thompson, 2000), where females with higher body condition having more male offspring. This could also be a consequence of elevated diets and/or lack of physical exercise, and other unidentified factors due to captive husbandry conditions (Faust and Thompson, 2000). Monard, et al. found fetal-sex differentiated maternal investment had an effect on subsequent calf sex. A trend in calf sex bias due to subspecies was identified in black rhinos perhaps due to genetic or husbandry differences (Dennis et al., 2007). Stress, as a consequence of recent translocations and/or repeated translocations to new institutions has been identified as having an influence on rhino birth sex, with a differential sex bias occurring depending on the time of the stress event relative to gestation period (Linklater, 2007). All these factors were considered as we constructed models based on hypotheses of birth sex bias proposed by other authors and our own observations.

The aim of this paper is to apply an information theoretic approach to the African rhino (black rhinos: Diceros bicornis: Perissodactyla, Linnaeus, 1758; white 
rhinos: Ceratotherium simum simum: Perissodactyla, Burchell, 1817) studbooks to determine whether the information provided is predictive of captive rhinoceros birth sex ratios.

\subsection{Methods}

Data on 464 black rhinoceros (Diceros bicornis: Perissodactyla, Linnaeus, 1758) calves born to 160 dams at 78 institutions, and 693 white rhino (Ceratotherium simum simum: Perissodactyla, Burchell, 1817) calves from 202 known dams at 100 institutions was transferred into electronic form from each species international studbook (Ochs, 2005a; Ochs, 2005b). We compiled and collated information on calf sex and birth dates, and the birthplace, transfer date, and institution of their mother to construct 13 independent predictors of calf sex (Table 4.4.1). 
Table 4.4.1. A list of the models using in this study, the predictors they contain, and their supporting literature.

\begin{tabular}{|c|c|c|}
\hline Model/Hypothesis & predictor(s) & Reference \\
\hline Dam's age & dam's age & $\begin{array}{l}\text { Atkinson, 1997; } \\
\text { Clutton-Brock et } \\
\text { al., 1984; Owen- } \\
\text { Smith, 1988; } \\
\text { Saltz, 2001 }\end{array}$ \\
\hline Maternal output & fecundity & Faust, 2000 \\
\hline Sex of previous calf & previous calf male & $\begin{array}{l}\text { Dennis et al., } \\
2007\end{array}$ \\
\hline Origins & dam wild or captive born & $\begin{array}{l}\text { Dennis et al., } \\
\text { 2007; Monard, } \\
1997\end{array}$ \\
\hline Prior maternal investment & $\begin{array}{l}\text { number of prior male calves, } \\
\text { number of males in sequence }\end{array}$ & Faust, 2000 \\
\hline $\begin{array}{l}\text { Origins and prior } \\
\text { investment }\end{array}$ & $\begin{array}{l}\text { dam wild or captive born, number } \\
\text { of prior male calves, number of } \\
\text { males in sequence }\end{array}$ & $\begin{array}{l}\text { Atkinson, 1997; } \\
\text { Faust, } 2000\end{array}$ \\
\hline Prior calves & prior reproductive rate & $\begin{array}{l}\text { Dennis et al., } \\
\text { 2007; Faust, } 2000\end{array}$ \\
\hline Origins and translocation & $\begin{array}{l}\text { dam wild or captive born, } \\
\text { translocation impact, number of } \\
\text { prior translocations }\end{array}$ & $\begin{array}{l}\text { Dennis et al., } \\
\text { 2007; Linklater, } \\
2007\end{array}$ \\
\hline Translocation & $\begin{array}{l}\text { translocation impact, number of } \\
\text { prior translocations }\end{array}$ & Linklater, 2007 \\
\hline Dam's age and region & $\begin{array}{l}\text { dam's age, North America, } \\
\text { Europe, Australasia, Asia, South } \\
\text { America }\end{array}$ & $\begin{array}{l}\text { Atkinson, 1997; } \\
\text { Clutton-Brock et } \\
\text { al., 1984; Owen- } \\
\text { Smith, 1988; } \\
\text { Saltz, } 2001\end{array}$ \\
\hline Husbandry & $\begin{array}{l}\text { calf's year of birth, North } \\
\text { America, Europe, Australasia, } \\
\text { Asia, South America }\end{array}$ & Atkinson, 1997 \\
\hline Region & $\begin{array}{l}\text { North America, Europe, } \\
\text { Australasia, Asia, South America }\end{array}$ & Atkinson, 1997 \\
\hline Subspecies & $\begin{array}{l}\text { D.b. michaeli or D.b. minor } \\
\text { (black rhinos only) }\end{array}$ & $\begin{array}{l}\text { Dennis et al., } \\
2007\end{array}$ \\
\hline Origins and husbandry & $\begin{array}{l}\text { dam wild or captive born, calf's } \\
\text { year of birth, North America, } \\
\text { Europe, Australasia, Asia, South } \\
\text { America }\end{array}$ & $\begin{array}{l}\text { Atkinson, 1997; } \\
\text { Dennis et al., } \\
\text { 2007; Monard, } \\
1997\end{array}$ \\
\hline
\end{tabular}


Some independent variables were calculated to represent a dams reproductive success and investment (i.e., overall fecundity rate in calves per year), origin (i.e., captive or wild born), and age (i.e., number of years over sexual maturity where sexual maturity is assumed to be $>4$ years for black, and $>5$ years for white, rhinoceros). Others were calculated to represent a dam's reproductive history prior to the birth of each calf (e.g., number of previous male calves, whether the previous calf was male and the number of previous male calves in sequence, and prior reproductive rate in calves per year over sexual maturity). The influence of metapopulation management on birth sex was investigated by including variables describing the number of translocations by the dam prior to calving and the time of calf birth since the dam's last translocation. Translocation is a stressor (Linklater et al. 2010) and we were interested in whether the timing of a recent translocation or more frequent translocation influenced the sex of a subsequent offspring. Translocation frequency was represented by a count of translocations and the timing of the most recent translocation were grouped into categories based on their potential for influencing birth sex, using a gestation length of 460 days for D. bicornis and 495 days for $C$. simum (Linklater, 2007: i.e., 0.2 and 0.21-1.0 of gestation length, > 0-6 months $>6$ months to 1 year $>1$ year to 2 years, $>2$ to 4 years, $>4$ to 8 years, $>$ 8 to 16 years, $>16$ years prior to calving. Institutions were categorized by region (i.e., Africa, North America, Europe, Australasia, Asia and South America). I also included a category for subspecies in black rhinoceros (i.e., var. michaeli or minor). The number of Northern white rhinos (C. s. var. cottoni) born in captivity (six calves from two dams at the same institution) was too small to also test the influence of sub-species in white rhinos. Lastly, I categorised the year of birth for calves into six 
ordinal periods (i.e. for white rhinos the categories were: 1: 1966-1979, 2: 19801984, 3: 1985-1990, 4: 1991-1998, 5: 1998-2005) to investigate the possibility that birth sex ratio skew has changed over time, perhaps due to longitudinal improvements in husbandry (i.e. housing, diet; Faust, 2000).

A posteriori tests of multivariate databases not designed for the purpose are particularly susceptible to over- and under-fitting (Whittingham et al., 2006). For this reason I adopted an information-theoretic approach to testing hypotheses for birth sex ratio skew amongst captive rhinoceros (Burnham and Anderson, 2002; Johnson and Omland, 2004). Fourteen candidate models were constructed from single or combinations of the 13 predictors to test hypotheses about the influence of geographic region, husbandry, maternal characters and reproductive history, or their combinations, on calf sex in black and white rhinoceros.

Dams could give birth to multiple calves and shared institutions and so models were hierarchical logistic regression models with mother and institution random effects for the binary dependent variable (i.e., female 0 , or male 1 ). I used a Bayesian inference approach to test models in OpenBUGS (Thomas et al., 2006). Parameters (estimated values of the regression coefficients and their posterior distributions or credible intervals) were estimated using Markov Chain Monte Carlo methods (Spiegelhalter et al., 2002). Model convergence was evaluated by simultaneously running two Markov chains (each with different initial values) and checking the Gelman-Rubin statistic (Brooks and Gelman, 1998; Gelman and Rubin, 1992).

Models were run for 40,000 iterations after the first 10,000 iterations were discarded and posterior distributions of the parameters examined. The deviance information criteria (DIC) of the models were ranked lowest to highest, models with 
change in DIC ( $\triangle \mathrm{DIC})$ within two units of the lowest value are considered not substantially different, two to four $\Delta \mathrm{DIC}$ units showing moderate support, four to seven $\triangle \mathrm{DIC}$ units greater than the minimum value have considerably less support, and greater than ten units, no support (Burnham and Anderson, 1998; Spiegelhalter et al., 2002). To identify important predictors with strongest relative effect, I examined the credible intervals of all predictors in each model for overlap with zero and compared the absolute median values of coefficients for binary values and the scaled continuous coefficients (calculated by multiplying each by two standard deviations of the predictor) and compared their absolute values (Gelman and Hill, 2006).

\subsection{Results}

The overall birth sex ratio for black rhinos was $48.5 \%$ male and $53.2 \%$ male for white rhinos and it was not possible to distinguish empirically between the importance of most hypotheses for calf sex because most hypotheses were at least weakly supported (i.e., $\Delta \mathrm{DIC}<7$, Table 4.51 and 4.5.2). Nevertheless, the model combining white rhino dam origins (captive or wild born), year of birth, and region received no support (i.e., $\Delta \mathrm{DIC}>10$ ) and some models in both species received substantially less support than the leading models. For example, a black rhinoceros dam's origins and translocation history prior to calving received substantially less support than models describing proxies for potential changes and differences in husbandry (i.e., period of birth and region), a dams prior reproductive history, including the sex of the previous calf, and subspecies. Similarly in white rhinoceros, maternal characters like prior reproductive investment and sex of her previous calf 
also performed substantially better than proxies for husbandry change and translocation history. In contrast, however, the institutions region received substantially less support, and age, origins and fecundity greater support for white rhinoceros.

The parameters and credible intervals for all predictors' coefficients in leading models (i.e., $\Delta \mathrm{DIC}<4$ ), were small and overlapped with zero such that their influence is likely weak, at most, and the magnitude and direction of predictors' influence on calf sex is somewhat uncertain (Figure 4.5.1). Comparisons of absolute scaled coefficients (i.e., effect sizes) also indicate that most predictors had trivial influence on calf sex (Figure 4.5.1). Nevertheless, some predictors of maternal output and reproductive history should be considered further because they had the largest coefficients and effect sizes. More fecund dams were more likely to give birth to female calves in both species. In black rhinoceros, male calves were also more likely if a dam's prior reproductive rate was relatively low and where the previous calf was also male. 
Table 4.5.1. Summary of the 14 candidate models for influences on black rhino calf sex $(n=464$ calves). The models are in descending order indicating the most to least supported based on the change in the deviance information criteria $(\Delta \mathrm{DIC}), \mathrm{pD}=$ estimated number of parameters in the model, $*=$ these models include data at multiple levels.

\begin{tabular}{|c|c|c|c|c|}
\hline Model/Hypothesis & Predictor(s) & pD & DIC & $\Delta \mathrm{DIC}$ \\
\hline Region & North America, Europe, Australasia, Asia, South America & 20 & 643.6 & 0.0 \\
\hline Dam's age and region* & dam's age; North America, Europe, Australasia, Asia, South America & 22 & 644.4 & 0.8 \\
\hline Prior maternal investment & number of prior male calves, number of males in sequence & 35 & 644.5 & 0.9 \\
\hline Husbandry & $\begin{array}{l}\text { calf's year of birth, North America, Europe, Australasia, Asia, South } \\
\text { America }\end{array}$ & 22 & 644.7 & 1.1 \\
\hline Subspecies & subspecies & 18 & 645.3 & 1.7 \\
\hline Sex of previous calf & previous calf male & 28 & 645.6 & 2.0 \\
\hline Origins and prior investment & $\begin{array}{l}\text { dam wild or captive born, number of prior male calves, number of } \\
\text { males in sequence }\end{array}$ & 37 & 646.2 & 2.6 \\
\hline Origins and husbandry* & $\begin{array}{l}\text { dam wild or captive born, calf's year of birth, North America, Europe, } \\
\text { Australasia, Asia, South America }\end{array}$ & 23 & 646.5 & 2.9 \\
\hline Maternal output & fecundity & 22 & 647.2 & 3.6 \\
\hline Prior calves & prior reproductive rate & 22 & 647.4 & 3.8 \\
\hline Dam's age & Dam's age & 21 & 647.4 & 3.8 \\
\hline Origins & dam wild or captive born & 20 & 648.5 & 4.9 \\
\hline Translocation & translocation impact, number of prior translocations & 22 & 649.6 & 6.0 \\
\hline Origins and translocation & $\begin{array}{l}\text { dam wild or captive born, translocation impact, number of prior } \\
\text { translocations }\end{array}$ & 22 & 651.6 & 8.0 \\
\hline
\end{tabular}


Table 4.5.2. Summary of the 13 candidate models for influences on white rhino calf sex $(n=693$ calves). The models are in descending order indicating the most to least supported based on the change in the deviance information criteria $(\triangle \mathrm{DIC}), \mathrm{pD}=$ estimated number of parameters in the model, $*=$ these models include data at multiple levels.

\begin{tabular}{|c|c|c|c|c|}
\hline Model/Hypothesis & Predictor(s) & pD & DIC & $\Delta \mathrm{DIC}$ \\
\hline Dam's age & dam's age & 12 & 962.6 & 0.0 \\
\hline Maternal output & fecundity & 13 & 963.7 & 1.1 \\
\hline Sex of previous calf & previous calf male & 11 & 963.7 & 1.1 \\
\hline Origins & dam wild or captive born & 13 & 964.1 & 1.5 \\
\hline Prior maternal investment & number of prior male calves, number of males in sequence & 15 & 964.6 & 2.0 \\
\hline Origins and prior investment & $\begin{array}{l}\text { dam wild or captive born, number of prior male calves, number of } \\
\text { males in sequence }\end{array}$ & 17 & 964.9 & 2.3 \\
\hline Prior calves & prior reproductive rate & 12 & 965.4 & 2.8 \\
\hline Origins and translocation & $\begin{array}{l}\text { dam wild or captive born, translocation impact, number of prior } \\
\text { translocations }\end{array}$ & 16 & 968.2 & 5.6 \\
\hline Translocation & translocation impact, number of prior translocations & 15 & 969.3 & 6.7 \\
\hline Dam's age and region* & dam's age, North America, Europe, Australasia, Asia, South America & 21 & 971.2 & 8.6 \\
\hline Husbandry & $\begin{array}{l}\text { calf's year of birth, North America, Europe, Australasia, Asia, South } \\
\text { America }\end{array}$ & 23 & 972.2 & 9.6 \\
\hline Region & North America, Europe, Australasia, Asia, South America & 20 & 972.2 & 9.6 \\
\hline Origins and husbandry* & $\begin{array}{l}\text { dam wild or captive born, calf's year of birth, North America, Europe, } \\
\text { Australasia, Asia, South America }\end{array}$ & 24 & 973.4 & 10.8 \\
\hline
\end{tabular}


Figure 4.5.1(A) Legend on second following page.

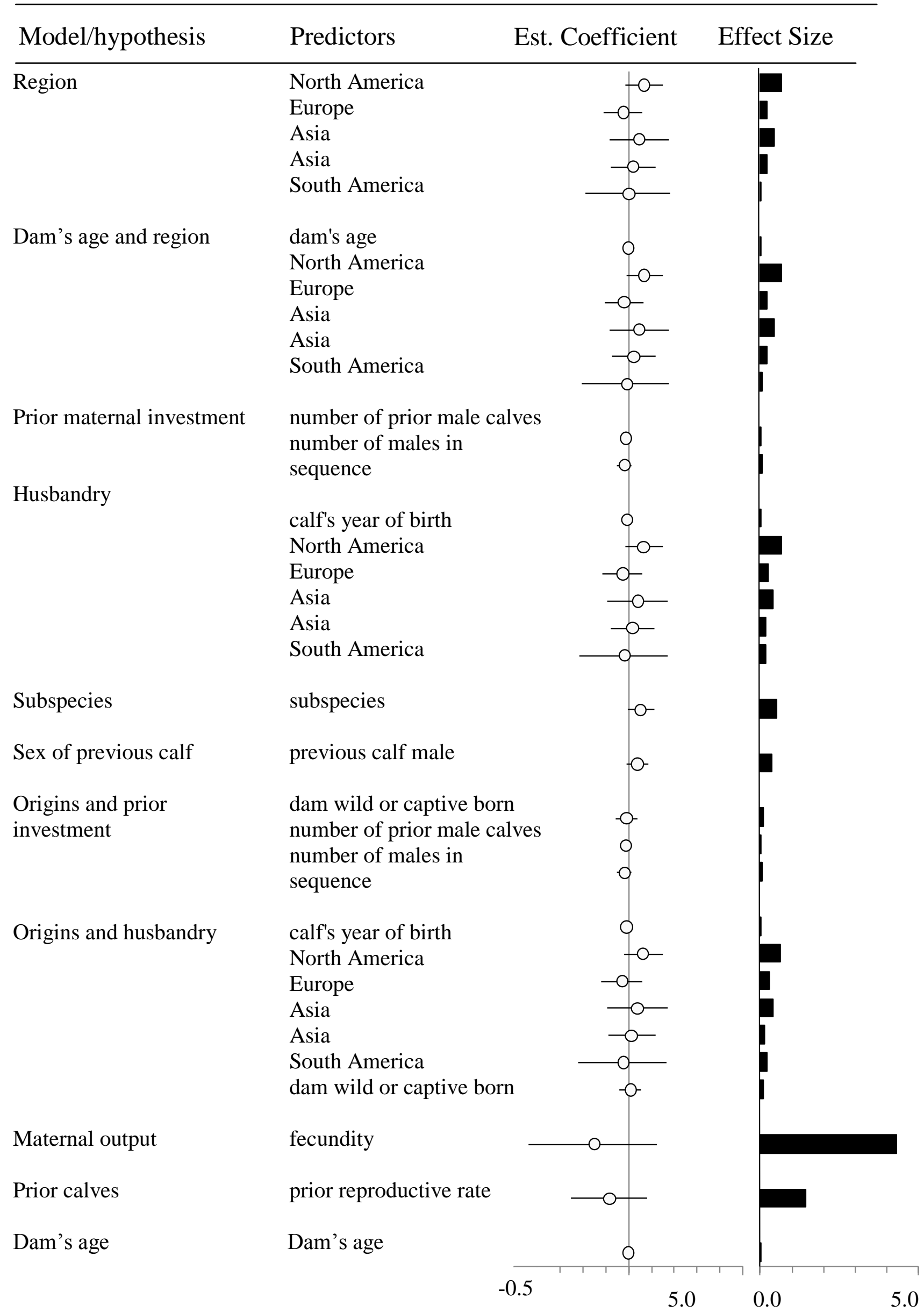


Figure 4.5.1(B) Legend on following page.

Model/hypothesis Predictors $\quad$ Est. Coefficient Effect Size

Dam's age

Maternal output

Sex of previous calf

Origins

Prior maternal investment

Origins and prior investment

Prior calves
Dam's age

fecundity

previous calf male

dam wild or captive born

number of prior male calves

number of males in sequence

dam wild or captive born

number of prior male calves

number of males in sequence

prior reproductive rate 
Figure 4.5.1.(On previous two pages) Parameter estimates from posterior densities and scaled effect size of coefficients for each predictor in the leading models. For black (A) and white (B) rhinoceros calf sex (female 0, male 1) that received some support (i.e., $\Delta \mathrm{DIC} \leq 2$, Tables 4.5.1 and 4.5.2). The open circle $(O)$ represents mean parameter (coefficient) estimate and the horizontal lines represent their credible intervals. A value of zero indicates that the predictor had no influence on calf sex. A positive value indicates a positive relationship between the predictor and calf sex. To calcualate effect size, coefficients were scaled by multiplying each by two standard deviations of the corresponding predictor and converting to absolute values for comparison of their relative effect size.

\subsection{Discussion}

This analysis demonstrated that most hypotheses currently proposed for birth sex bias in captivity are poorly supported. The effect sizes were generally small but even the predictors with the largest effect sizes were in models that were less supported (i.e. fecundity). The power of studbook data to explain birth sex bias was either poor or the observed birth sex bias in captivity cannot be attributed to the sex allocation theories tested.

Dennis et al. (2007) attributed birth sex bias to the wild-born versus captiveborn origins of dams. No relationships could be found for captive born dams but wild born dam calf sex was explained by the dams' time in captivity and age. These measures were likely to be highly correlated and so it was not possible in their analysis to differentiate which was more important, though there may be a trend for subspecies in black rhinos. Others however, conclude weak or no relationship with age and time in captivity, respectively (Atkinson, 1997).

All of these previous studies, however, suffer from the problems of multivariate analyses without control for hierarchical non-independent predictors and the absence of a priori model selection and inference. Such analyses often 
erroneously elevate the important of higher level factors (e.g., wild or captive born, sub-species). For example, the differences between the black rhino subspecies var. michaeli showed greatest deviation from parity, but none of the tested models yielded substantial support in the current study.

Numerous theories have been proposed to explain sex allocation in vertebrates with $\mathrm{XY}$ chromosomal sex determination and why offspring sex ratio biases in both directions occur. Currently, chief among these is the Trivers-Willard (TWH; 1973) and local resource competition hypotheses (LRC; Clark, 1978) and modifications of the latter depending on maternal quality or competitiveness (Silk, 1983). The TWH states that mothers in good condition will invest in the sex of offspring that give the greatest reproductive benefit. In contrast the LRC states that where parents compete with their offspring for local resources, the parent will invest in the less competing sex (or invest in the more supportive sex).

A consequence of these theories has been the expectation that circumstances in captivity might cause extreme birth sex ratio skew because they modify a mother's ability to invest in her offspring. Thus, many have attempted analyses to attribute cause to birth sex ratio skews in captive populations (i.e. Faust, 2000; Glatston, 1997) and rhinoceros have attracted more interest than most (Atkinson, 1997, Dennis, 2007). Unfortunately, previous analyses have not explicitly treated the hierarchical structure amongst independent variables and not tested multiple hypotheses simultaneously (aka model selection and inference; Burnham and Anderson, 1998), but relied on multiple regression and correlation techniques. Such analyses will over-estimate the influence of higher level predictors (e.g., region, subspecies) and are susceptible to under- and over-fitting such that Type I and II errors are likely. Moreover, populations and species with apparent birth sex skew in 
captivity garner greater attention and so, without independent tests, analyses tend to confirm expectations. A type of confirmation bias is reinforced. We do not dispute that facultative sex allocation occurs (Berkeley and Linklater, 2010; Cameron et al., 2007; Linklater, 2007), but that data available in studbooks and conventional tests of them are unlikely to explain birth sex skew in captivity. Either the datasets do not contain the appropriate information or birth sex skew in captivity is a consequence of random Mendelian assortment of sex chromosomes in the small populations that constitute animal collections. Apparent differences between regions, institutions, sub-species in birth sex ratios are likely to be spurious consequences of small sample size (Cockburn et al. 2002).

A mother's ability to invest in the sex of her offspring has been correlated to her previous amount of investment in ungulates and other mammals (Drickamer, 1990; Robert, 2010), either as a consequence of her previous energetic investment in producing and raising progeny or as a reflection of her genetic fitness.

Environmental cues apparently act as extrinsic signals that modify body condition, leading to production of the more costly sex during favourable times (Blanchard, 2005; Garroway and Broders, 2007). In fact, our rainfall study found that black rhinos in Hluhluwe-iMfolozi Park in South Africa do demonstrate sex allocation in response to environmental cues as would be predicted by the TWH, also observed in the Pilanesberg National Park black rhinos (Berkeley and Linklater, 2010; Hrabar and Du Toit, 2005). Individual characteristics such as age have been identified as an important predictor of offspring sex ratio in ungulates such as the Asiatic wild ass and reindeer (Saltz 2001, 2003; Weladji, 2003). Overall population productivity has been associated with increased birth sex ratio in elephant seals (Lee and Sydeman, 2009). From this research, it appears that multiple triggers may work in tandem and 
it is only recently that the specific physiological mechanisms are being identified (i.e. Cameron, 2004; Rosenfield, 2004). However, none of the potential causes of birth sex bias tested in the present study were capable of strongly predicting calf sex in either black rhinos or white rhinos. We conclude that the whole complex of models we constructed were therefore not good at predicting calf sex.

The exact mechanism for sex allocation remains unknown but substantial evidence in a wide range of species points towards the role of increasing or decreasing planes of nutrition cuing the female to invest in one sex or the other (Cameron and Linklater, 2007; Clout, 2002; Roche et al., 2006; Rosenfeld and Roberts, 2004). Our results indirectly support this conclusion by eliminating the other suggested predictors such as region and maternal investment. Pre-selection or influence of calf sex around the time of conception is suggested as an important future focus of research efforts for captive and small population animal managers.

\subsection{References}

Atkinson S. 1997. Possible determinants of skewed natal sex ratios in captive black and Indian rhinoceros in North America. International Rhinoceros Foundation. $81 \mathrm{p}$.

Berkeley EV, Linklater WL. 2010. Annual and seasonal rainfall may influence progeny sex ratio in the black rhinoceros. South African Journal of Wildlife Research 40:53-57.

Blanchard P, Festa-Bianchet M, Gaillard J-M, Jorgenson JT. 2005. Maternal condition and offspring sex ratio in polygynous ungulates: a case study of bighorn sheep. Behavioral Ecology 16(1):274-279. 
Brooks SP, Gelman A. 1998. General methods for monitoring convergence of iterative simulations. Journal of Computational and Graphical Statistics 7(4):434-455.

Burnham KP, Anderson DR. 1998. Model selection and inference: A practical information-theoretic approach. Springer-Verlag New York, Inc.; SpringerVerlag. $353 \mathrm{p}$.

Cameron E. 2004. Facultative adjustment of mammalian sex ratios in support of the Trivers-Willard hypothesis: evidence for a mechanism. Proceedings of the Royal Society of London Series B-Biological Sciences 271(1549):1723 - 1728.

Cameron EZ, Linklater WL. 2007. Extreme sex ratio variation in relation to change in condition around conception. Biology Letters 3(4):395-397.

Cassinello J, Pieters I. 2000. Multi-male captive groups of endangered dama gazelle: Social rank, aggression, and enclosure effects. Zoo Biology 19:121-129.

Clark AB. 1978. Sex ratio and local resource competition in a prosimian primate. Science 201(4351):163-165.

Clout MN, Elliott GP, Robertson BC. 2002. Effects of supplementary feeding on the offspring sex ratio of kakapo: a dilemma for the conservation of a polygynous parrot. Biological Conservation 107(1):13-18.

Clutton-Brock T, Albon S, Guinness F. 1984. Maternal dominance, breeding success and birth sex-ratios in red deer. Nature 308:358-360.

Cockburn A, Legge S, Double M. 2002. Sex ratios in birds and mammals: can the hypotheses be disentangled? Sex Ratios: Concepts and Research Methods. Cambridge: Cambridge University Press. p 266-286.

Dennis PM, Rajala-Schultz PJ, Funk JA, Blumer ES, Miller RE, Wittum TE, William JA. 2007. Risk factors associated with a skewed natal sex ratio in 
captive black rhinoceroses (Diceros bicornis) in the United States. Journal of Zoo and Wildlife Medicine 38(4):533-539.

Drickamer LC. 1990. Seasonal-variation in fertility, fecundity and litter sex-ration in laboratory and wild stocks of house mice (Mus domesticus). Laboratory Animal Science 40(3):284-288.

Faust LJ, Thompson SD. 2000. Birth sex ratio in captive mammals: Patterns, biases, and the implications for management and conservation. Zoo Biology 19(1):11-25.

Garroway CJ, Broders HG. 2007. Adjustment of reproductive investment and offspring sex ratio in white-tailed deer (Odocoileus virginianus) in relation to winter severity. Journal of Mammalogy 88:1305-1311.

Gelman A, Hill J. 2007. Data Analysis Using Regression and Multilevel/Hierarchical Models. Cambridge: Cambridge University Press.

Gelman A, Rubin DB. 1992. Inference from iterative simulation using multiple sequences. Statistical Science 7:457-511.

Glatston AR. 1997. Sex ratio research in zoos and its implications for captive management. Applied Animal Behaviour Science 51(3-4):209-216.

Hrabar H, Du Toit JT. 2005. Dynamics of a protected black rhino Diceros bicornis population: Pilanesberg National Park, South Africa. Animal Conservation $8(3): 259-267$.

Lee D, Sydeman W. 2009. North Pacific climate mediates offspring sex ratio in Northern Elephant Seals. Journal of Mammalogy 90(1):1-8.

Linklater WL. 2007. Translocation reverses birth sex ratio bias depending on its timing during gestation: evidence for the action of two sex-allocation mechanisms. Reproduction Fertility and Development 19(7):831-839. 
Monard AM, Duncan P, Fritz H, Feh C. 1997. Variations in the birth sex ratio and neonatal mortality in a natural herd of horses. Behavioral Ecology and Sociobiology 41(4):243-249.

Ochs A. 2005a. International studbook for the black rhinoceros, Diceros bicornis (Linne 1758). Berlin AG: Zoologischer Garten Berlin AG. Report nr Volume 10. $233 \mathrm{p}$.

Ochs A. 2005b. International studbook for the white rhinoceros, Ceratotherium simum (Burchell 1817). Berlin AG: Zoologischer Garten Berlin AG. Report nr Volume 10. 409 p.

Owen-Smith N. 1988. Megaherbivores: The influence of very large body size on ecology. 1st ed. Cambridge: Cambridge University Press.

Robert KA, Schwanz LE, Mills HR. 2010. Offspring sex varies with maternal investment ability: empirical demonstration based on cross-fostering. Biology Letters 6(2):242-245.

Roche JR, Lee JM, Berry DP. 2006. Pre-conception energy balance and secondary sex ratio - Partial support for the Trivers-Willard hypothesis in dairy cows. Journal of Dairy Science 89(6):2119-2125.

Rosenfeld CS, Roberts RM. 2004. Maternal diet and other factors affecting offspring sex ratio: a review. Biology of Reproduction 71(4):1063-1070.

Saltz D. 2001. Progeny sex ratio variation in ungulates: maternal age meets environmental perturbation of demograpgy. Oikos 94(2):377-384.

Saltz D, Kotler BP. 2003. Maternal age is a predominant determinant of progeny sex ratio variation in ungulates: a reply to Hewison et al. Oikos 101(3):646-648. 
Saragusty J, Hermes R, Göritz F, Schmitt DL, Hildebrandt TB. 2009. Skewed birth sex ratio and premature mortality in elephants. Animal Reproduction Science $115(1-4): 247-254$.

Silk JB. 1983. Local Resource Competition and Facultative Adjustment of Sex Ratios in Relation to Competitive Abilities. The American Naturalist 121(1):56-66.

Spiegelhalter DJ, Best NG, Carlin BR, van der Linde A. 2002. Bayesian measures of model complexity and fit. Journal of the Royal Statistical Society Series BStatistical Methodology 64:583-616.

Thomas A, O'Hara B, Ligges U, Sturtz S. 2006. Making BUGS Open. R News 6:1217.

Trivers R, Willard D. 1973. Natural selection of parental ability to vary the sex ratio of offspring. Science 179:90-92.

Veasey J. 2006. Concepts in the care and welfare of captive elephants. International Zoo Yearbook 40(1):63-79.

Weladji RB, Holand O, Yoccoz NG, Lenvik D. 2003. Maternal age and offspring sex ratio variation in reindeer (Rangifer tarandus). Annales Zoologici Fennici 40(4):357-363.

West SA. 2009. Sex Allocation. Levin SA, Horn HS, editors. 1st ed. Princeton, New Jersey: Princeton University Press. 466 p. 


\section{Chapter 5. Dietary impact on circulating glucose profiles in the white rhinoceros.}

\subsection{Preface}

The previous chapters have demonstrated that environmentally cued sex allocation occurs in rhinos, and can have deleterious effects on population growth, but the studbook analysis demonstrated that distal cues, such as age and a female's reproductive history, were not strong predictors of calf sex. Therefore, I examined more proximal cues for biasing birth sex closer to the time of conception. Changes in body condition and diet have both been suggested as important cues in other species. Over a 22-month period, I traveled to zoos worldwide to test several different methods for assessing changes in body condition (detailed in Appendix A). None proved satisfactory. Since changes in circulating glucose concentrations has been demonstrated in laboratory animals and in vitro fertilization assays to influence sex ratios at conception, glucose could be a trigger of interest. I took the unique approach of measuring changes in circulating glucose levels in unrestrained unsedated rhinos (Figure 5.1.1). This sort of research is rarely conducted in captive wildlife but the methodology needs to be validated before experiments to manipulate diet and body condition can be conducted. The rhinos that participated in this dissertation research are in captivity primarily for education and display purposes at zoos and conservation breeding centers. They are valuable animals and it is challenging to get permission to be able to manipulate them. Since I wanted to ensure and demonstrate that the methods I proposed for this chapter would not unduly stress the rhinos, I conducted a pilot study on serum changes in blood glucose after a glucose meal (detailed in Appendix B). 
This chapter was previously published as:

Berkeley, E. V., Linklater, W. L., and E. S. Dierenfeld. Dietary impact on circulating glucose profiles in the white rhinoceros. Journal of Animal Physiology and Animal Nutrition (Early View Access: DOI: 10.1111/j.1439-0396.2010.01047.x), 2010.

Subsequent changes for inclusion in this dissertation are enclosed between brackets: [].

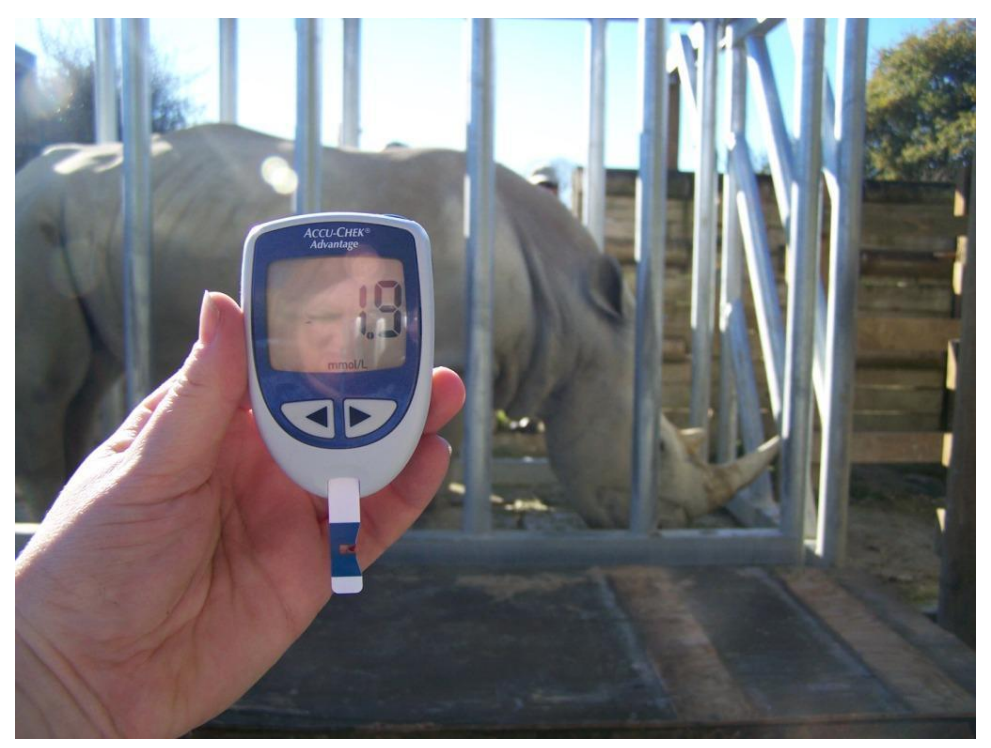

Figure 5.1.1. Hand held glucose meter and blood glucose results from a white rhino female in a restraining chute at the Hamilton Zoo, Hamilton, New Zealand. 


\subsection{Abstract}

Excess dietary glucose may be a factor in several captive wildlife diseases and reproductive abnormalities. The first step in understanding the health consequences of diets high in glucose is to characterize how dietary glucose concentrations change circulating glucose profiles. We adapted the glycemic index approach to detect differences in blood glucose concentrations in white rhinos [Ceratotherium simum simum: Perissodactyla, Burchell, 1817] in response to different meals. Six white rhinos were fasted overnight then randomly assigned to be fed $5 \mathrm{~kg}$ of grass hay and one of 5 meals varying in digestible energy (DE) availability and source (10\% DE glucose, $5 \%$ DE glucose, $10 \%$ DE pelleted horse feed, $10 \%$ DE lucerne hay, 10\% DE grass hay). After eating, the blood glucose response peaked 45-90 minutes later and remained elevated up to 180 minutes. Area under the curve results demonstrated that the blood glucose response was not different between diets. However, at 90 minutes, serum glucose levels in rhinos eating the $10 \%$ lucerne hay diet were significantly lower than the 5\% glucose and $10 \%$ glucose diets but not the $10 \%$ pellet nor $10 \%$ grass hay diets. The changes in blood glucose responses to different diets were similar in magnitude to reported domestic horse profiles but are higher than predicted by allometric scaling. We conclude that the grass hay, lucerne hay and low glycemic index horse pellets fed in this study resulted in similar blood glucose responses in white rhinos. The validation of the methodology used in this study is a first step towards elucidating the relationship between glucose, obesity, health and reproduction in rhinos. 


\subsection{Introduction}

Diets for wildlife in captivity are often nutrient-rich approximations of poorly understood wild diets (Dierenfeld 1997; Jordan 2005). Availability and convenience dictate that captive wildlife species are commonly fed commercial domestic livestock foods. The dietary requirements of wildlife, however, may differ from the production goals of livestock feeding. Domestic animal diets are largely developed for rapid weight gain or high performance and can be energy dense. Such diets are potentially a problem for captive wildlife because they may cause hyperglycemia, weight gain and obesity, since the caloric energy needed for survival and reproduction in captivity is less than in the wild (Crissey 2005).

Animals in captivity may experience chronic activation of the hypothalamicpituitary axis, i.e. distress (Carlstead and Brown 2005; Linklater et al. 2009). Distress can also lead to obesity by activating chemical signals, such as neuropeptide $\mathrm{Y}$ which is released by the sympathetic nervous system and stimulates fat accumulation (Kuo et al. 2007). In primates, these triggers lead to metabolic syndrome, which is a proinflammatory state characterized by increased visceral fat, elevated blood pressure, hyperlipidemia, and impaired glucose tolerance (Shively et al. 2009). A similar metabolic pathway may exist in rhinos. Excess dietary energy may also, in turn, increase glucocorticoid release and insulin insensitivity, as has been shown in equids (Hoffman et al. 2003).

The triad of obesity, stress, and hyperglycemia leads to insulin resistance and the development of laminitis, endotoxemia, hyperlipemia, osteochondrosis, exertional rhabdomyolysis and metabolic syndrome in horses (Hoffman et al. 2003; Pratt et al. 2006; Treiber et al. 2006a; Treiber et al. 2006b; Firshman and Valberg 
2007). Maternal diets high in glucose are also detrimental to offspring health and reproductive function (Rhind 2004; Vick et al. 2006; Vick et al. 2007). Knowledge of the glucose response to different diets in equids might be adapted to understand disease and poor fertility in other Perissodactyla such as the white rhinoceros (Ceratotherium simum: Rhinocerotidae, L.) because they are also grazers (reviewed in Clauss and Hatt 2006).

The global captive white rhinoceros population is approximately 800 animals and not self-sustaining due to low fertility and long periods of reproductive senescence, especially amongst captive born females (Hermes et al. 2006; Roth 2006; Emslie 2008). The reproductive pathologies contributing to poor fertility in captive white rhinos include polycystic ovaries, uterine tumors, extended luteal phases or cycle lengths, and may be partially due to dietary imbalances, including overcondition (Patton et al. 1999; Hermes et al. 2005; Swaisgood et al. 2006; Morrow et al. 2008).

In nature, white rhinos live in highly seasonal environments. Warm wet summers of southern and eastern Africa provide an abundance of high quality forage, while during the cool dry winters, grass can be scarce and of poorer quality (Perrin and Brereton-Stiles 1999). White rhinos apparently compensate for the reduced quality of nutrition in grass in the winter dry season by living off stored body fat (Shrader et al. 2006). Thus, body condition in wild white rhinos cycles annually. Seasonal changes in body condition have already been correlated to reproductive status in other Perissodactlya (Gastal et al. 2004; Lemma et al. 2006). If white rhino disease syndromes and reproductive failure are related to sustained higher energy diets in captivity, some of the observed health problems might be resolved by reducing energy intake, as has been the case for horses (Treiber et al. 2006b). In 
Shetland ponies, for example, restricting caloric intake to induce weight loss rate of $1 \%$ of ideal body weight per week for 17 weeks reversed insulin resistance (Van Weyenberg et al. 2008).

Wild white rhinoceros select a wide variety of grasses to eat that vary seasonally in their availability and nutrient value (Shrader et al. 2006; Arsenault and Owen-Smith 2008; Waldram et al. 2008). Wild diets contain high levels of crude fiber (e.g. 36\%), and low to moderate protein (e.g. 4.5-14.9\% dry biomass; OwenSmith 1988; Kiefer 2002). Captive rhino diets, however, are based on a few species of mono-cultured grass and legume hays supplemented with local browse, pelleted concentrates, fruits, and vegetables (Dierenfeld 1996). Dietary recommendations for captive white rhinoceros suggest up to one third of their daily caloric intake can be delivered in commercially available concentrated pellets, with no specific differentiation between grain- or forage-based pellets (Dierenfeld 1996, Lintzenich and Ward, 1997). More recently, Clauss and Hatt (2006) advocate an even lower percentage of pellets in diets for captive rhinos, and warn particularly against the use of grain-based products. Processing of grains - including initial grinding to incorporate ingredients into pellets - but also the heat generated in the pelleting or extrusion processes, can increase digestibility of carbohydrates and affect glycemic index and glucose response to ingredients. Published feeding recommendations discourage the use of sugary produce (such as ripe bananas, melons, sweet potatoes, sweet corn); nonetheless, many institutions still regularly provide fresh produce or use it as a seemingly innocuous training or enrichment reward for rhinos (authors' observations). Thus, while not necessarily providing glucose per se, captive diets may provide higher available energy, as well as readily digestible carbohydrates, throughout the year than levels to which rhinos are physiologically adapted. 
Despite its potential importance and possible link to health and reproduction, almost nothing is known about circulating glucose concentrations in rhinoceros fed diets varying in glucose availability. The objective of this study was to determine the duration and magnitude of the blood glucose response to standard rhino diet ingredients, and to high and low glucose concentrations.

\subsection{Materials and Methods}

Meals representing diets varying in digestible energy content were fed to individual rhinos as an experiment to measure dietary influences on circulating blood glucose concentrations. The standard diet for the rhinos in this study included $30 \mathrm{~kg}$ grass hay, $2.5 \mathrm{~kg}$ lucerne hay daily, with $1 \mathrm{~kg}$ horse pellets or $1 \mathrm{~kg}$ chopped carrots and apples supplement per animal per week. This diet contained approximately 325 MJ digestible energy (DE) per day, calculated utilizing DE values for foods based on values derived from domestic horses (Kiefer 2002; Clauss and Hatt 2006). For each of the five diet trials, a percentage of the rhinos' daily estimated digestible energy intake was fed as either $10 \%$ DE glucose powder $(1.76 \mathrm{~kg}$, mixed to paste consistency with water and layered on top of grass hay: Healtheries, Auckland, New Zealand), $5 \%$ DE glucose powder $(0.88 \mathrm{~kg}), 10 \%$ DE pelleted grain-based horse feed (2.1 kg; NRM, Auckland, New Zealand), 10\% DE lucerne hay (3 kg; Medicago sativa), or $10 \%$ DE grass hay ( $5 \mathrm{~kg}$; Lolium spp.) for the first meal of the day (Table 5.4.1). Each rhino received each meal over the course of the study. Additional grass hay was made available (up to $5 \mathrm{~kg}$ total) to rhinos during the three hour period of blood sampling, and as a training aid. Meals were fed once to each rhino in a random sequence (ranging from 1-90 days between meals) and no acclimation period was 
performed. At approximately 0800 hours each morning, the rhino was fed one of the meals and blood glucose measured immediately before feeding and every 45 minutes thereafter for three hours (five blood samples total). The grass hay and lucerne hay were sub-sampled (200g) for nutrient analysis and DE calculated using precalibrated near infrared spectroscopy at a commercial laboratory (Pagan, 1998; New Zealand Laboratory Services Ltd., Hamilton, New Zealand; Table 5.4.1). Nutrient composition, including DE, for the pelleted horse feed was provided by the manufacturer. 
Table 5.4.1. Nutritional constituents of meals used in this study.

\begin{tabular}{|c|c|c|c|}
\hline & NRM & Grass & Lucerne \\
\hline & Pellets ${ }^{1}$ & Hay & Hay \\
\hline$\% \mathrm{DM}$ & 88.0 & 88.3 & 87.2 \\
\hline $\mathrm{CP}$ & 12.5 & 6.7 & 15.3 \\
\hline $\mathrm{CF}$ & 7.0 & - & - \\
\hline NDF & 37.0 & 78.7. & 56.1 \\
\hline $\mathrm{ADF}$ & 12.0 & 45.1 & 44.6 \\
\hline $\mathrm{DE}$ & 12.0 & 6.6 & 7.5 \\
\hline
\end{tabular}

Note: $\mathrm{DM}=$ dry matter; $\mathrm{CP}=$ crude protein $\mathrm{CF}=$ crude fat $\mathrm{NDF}=$ nondetergent fiber; $\mathrm{ADF}=$ acid detergent fiber; all constituents are expressed as percent $(\%)$, except digestible energy (DE) is $\mathrm{MJ} / \mathrm{kg}$.

${ }^{1}$ The pellet ingredients included unspecified amounts of wheat, maize, oats, wheat by-products, maize by-products, barley, barley by-products, extracted soyabean meal, rapeseed meal, peas, lucerne meal, molasses, vegetable oils, limestone, dicalcium phosphate, salt, KER vitamins and minerals premix (information provided by manufacturer, NRM, Auckland, New Zealand).

Experiments were conducted over ten months from May, 2008 to February, 2009 on six white rhinoceros (one male and three females at Hamilton Zoo and two males at Auckland Zoo, New Zealand). All rhinos were 5-20 year old adults trained for blood collection by venipuncture of the pinea. Training required three months and was accomplished prior to initiating the feeding experiments. Blood was aspirated with a $1 \mathrm{ml}$ syringe and a 23 or 25 gauge needle or the skin was pricked 
with a needle to draw blood onto the surface. Blood glucose concentrations were measured immediately using a handheld glucose meter (Accu-Chek, Roche Diagnostics, New Zealand). To validate the accuracy of the glucose meter, one blood sample from each rhino was drawn into a fluoride oxalate tube, stored on ice and sent within four hours to a commercial laboratory (Gribbles Veterinary Pathology Ltd, Auckland, New Zealand) for comparison.

Blood glucose results are reported as averaged $\mathrm{mmol} / \mathrm{L} \pm$ standard error of the mean. The glucose values from the handheld meter and the laboratory analysis were correlated using a Pearson's correlation test in SPSS (2007). Area under the curve (AUC) glucose profiles were calculated using the zeroed incremental trapezoid method as in Wolever 2004 and Gordon et al. 2007. The glucose value at time zero was considered baseline for each animal and subsequent values were zeroed against it, then the means were compared by repeated measures ANOVA, and post-hoc ttests.

To compare the effects of time and treatment, repeated measures analysis of variance for the five diets (sampled at $0,45,90,135,180$ minutes) were performed using General Linear Model procedures. Levene's test of equality of error variances was performed and indicated that variances were not equal therefore the Tamhane's test was used in post-hoc univariate tests amongst time and treatments. All tests were considered significant at the 0.05 level. We considered a $\mathrm{P}<0.1$ as a statistical trend requiring closer examination. This study was performed with the approval of the Victoria University of Wellington Animal Ethics Committee (protocol no. 2006R27). 


\subsection{Results:}

The diets were all consumed within 45 minutes of presentation. The rhinos had different reactions to the glucose paste; some ate the hay around it and consumed it last. Others ate the glucose paste preferentially even to the extent of licking remnants of the paste from the concrete floor afterwards. The paired glucose meter and laboratory blood glucose values $(\mathrm{n}=6)$ were positively correlated $(\mathrm{r}=0.96 ; \mathrm{P}<$ $0.01)$. Glucose meter values were, on the average, $11 \% \pm 0.3 \%$ lower than the laboratory values, similar to previous comparisons in the horse (Russell et al. 2007).

Glucose concentrations in the blood rose, peaking at 45-90 minutes, and remained elevated for up to 180 minutes after meals with the exception of the $10 \%$ lucerne which went below baseline by 90 minutes. The magnitude of the response in circulating glucose depended on the energy content of the meal. Raw values ranged from a low of $2.4 \mathrm{mmol} / \mathrm{L}$ at 0 minutes for the $10 \%$ grass hay diet to $5.8 \mathrm{mmol} / \mathrm{L}$ at 90 minutes after eating the $10 \%$ glucose diet (both values from the same lactating female). The highest averaged values were at $4.95 \pm 0.68 \mathrm{mmol} / \mathrm{L} 90$ minutes after eating the $10 \%$ glucose diet (Figure 5.1). The AUC blood glucose response was not different between diets (RM-ANOVA, F4, $26 \mathrm{P}=0.205$ ), and no post-hoc t-tests were significant $(\mathrm{P}<.05)$. The zeroed AUC values $(\mathrm{mmol} / \mathrm{L} \pm$ s.e.m. $)$ were: $6.1 \pm 3.3$ for $10 \%$ glucose powder, $2.2 \pm 0.9$ for $5 \%$ glucose powder, $2.2 \pm 1.7$ for $10 \%$ pellets, 1.7 \pm 0.9 for $10 \%$ grass hay, and $0.5 \pm 0.3$ for $10 \%$ lucerne hay.

For the time and treatment effects, there was a significant effect of time (ANOVA, F4, $100=11.713, \mathrm{P}<0.001)$ and a weak interaction between time and 
treatment (ANOVA, F16, $100=1.593, \mathrm{P}=0.084$ ) so post-hoc tests were performed to investigate differences between treatments at individual time periods. No differences were detected at $0,45,135$ or 180 minutes between diets. However, at 90 minutes, differences between diets were detected (ANOVA, F 4, $25=5.633, \mathrm{P}<0.01$ ). The $10 \%$ lucerne hay diet was significantly lower than both the $10 \%$ glucose (mean difference $=-1.33 \pm 0.32)$ and the $5 \%$ glucose diets (mean difference $=-0.87 \pm 0.23)$.

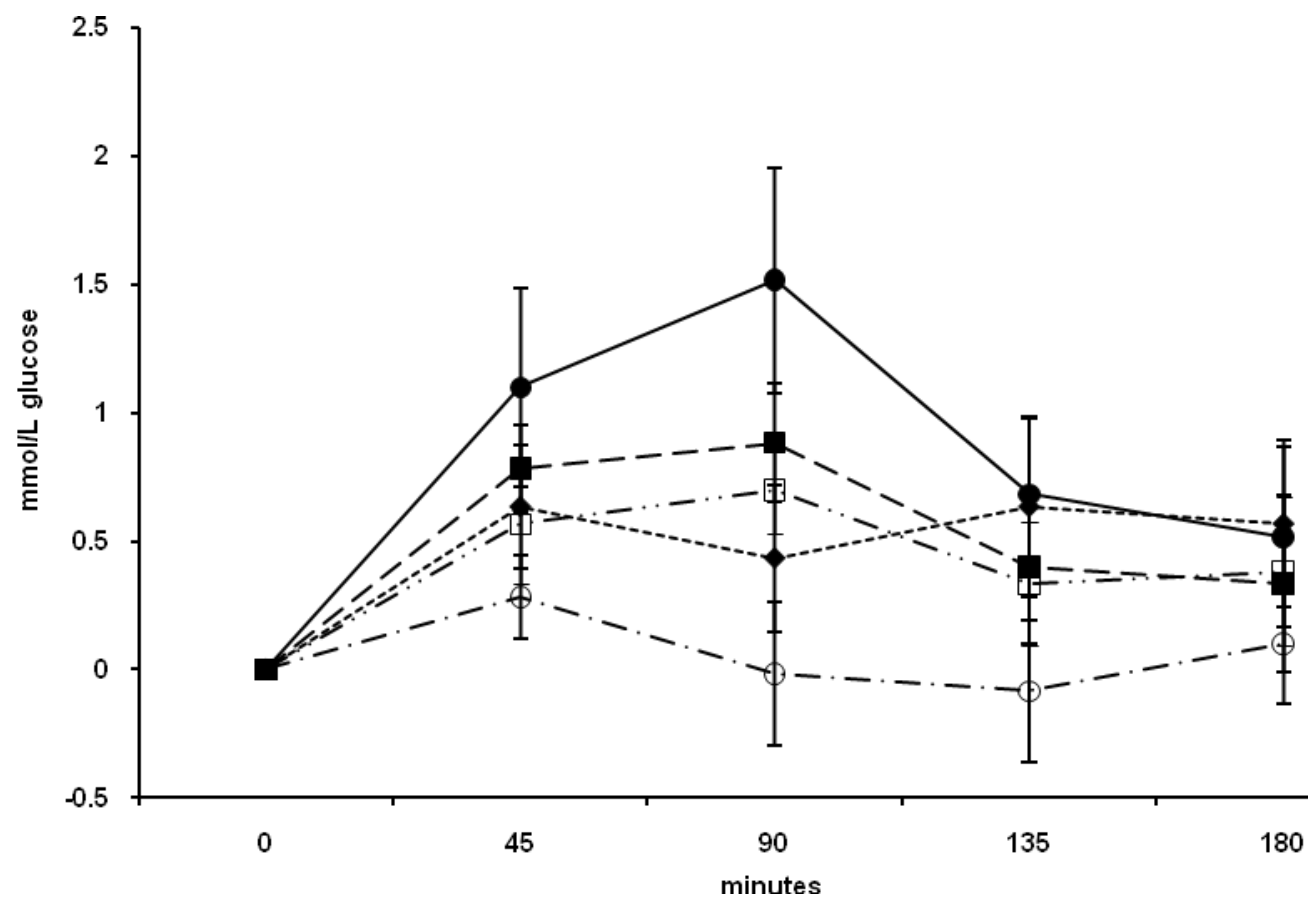

Figure 5.5.1. Zeroed changes in blood glucose values in white rhinos fed meals varying in digestible energy (\% of total daily DE intake) $\circ=10 \% \mathrm{DE}$ lucerne hay, $=10 \% \mathrm{DE}$ glucose, $\mathbf{\square}=5 \% \mathrm{DE}$ glucose, $=10 \%$ DE pellets, $\square=10 \% \mathrm{DE}$ grass hay ( $\mathrm{n}=6 ; \pm$ s.e.m.). For each meal, an additional $5 \mathrm{~kg}$ of grass hay was provided ad libitum. 


\subsection{Discussion:}

The AUC analysis demonstrated no significant differences between diets. The magnitude of the response is $40 \%$ lower compared than that reported in the horse, but our sampling time was not as frequent or as long (i.e. Rodiek and Stull 2007). Allometric theory suggests that rhinos would have lower circulating glucose concentrations compared to horses (Umminger, 1975; Gordon et al. 2007; Kjeld and Olafsson 2008). Using Kjeld and Olafsson's equation, with the rhinos' body weights of 1400-2050 kg, we would expect glucose measurements to range from 1.29-1.8 $\mathrm{mmol} / \mathrm{L}$. Our results were higher (2.8-5.4 mmol/L), but do fall within the reported range in the ISIS MedArks (2003) records for white rhinos $(1.10-14.1 \mathrm{mmol} / \mathrm{L}, \mathrm{n}=$ 98). Information on wild white rhino glucose values is limited to animals already stressed by capture and anesthesia. In 84 blood samples drawn from 16 white rhinos immobilized over a 2 day period, Seal et al. (1976) found glucose measurements of $35-117 \mathrm{mg} / \mathrm{dl}$ (equivalent to $1.94-6.5 \mathrm{mmol} / \mathrm{L}$ ). These values are also similar to our results, though it is not clear how the blood samples were handled in the field, which could affect assay sensitivity. The glucose profile of non-stressed, wild white rhinos is unknown, but our data and other reported values (both captive and wild) appear to indicate relatively high circulating glucose as an atypical "norm" for such a large animal.

In this study, glucose was administered as "proof of principle" of the methodology and does not necessarily reflect a physiological response to items typically in a rhino diet, although honey, fruit juices, and molasses are included in some training/enrichment food lists for the species. Furthermore, fruits (bananas, 
pineapples, papaya, grapes, melons) and vegetables (sweet corn, pumpkin, potatoes, beets) are often used for these purposes. Although feeding recommendations discourage their use, quantities of these items fed to large herbivores are not insubstantial in some instances, and must be considered in total diet evaluations. Nonetheless, we did not compare glucose response following "produce" or sweet feed meals, which would be interesting to do in the future.

Overall, the foods fed in this study show similar glucose responses. The lucerne hay diet contained more than twice the protein content as the grass hay, and was eight-fold higher in insoluble fiber concentration than the pelleted feed (Table 5.1), which may account for the lower peak at 90 minutes relative to the other diets. Rodiek and Stull (2007) reported that the blood glucose responses in horses fed corn (maize) and oats, both components of the NRM pellets, were seven times higher than peaks following an alfalfa (lucerne) hay meal. We did not observe this, however the pellets used in this study were specifically formulated to produce a low glycemic response in horses, and appear to elicit a similar response in white rhinos. Protein can be insulinotropic, and can lower blood glucose concentrations when eaten with carbohydrates (e.g. in humans, Flint et al. 2004). Increased fiber concentrations of the forages may also slow the absorption of glucose into the bloodstream from the small intestine (Rodiek and Stull 2007). We did not test the high glucose 'treats' that are sometimes fed to rhinos. If high-glucose (sugary) ingredients are utilized for training/enrichment purposes, perhaps they should be fed jointly with higher fiber and/or protein feeds rather than singly - by adding beet pulp, rice bran, soy hulls, or browse/forage to the enrichment regimen.

One of the physiological sex allocation mechanisms may be female embryo intolerance of high in utero glucose concentrations (Gutierrez-Adan et al. 2001; 
Cameron 2004). Changes in maternal energy balance around the time of conception have been associated with changes in birth sex ratios in both cattle and horses (Roche et al. 2006; Cameron and Linklater 2007), with a positive energy balance resulting in fewer female births. In wild horses, the birth sex ratio can range from 3 to $81 \%$ male between mares depending on whether they were in negative or positive energy balance, respectively (Cameron and Linklater 2007). Male-biased birth sex ratios may occur in captive rhino populations, or at least at specific institutions, more than predicted by chance (Dennis et al. 2007b). We have identified rainfall, and inferred body condition, as influencing calf sex in wild black rhinos (Berkeley and Linklater 2010). If this mechanism is also the case for white rhinoceros, then a male birth sex bias might be a consequence of high glycemic diets.

Glucose profiles in response to different diets have not been reported previously for any large wild ungulate species. Not only do we have limited data on circulating glucose in response to diet, we do not know the consequences of diets high in glucose. Captive diets may underlie a number of pathological syndromes and diseases in rhinos, particularly black rhinos (Dennis et al. 2007a). We demonstrated significant blood glucose variation in response to diet, and higher glucose levels than expected by allometry. We also showed the handheld glucose meter to be a rapid, easy and reliable tool that could be applied more broadly to understand circulating glucose in wildlife with minimal animal handling. Our results suggest that diets of grass hay, lucerne hay, and low glycemic index horse pellets produce similar glucose responses in white rhinos. Our results support the use of a low glycemic diet in white rhinos to maintain low circulating glucose concentrations in accordance with existing management guidelines. We recommend further experiments to 1) compare glucose concentrations in captive and wild rhino diets, and 2) determine the relationship 
between circulating glucose concentrations, reproductive failure and pathological processes in all species of rhinos.

\subsection{Acknowledgements:}

Samantha Kudeweh, Mike Goold, Andrew Gore, Brenna Barber, Massey veterinary students, Nat Sullivan, John Potter, keepers at Auckland Zoo and Hamilton Zoo. Roche Diagnostics, New Zealand donated glucose meters, Healtheries New Zealand donated glucose powder. The comments by reviewer Marcus Clauss greatly improved this manuscript. Funding for this project was provided by the International Rhino Foundation to WLL and a Victoria University of Wellington PhD Scholarship to EVB.

\subsection{References:}

Arsenault, R., and N. Owen-Smith. 2008. Resource partitioning by grass height among grazing ungulates does not follow body size relation. Oikos 117: $1711-1717$.

Berkeley, E.V. and W. L. Linklater. Annual and seasonal variation in rainfall may influence progeny sex ratio in the black rhinoceros (Diceros bicornis). South African Journal of Wildlife Research 40(1): 53-57, 2010.

Cameron, E.Z. 2004. Facultative adjustment of mammalian sex ratios in support of the Trivers-Willard hypothesis: evidence for a mechanism. Proceedings of the Royal Society of London Series B-Biological Sciences 271: 1723-1728. 
Cameron, E.Z., and W.L. Linklater. 2007. Extreme sex ratio variation in relation to change in condition around conception. Biology Letters 3: 395-397.

Carlstead, K., and J.L. Brown. 2005. Relationships between patterns of fecal corticoid excretion and behavior, reproduction, and environmental factors in captive black (Diceros bicornis) and white (Ceratotherium simum) rhinoceros. Zoo Biology 24: 215-232.

Clauss, M., and J.-M. Hatt. 2006. The feeding of rhinoceros in captivity. International Zoo Yearbook 40: 197-209.

Crissey, S. 2005. The complexity of formulating diets for zoo animals: a matrix. International Zoo Yearbook 39: 36-43.

Dennis, P.M., J.A. Funk, P.J. Rajala-Schultz, E.S. Blumer, R.E. Miller, T.E. Wittum and W.J.A. Saville. 2007a. A review of some of the health issues of captive black rhinoceroses (Diceros bicornis). Journal of Zoo and Wildlife Medicine 38: 509-517.

Dennis, P.M., P.J. Rajala-Schultz, J.A. Funk, E.S. Blumer, R.E. Miller, T.E. Wittum and J.A. William. 2007b. Risk factors associated with a skewed natal sex ratio in captive black rhinoceroses (Diceros bicornis) in the United States. Journal of Zoo and Wildlife Medicine 38: 533-539.

Dierenfeld, E.S. 1996. Nutrition. pp. 52-53. Rhinoceros SSP Husbandry Manual. Fort Worth Zoological Park, Fort Worth, Texas.

Dierenfeld, E.S. 1997. Captive wild animal nutrition: a historical perspective. pp. 989-999. Proc Nutrition Society, Edinburgh, Scotland.

Emslie, R.H. 2008. Rhino population sizes and trends. Pachyderm 44: 88-95.

Firshman, A.M., and S.J. Valberg. 2007. Factors affecting clinical assessment of insulin sensitivity in horses. Equine Veterinary Journal 39: 567-575. 
Flint, A., B.K. Møller, A. Raben, D. Pedersen, I. Tetens, J.J. Holst and A. Astrup. 2004. The use of glycaemic index tables to predict glycaemic index of composite breakfast meals. British Journal of Nutrition 91: 979-989.

Gastal, M.O., E.L. Gastal, V. Spinelli and O.J. Ginther. 2004. Relationships between body condition and follicle development in mares. Animal Reproduction 1: $115-121$.

Gordon, M.E., M.L. Jerina, S.L. King, K.E. Davison, J.K. Young and R.H. Raub. 2007. The effects of nonstructural carbohydrate content and feeding rate on glucose and insulin response to meal feeding in equine. Journal of Equine Veterinary Science 27: 489-493.

Gutierrez-Adan, A., J. Granados, B. Pintado and J. De La Fuente. 2001. Influence of glucose on the sex ratio of bovine IVM/IVF embryos cultured in vitro. Reproduction Fertility and Development 13: 361-365.

Hermes, R., T.B. Hildebrandt, S. Blottner, C. Walzer, S. Silinski, M.L. Patton, G. Wibbelt, F. Schwarzenberger and F. Goritz. 2005. Reproductive soundness of captive southern and northern white rhinoceroses (Ceratotherium simum simum, Cs. cottoni): evaluation of male genital tract morphology and semen quality before and after cryopreservation. Theriogenology 63: 219-238.

Hermes, R., T.B. Hildebrandt, C. Walzer, F. Goritz, M.L. Patton, S. Silinski, M.J. Anderson, C.E. Reid, G. Wibbelt, K. Tomasova and F. Schwarzenberger. 2006. The effect of long non-reproductive periods on the genital health in captive female white rhinoceroses (Ceratotherium simum simum, Ceratotherium simum cottoni). Theriogenology 65: 1492-1515. 
Hoffman, R.M., R.C. Boston, D. Stefanovski, D.S. Kronfeld and P.A. Harris. 2003. Obesity and diet affect glucose dynamics and insulin sensitivity in Thoroughbred geldings. Journal of Animal Science 81: 2333-2342.

International Species Information System (ISIS). 2003. MedARKS 5.40. ISIS Physiologic Data. ISIS, Apple Valley, Minnesota.

Jordan, M.J.R. 2005. Dietary analysis for mammals and birds: a review of field techniques and animal-management applications. International Zoo Yearbook 39: 108-116.

Kiefer, B. 2002. Qualität und Verdaulichkeit der vom Breitmaulnashorn (Ceratotherium simum simum) aufgenommenen Nahrung. University of Munich, Munich, Germany.

Kjeld, M., and O. Olafsson. 2008. Allometry (scaling) of blood components in mammals: connection with economy of energy? Canadian Journal of Zoology 86: 890-899.

Kuo, L.E., J.B. Kitlinska, J.U. Tilan, L. Li, S.B. Baker, M.D. Johnson, E.W. Lee, M.S. Burnett, S.T. Fricke, R. Kvetnansky, H. Herzog and Z. Zukowska. 2007. Neuropeptide $\mathrm{Y}$ acts directly in the periphery on fat tissue and mediates stress-induced obesity and metabolic syndrome. Nature Medicine 13: 803811.

Lemma, A., M. Bekana, H.J. Schwartz and T. Hildebrandt. 2006. The effect of body condition on ovarian activity of free ranging tropical jennies (Equus asinus). Journal of Veterinary Medicine Series a-Physiology Pathology Clinical Medicine 53: 1-4.

Linklater, W.L., E.A. MacDonald, J.R.B. Flamand and N.M. Czekala. 2009. Declining and low fecal corticoids are associated with distress, not 
acclimation to stress, during the translocation of African rhinoceros. Animal Conservation 13(1):104-111.

Lintzenich, B. A., and A. M. Ward. 1997. Hay and pellet ratios: considerations in feeding ungulates. Pp. 1-12 in Nutrition advisory group handbook. Fact sheet 006 (D. E. Ullrey, M. R. Murphy, and E. T. Clemens, eds.). Chicago Zoological Society, Brookfield Zoo, Chicago, Illinois.

Morrow, C., S. Kudeweh, M. Goold and S. Standley. 2008. Reproductive cycles, pregnancy and reversal of long term acyclicity in captive southern white rhinoceros at Hamilton Zoo. Reproduction Fertility and Development 21: 180.

Owen-Smith, N. 1988. Megaherbivores: The influence of very large body size on ecology. Cambridge University Press, Cambridge.

Pagan, J.D. 1998. Measuring the digestible energy content of horse feeds. In: Pagan JD, editor. Advances in Equine Nutrition. Nottingham: Nottingham University Press. p 71-76.

Patton, M.L., R.R. Swaisgood, N.M. Czekala, A.M. White, G.A. Fetter, J.P. Montagne, R.G. Rieches and V.A. Lance. 1999. Reproductive cycle length and pregnancy in the southern white rhinoceros (Ceratotherium simum simum) as determined by fecal pregnane analysis and observations of mating behavior. Zoo Biology 18: 111-127.

Perrin, M.R., and R. Brereton-Stiles. 1999. Habitat use and feeding behaviour of the buffalo and the white rhinoceros in the Hluhluwe-Umfolozi Game Reserve. South African Journal of Wildlife Research 29: 72-80.

Pratt, S.E., R.J. Geor and L.J. McCutcheon. 2006. Effects of dietary energy source and physical conditioning on insulin sensitivity and glucose tolerance in standardbred horses. Equine Veterinary Journal Supplement 36: 579-584. 
Rhind, S.M. 2004. Effects of maternal nutrition on fetal and neonatal reproductive development and function. Animal Reproduction Science 82-83: 169-181.

Roche, J.R., J.M. Lee and D.P. Berry. 2006. Pre-conception energy balance and secondary sex ratio - Partial support for the Trivers-Willard hypothesis in dairy cows. Journal of Dairy Science 89: 2119-2125.

Rodiek, A.V., and C.L. Stull. 2007. Glycemic Index of Ten Common Horse Feeds. Journal of Equine Veterinary Science 27: 205-211.

Roth, T.L. 2006. A review of the reproductive physiology of rhinoceros species in captivity. International Zoo Yearbook 40: 130-143.

Russell, C., J.E. Palmer, R.C. Boston and P.A. Wilkins. 2007. Agreement between point-of-care glucometry, blood gas and laboratory-based measurement of glucose in an equine neonatal intensive care unit. Journal of Veterinary Emergency and Critical Care 17: 236-242.

Seal, U., R.A. Barton, L. Mather and C. Gray. 1976. Baseline laboratory data for the white rhinoceros (Ceratotherium simum simum). Journal of Zoo Animal Medicine 7: 11-16.

Shively, C.A., T.C. Register and T.B. Clarkson. 2009. Social stress, visceral obesity, and coronary artery atherosclerosis: product of a primate adaptation. American Journal of Primatology 71: 742-751.

Shrader, A.M., N. Owen-Smith and J.O. Ogutu. 2006. How a mega-grazer copes with the dry season: food and nutrient intake rates by white rhinoceros in the wild. Functional Ecology 20: 376-384.

SPSS for Windows, Release 16.0. 2007. Chicago, SPSS Inc. 
Swaisgood, R.R., D.M. Dickman and A.M. White. 2006. A captive population in crisis: Testing hypotheses for reproductive failure in captive-born southern white rhinoceros females. Biological Conservation 129: 468-476.

Treiber, K.H., D.S. Kronfeld and R.J. Geor. 2006a. Insulin resistance in equids: possible role in laminitis. Journal of Nutrition 136: 2094-2098.

Treiber, K.H., D.S. Kronfeld, T.M. Hess, B.M. Byrd, R.K. Splan and W.B. Staniar. 2006b. Evaluation of genetic and metabolic predispositions and nutritional risk factors for pasture-associated laminitis in ponies. Journal of the American Veterinary Medical Association 228: 1538-1545.

Umminger B.L. 1975. Body size and whole blood sugar concentrations in mammals. Comparative Biochemistry and Physiology Part A: Physiology 52:455-458.

Van Weyenberg, S., M. Hesta, J. Buyse and G.P.J. Janssens. 2008. The effect of weight loss by energy restriction on metabolic profile and glucose tolerance in ponies. Journal of Animal Physiology and Animal Nutrition 92: 538-545.

Vick, M.M., A.A. Adams, B.A. Murphy, D.R. Sessions, D.W. Horohov, R.F. Cook, B.J. Shelton and B.P. Fitzgerald. 2007. Relationships among inflammatory cytokines, obesity, and insulin sensitivity in the horse. Journal of Animal Science 85: 1144-1155.

Vick, M.M., D.R. Sessions, B.A. Murphy, E.L. Kennedy, S.E. Reedy and B.P. Fitzgerald. 2006. Obesity is associated with altered metabolic and reproductive activity in the mare: effects of metformin on insulin sensitivity and reproductive cyclicity. Reproduction Fertility and Development 18: 609617. 
Waldram, M.S., W.J. Bond and W.D. Stock. 2008. Ecological engineering by a mega-grazer: white rhino impacts on a South African savanna. Ecosystems 11: $101-112$.

Wolever, T.M.S. 2004. Effect of blood sampling schedule and method of calculating the area under the curve on validity and precision of glycaemic index values. British Journal of Nutrition 91: 295-300. 


\section{Chapter 6. Synopsis. Understanding the role of sex allocation theory explains biased sex ratios in rhinos and improves small population management.}

\subsection{Summary}

The purpose of this dissertation research was to determine the causes of a perceived bias in birth sex ratios in the captive African rhinoceros (black rhinoceros: Diceros bicornis: Perissodactyla, Linnaeus, 1758; white rhinoceros: Ceratotherium simum simum: Perissodactyla, Burchell, 1817) population and to develop strategies to remedy this situation. Developing ways to manipulate calf sex could be extremely useful. Any excess male calf is a problem; these large, sometimes belligerent animals require a significant investment in enclosure design and, due to their large size, can be expensive to feed. I wanted to find what environmental factors drive calf sex. Chapter 2 demonstrates that rainfall variation is an important cue for calf sex for black rhinos in the wild.

In Chapter 3 I demonstrated the effect calf sex biases can have on small population survival. The computer models confirmed that while random annual increases in birth sex ratios can have a positive effect on population persistence, sequential years of biases have the opposite effect. It is not just the percentage of biased sex ratios but the manner in which they come into a population. Five year pulses of male or female birth sex biases are extremely deleterious to population growth. This is useful information to know now when stocking new reserves (food availability could produce a pulse of male calves right away: Linklater et al., 2008). Climate change is looming issue for all biologists. While the specific changes aren't fully understood yet, most reports state that rainfall duration and frequency will be 
more variable (Lumsden et al., 2009; Rutherford et al., 1999; Wadge, 2007). Chapter 3 demonstrates a previously undescribed consequence of changes in rainfall patterns for rhinos and is another factor to consider when conducting population viability analyses in any endangered species.

In Chapter 4, I found that there is not a birth sex bias in the rhinos in the international black rhino and white rhino studbook populations (Ochs, 2005a; Ochs, $2005 \mathrm{~b}$ ), the reported excess of males is not different from wild birth sex ratios and there are only a few zoos that have more male calves than would be expected statistically. Furthermore, the studbook analysis eliminated a whole host of suspected factors, thus lending indirect support to the idea that energy availability is most likely the main cue triggering calf sex and is further supported by in vitro and in vivo evidence in other species (Cameron, 2004; Roche, 2006).

In order to test some of the 'more interesting' hypotheses, I needed to validate methodology. One of the central hypotheses is the role of glucose in differential sex conception and early embryo survival. Rhino diets in captivity were suspected to be poor mimics of wild rhino diets. By testing how glucose is metabolized in rhinos after meals, I gained understanding of how well captive diets mimic wild ones. The results can now be compared to energy intake in wild white rhino diets.

What this $\mathrm{PhD}$ research was not able to achieve was to develop a clear strategy for causing female rhinos to produce one sex of calf or the other. Obviously females would be preferred, as they are the limiting sex. But understanding the mechanisms for sex allocation would be extremely useful, not only for African rhinos, but for the much more critically endangered Asian species. Chapter 5 was an initial step towards developing these protocols. 


\subsection{Directions for future research}

This dissertation research confirms that environmentally cued sex allocation occurs in black rhinos. This also has implications for managers of small populations of wild rhinos and for establishing guidelines for new reserves. If a cohort of female rhinos are introduced to an area that did not previously hold rhinos, the amount of preferred forage available may be excessive and may cause a temporary increase in body condition, resulting in a pulse of male calves. This pulse could have long-term consequences for population growth rates.

We need to test the environmentally cued sex allocation hypothesis in the other four species of rhinos. Having the ability to test these hypotheses on closely related taxa that have different dietary requirements, will not only benefit their conservation management, but would increase our understanding of the range of variation in the sex allocation response in mammals. Black rhinos are browsers, white rhinos are grazers and Greater One-horned rhinos are considered mixed feeders (Clauss and Hatt, 2006; Owen-Smith, 1988). I would like to make predictions on the range of the sex allocation response in these three species based on the seasonal variation in their diets.

While studbooks do not appear to be useful for testing hypotheses of biased birth sex ratios, they still may be useful for testing theories on calf mortality and survival. The factors that improve calf survival to year one in captivity is an understudied part of rhino population demography. Though I suspect that we would reach similar conclusions, that a mother's reproductive history or quality are not important predictors of calf survival, I think it is important to eliminate these factors, 
in order to focus on aspects such as diet and environment during the first year after birth.

Even though I was not able to demonstrate a conclusive cause for biased sex ratios, this inconclusive result leads to more interesting hypotheses that are supported by results in other species. Based on research ongoing in other species, protocols to change body condition and diet in the pre- and peri-conception periods seem most likely to be able to influence calf sex. In vitro evidence of the cellular mechanisms needs to be confirmed. The role of circulating glucose on uterine and follicular glucose concentrations needs to be further explored. The relationship between dietary glucose, circulating glucose and steroid hormones during follicular recruitment, oocyte maturation and fertilization, blastocyst development and implantation all need to be further characterized. The challenge of finding a large enough research population to do all these experiments is great. We need to first develop these approaches in a model species for rhinos. Domestic horses would be quite suitable as they have a similar diet and physiology and are the most closely related domesticated mammal, also in the Order Perissodactyla.

\subsection{Concluding remarks}

The threats to the continuing existence of all species of rhinos are constant and significant. Poaching is once again on the rise in South Africa and Kenya (Milliken, 2009) and the demand for rhino horn in Asia as traditional medicine shows no sign of decreasing. We must continue to address rhinoceros conservation from multiple fronts. Developing new approaches for influencing a female to 
conceive a calf of a desired sex will enable us to better manage these glorious creatures.

\subsection{References}

Cameron E. 2004. Facultative adjustment of mammalian sex ratios in support of the Trivers-Willard hypothesis: evidence for a mechanism. Proceedings of the Royal Society of London Series B-Biological Science 271(1549):1723 - 1728.

Clauss M, Hatt J-M. 2006. The feeding of rhinoceros in captivity. International Zoo Yearbook 40(1):197-209.

Linklater WL, Law PR, Zekala N. 2008. Understanding the mechanism and causes of male-biased birth sex ratios (BSR) in captivity: capitalizing on preliminary findings from investigations of black rhinoceros translocations. International Rhino Foundation. 79 p.

Lumsden T, Schulze R, Hewitson B. 2009. Evaluation of potential changes in hydrologically relevant statistics of rainfall in Southern Africa under conditions of climate change. Water SA 35(5):649-656.

Milliken T, Emslie RH, Talukdar B. 2009. African and Asian rhinoceroses: A report from the IUCN Species Survival Commission (IUCN/SSC) African and Asian Rhino Specialist Groups and TRAFFIC to the CITES Secretariat pursuant to Resolution Conf. 9.14 (Rev. CoP14) and Decision 14.89. Doha: IUCN. 1-18 p.

Ochs A. 2005a. International studbook for the black rhinoceros, Diceros bicornis (Linne 1758). Berlin AG: Zoologischer Garten Berlin AG. Report nr Volume 10. $233 \mathrm{p}$. 
Ochs A. 2005b. International studbook for the white rhinoceros, Ceratotherium simum (Burchell 1817). Berlin AG: Zoologischer Garten Berlin AG. Report nr Volume 10. 409 p.

Owen-Smith N. 1988. Megaherbivores: The influence of very large body size on ecology. 1st ed. Cambridge: Cambridge University Press.

Roche JR, Lee JM, Berry DP. 2006. Pre-conception energy balance and secondary sex ratio - Partial support for the Trivers-Willard hypothesis in dairy cows. Journal of Dairy Science 89(6):2119-2125.

Rutherford MC, Powrie LW, Schulze RE. 1999. Climate change in conservation areas of South Africa and its potential impact on floristic composition: A first assessment. Diversity and Distributions 5(6):253-262.

Wadge MJH. 2007. A vulnerability analysis of Hluhluwe Imfolozi Park for the period 1980 to 2000. [M.S.]. Johannesburg: University of Witwatersrand. 159 p. 


\section{Appendix A. Quantification of black rhino and white rhino body condition by}

visual assessment, ultrasound, and morphometrics.

\section{A.1 Preface}

In order to better measure changes in body condition that could influence sex allocation, I tested several metrics for assessing body condition in white rhinos and black rhinos at 12 different zoos in the United States of America, Australia and New Zealand (Fig. A.1.1).

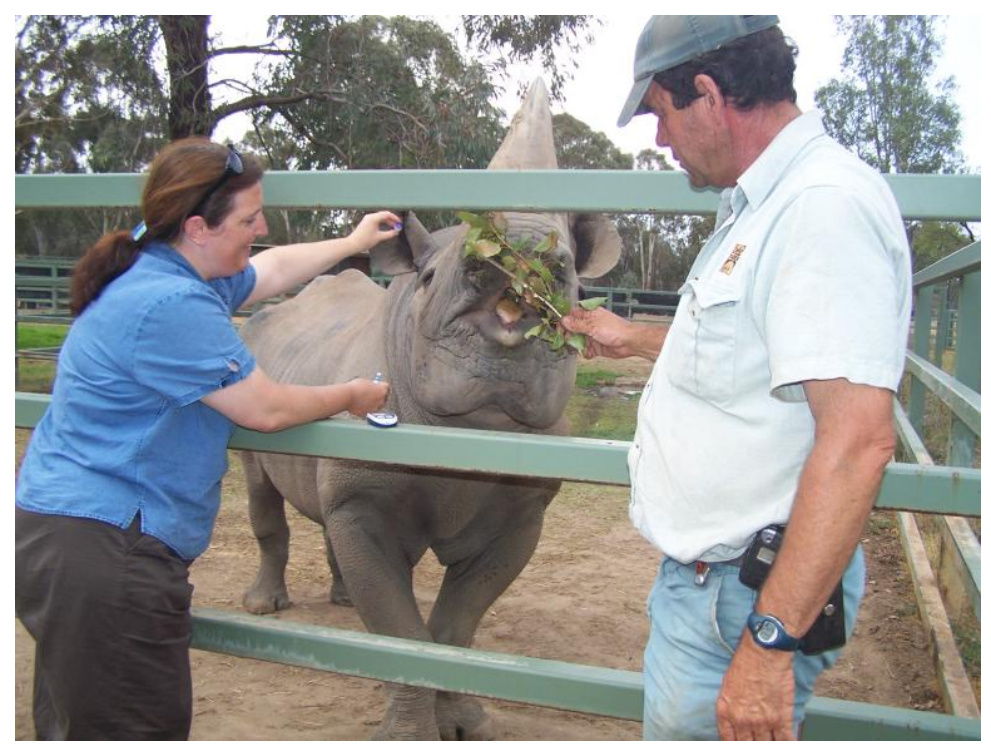

Figure A.1.1. Determining the suitability of a young male black rhino for blood collection, Western Plains Zoo, Dubbo, Australia 


\section{A. 2. Abstract}

I evaluated several methods for measuring body condition in both African rhino species. Visual scores of body condition were performed on 23 rhinos. Transdermal ultrasound was performed on four white rhinos. Morphometric measurements were taken from six white rhinos. Preliminary results demonstrate that visual assessment could be useful for monitoring long-term changes in body condition in both species of rhino. Transdermal ultrasound was not able to penetrate the thick rhino skin. Morphometric measurements suggest sex differences in rhino body mass indices. Further research needs to be done in all areas to confirm the utility of these methods for measuring short-term changes in body condition.

\section{A.3. Introduction}

Anecdotal evidence suggests that rhinos in captivity are overweight compared to their wild counterparts. Excess weight in captive zoo animals can result in adverse health effects (i.e. inflammatory-mediated diseases) and interfere with captive breeding efforts (Leigh, 1994; Videan, 2007). Regular use of quantitative tools, such as body weight and visual body condition scores, can also provide insight on long-term changes on individual and herd health (Stephenson, et al, 2002). There are few reports comparing captive and wild rhino morphometric measurements (Dinerstein, 1991; Freeman, et al., 1969; Rivera, Citino and Bush, unpublished). In order to support the idea that captive rhinos are overweight compared to their wild counterparts, a body mass index, similar to that which is used in humans to measure obesity, is being constructed (Brewer, 2010). 


\section{A.4. Methods}

Body condition was scored for each rhino, based on the method of Reuter et al. (1998). In addition, A-mode ultrasound of several sites on the rhino (i.e. flank, shoulder, and tail head) was measured with the PregAlert Pro handheld ultrasound (Renco Corporation, Minneapolis, MN; Ganaie et al., 2009). Morphometric measurements were taken of body weight, height at the withers and body length from top of skull to prominent point over the withers to the tailhead. Body condition was plotted by comparing body weight to body length and body weight to body condition score for each sex.

\section{A.5. Results}

Ten different zoos were visited to review for participation in this study (Table A.5.1) but not all rhinos participated in all measurements due to inability to approach them. Body condition scores were assessed for 16 white rhinos (11 females, 5 males) and 7 black rhinos (6 females, 1 male; Table A.5.2). Body condition scores (BCS) values ranged from 3 to 5 . 
Table A.5.1. List of Research Trips, December, 2006-September, 2008.

\begin{tabular}{ll}
\hline Date & Zoological Institution \\
\hline December, 2006 & Western Plains Zoo, New South Wales, \\
April, 2007 & Mustralia \\
April, 2007 & Werribee Zoo, Victoria, Australia \\
& Western Plains Zoo, New South Wales, \\
April, 2007 & Australia \\
June, 2007 & Hamilton Zoo, Hamilton, New Zealand \\
August, 2007 & Busch Gardens, Florida, USA \\
August, 2007 & White Oak Conservation Center, Florida, USA \\
October, 2007 & Busch Gardens, Florida, USA \\
October, 2007 & White Oak Conservation Center, Florida, USA \\
November, 2007 & Cincinnati Zoo, Ohio, USA \\
November, 2007 & Cleveland Zoo, Ohio, USA \\
November, 2007 & Columbus Zoo, Ohio, USA \\
May, 2008 & Hamilton Zoo, Hamilton, New Zealand \\
August, 2008 & Hamilton Zoo, Hamilton, New Zealand \\
September, 2008 & Hamilton Zoo, Hamilton, New Zealand \\
September, 2008 & Auckland Zoo, Auckland, New Zealand \\
\hline
\end{tabular}


Table A.5.2 Body condition scores (BCS) from black rhinos and white rhinos.

\begin{tabular}{llllll}
\hline Institution & Species & ID & Sex & BCS & age \\
\hline Western Plains Zoo & Black & Musipando & F & 3.5 & adult \\
Western Plains Zoo & Black & Rocket & F & 4.0 & adult \\
Western Plains Zoo & Black & Bikita & F & 4.2 & adult \\
Western Plains Zoo & Black & Pepe Kalle & F & 3.5 & adult \\
Western Plains Zoo & Black & Dunjuma & F & 4.5 & adult \\
Western Plains Zoo & Black & Kalengwisi & F & 4.5 & adult \\
Western Plains Zoo & Black & Mpanze & M & 5.0 & subadult \\
Western Plains Zoo & White & Aluka & F & 5.0 & adult \\
Western Plains Zoo & White & Umgali & F & 3.5 & adult \\
Western Plains Zoo & White & Intombi & F & 3.5 & adult \\
Western Plains Zoo & White & Azizi & F & 5.0 & subadult \\
Western Plains Zoo & White & Inyeti & F & 4.5 & subadult \\
Western Plains Zoo & White & Amira & F & 4.5 & subadult \\
Werribee Open Range Zoo & White & Kapamba & M & 4.5 & adult \\
Auckland & White & Zambese & M & 4.5 & adult \\
Auckland & White & Inkosi & M & 3.5 & subadult \\
Auckland & White & Mtoto & M & 3.0 & subadult \\
Hamilton & White & Kruger & M & 4.0 & adult \\
Hamilton & White & Moesha & F & 4.0 & adult \\
Hamilton & White & Kito & F & 3.0 & adult \\
Hamilton & White & Caballe & F & 4.0 & adult \\
Werribee Open Range Zoo & White & Make & F & 5.0 & adult \\
Werribee Open Range Zoo & White & Sisi & F & 5.0 & adult \\
\hline
\end{tabular}

Where possible, BCS was correlated to weight and sex, (Figure A.5.1). Male white rhinos showed a greater correlation of body condition score to weight than females, $\left(R^{2}=0.9684, y=0.0018 x+0.7128\right.$, vs. $R^{2}=0.663, y=0.0018 x+1.0164$, respectively). The inverse was true for the body mass index, where male white rhinos had a poorer correlation of weight to height than females, $\left(\mathrm{R}^{2}=0.7194, \mathrm{y}=\right.$ $88.538 \mathrm{x}-3652.8$ vs. $\mathrm{R}^{2}=0.949, \mathrm{y}=255.08 \mathrm{x}-13842$, respectively). 


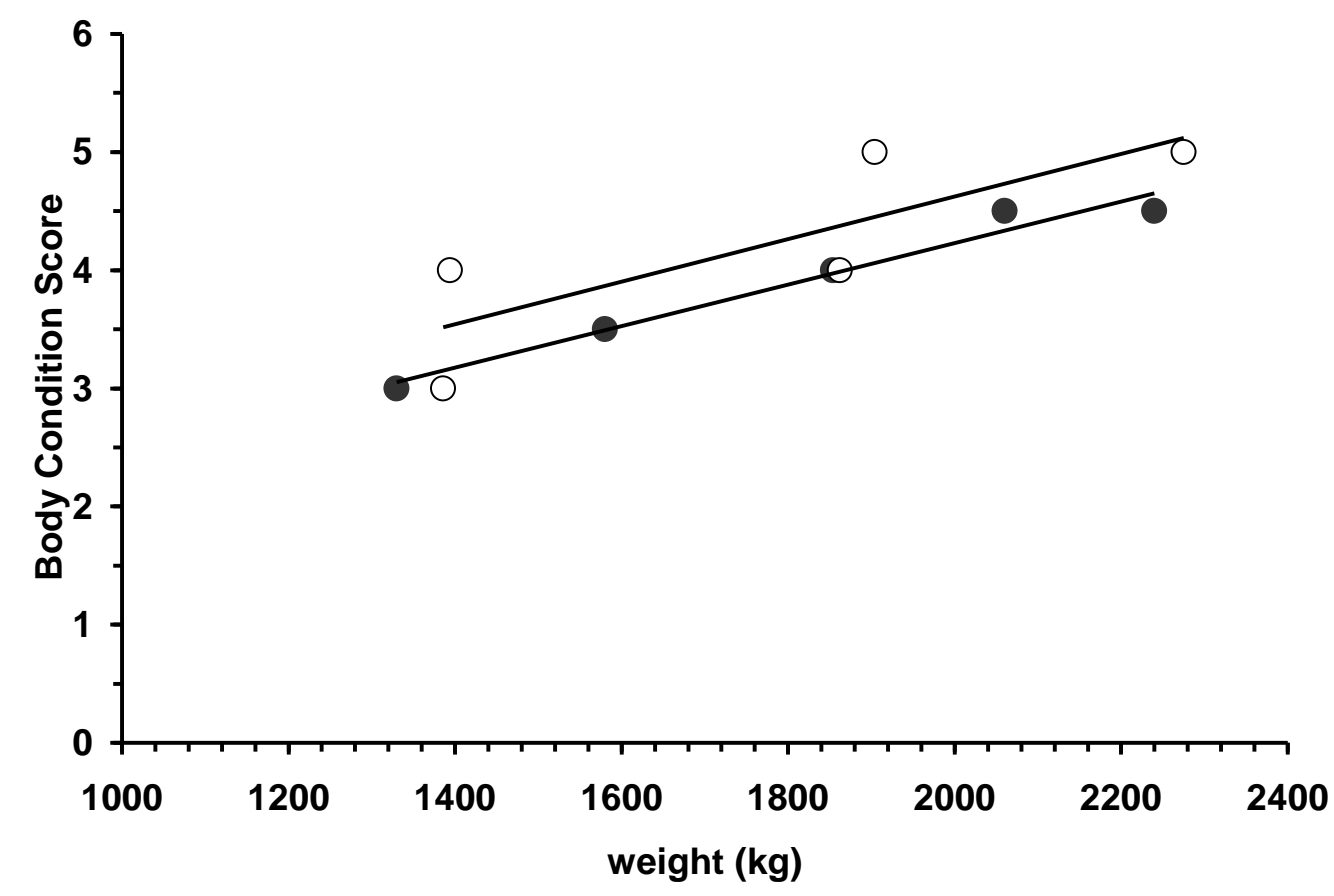

Figure A.5.1. Weights and body condition scores from Captive Male $(\mathrm{n}=5 ; \bullet)$ and Female $(\mathrm{n}=5 ; \circ)$ White Rhinos.

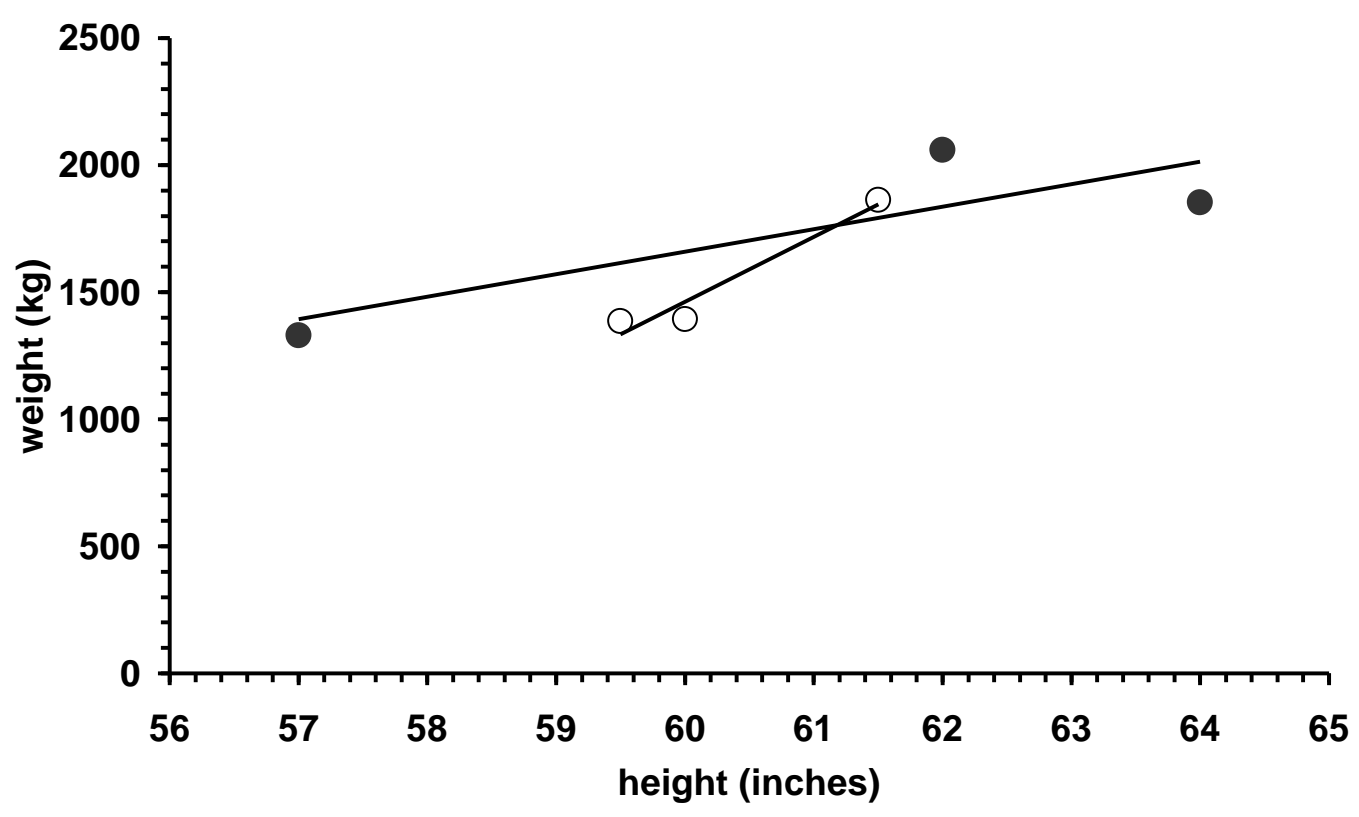

Figure A.5. 2. Weight versus height correlation for white rhinos male $(\mathrm{n}=3 ; \bullet)$ and female $(\mathrm{n}=3 ; \circ)$. 
In August 2007, I tested the PregAlert Pro on three rhinos, two white rhinos at White Oak Conservation Center in Yulee, Florida, and a black rhino at Busch Gardens in Tampa. The machine was in working order and calibrated properly, but could not penetrate the rhinos' skin. We also used a Sonosite Titan ultrasound with harmonics and a $5 \mathrm{MHz}$ transducer which was unable to penetrate the skin (Figure A.5.3).
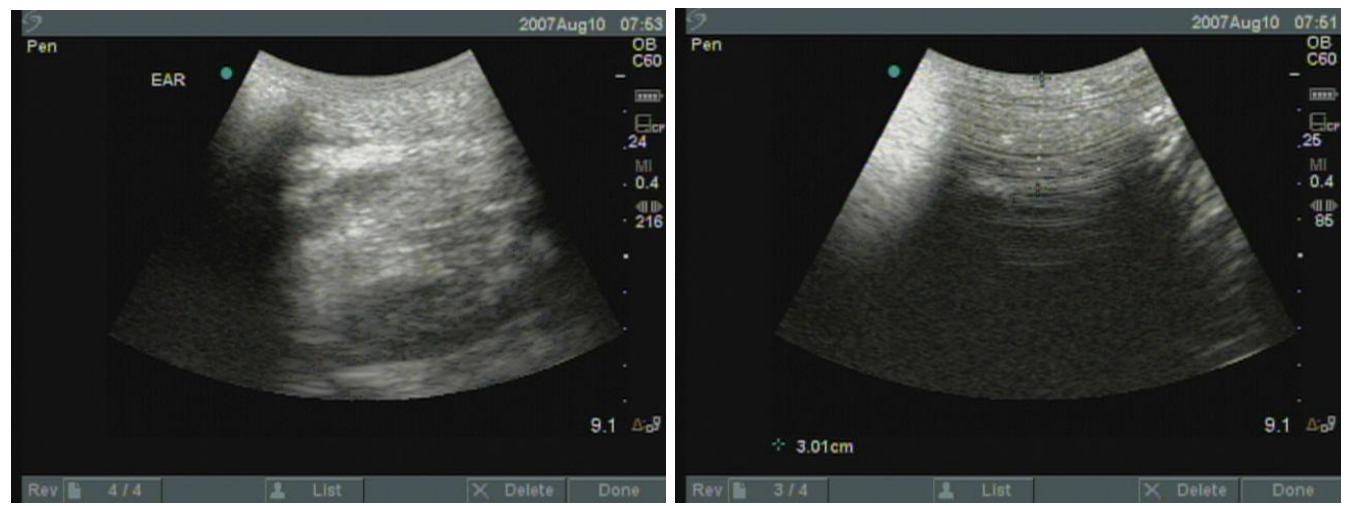

Figure A.5.3. Examples of black rhino B-mode transdermal ultrasound.

The PregAlert Pro was sent back for recalibration. After recalibration, the gain was increased for greater penetration. The results of the second attempt on four white rhinos at Busch Gardens were no better (Table A.5.3).

Table A.5.3. Transdermal A-mode ultrasound results from white rhinos.

\begin{tabular}{llllll}
\hline Rhino & Sex & Weight $(\mathbf{k g})$ & Withers & Tailhead & Flank \\
\hline Mlani & male & - & 13 & - & - \\
Dakari & female & 1390 & 5 & 5 & 5 \\
Lucy & female & 1089 & 7 & 15 & 7 \\
Kisiri & female & 1801 & 13 & 5 & 5 \\
\hline
\end{tabular}




\section{A.6. Discussion}

Ultrasound was not useful for assessing subcutaneous body fat thickness in the rhinos I tested. Unfortunately, the ultrasounds I used were not able to penetrate rhino skin which is up to $10 \mathrm{~cm}$ thick in places (Shadwick, et al., 1998). Lack of an appropriate landmark and inability to compare measurements between methods led to a decision to abandon ultrasonic measurements of body fat thickness until appropriate validations can be performed.

The initial morphometric measurements were encouraging. The data from this will provide insight into the optimal weight and body condition ranges in wild and captive rhinos that optimize reproductive success. Many zoos incorporate scales in their chute or restraint systems. Training of rhinos for handling aids in veterinary treatment and can act as a form of behavioral enrichment.

For future research, I will incorporate age of the rhinos to look at growth pattern differences between sexes both in captivity and in the wild. I suggest comparing morphometric data from wild rhinos with captive rhinos in order to validate the idea that rhinos are overweight and in elevated body condition in captivity. If this is the case, future studies will address how to change diet composition and husbandry practices to manage our captive populations in a manner that keeps them in the same body condition as their wild brethren. 


\section{A.7. References}

Brewer CJ, Balen AH. 2010. The adverse effects of obesity on conception and implantation. Reproduction 140(3):347-364.

Dinerstein, E. 1991. Sexual Dimorphism in the Greater One-Horned Rhinoceros (Rhinoceros unicornis). Journal of Mammalogy, 72(3):450-457.

Ganaie BA, Khan MZ, Islam R, Makhdoomi DM, Qureshi S, Wani GM. 2009. Evaluation of different techniques for pregnancy diagnosis in sheep. Small Ruminant Research 85(2/3):135-141.

Leigh, S.R. 1994. Relations between captive and noncaptive weights in anthropoid primates. Zoo Biology 13(1):21-43.

Reuter, H.-O. and K. Adcock. 1998. Standardised body condition scoring system for black rhinooceros (Diceros bicornis). Pachyderm 26:116-120.

Shadwick RE, Russell AP, Lauff RF. 1992. The structure and mechanical design of rhinoceros dermal armor. Philosophical Transactions of the Royal Society of London Series B-Biological Sciences 337(1282):419-428.

Stephenson, T.R., Bleich, V.C., Pierce, B.M. and G.P. Mulcahy. 2002. Validation of mule deer body composition using in vivo and post-mortem indices of nutritional condition. Wildlife Society Bulletin 30(2):557-564.

Videan, E.N., Fritz, J. and J. Murphy. 2007. Development of guidelines for assessing obesity in captive chimpanzees (Pan troglodytes). Zoo Biology 26(2):93-104.

Appendix B. Changes in circulating glucose after oral glucose administration: a pilot study in the white rhinoceros. 


\section{B.1. Preface}

Repeated blood sampling in unanaesthetised rhinos had not been attempted on such a large scale before and no established protocols existed to give a large oral dose of glucose powder to any captive wildlife species. Therefore, I conducted a small feasibility study on four white rhinos at the Hamilton Zoo and three white rhinos at the Auckland Zoo. These rhinos were unrestrained and able to walk away at any time (Fig. B.1.1). The aim was to see if they would tolerate repeated blood sampling each day and, additionally, which body sites were preferable for drawing blood. The amount of glucose given in this initial study was scaled up to rhino body size based on dosages reported in other studies in pigs and horses.

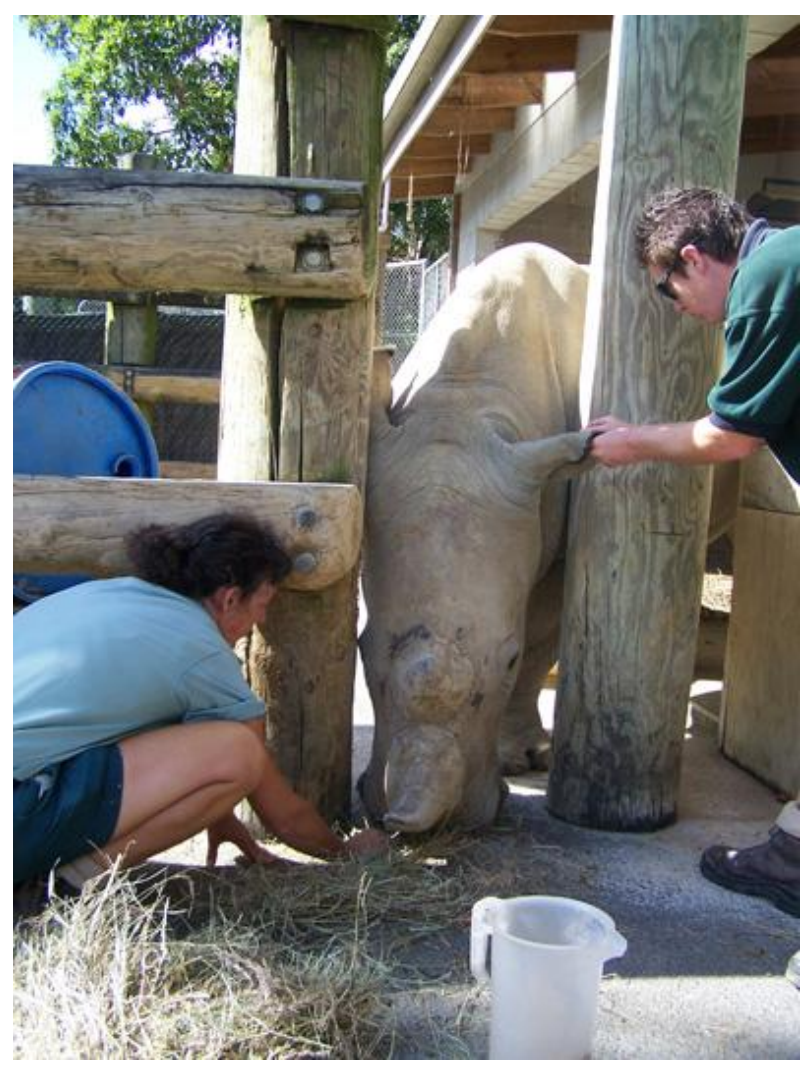

Figure B.1.1: Collecting blood from an unrestrained male white rhino at the Auckland Zoo, Auckland, New Zealand. 


\section{B.2. Introduction}

In order to determine the long-term consequences of exposure to high glucose diets, methods for assessing rhinos' biochemical responses to different diets need to be established. Blood glucose levels at the time of conception are correlated with subsequent offspring sex (Cameron, 2004; Cameron et al., 2008). Operantconditioning has been used to collect blood from unsedated rhinos previously, but for the purpose of the larger dietary trial, I needed to validate that a) rhinos would tolerate repeated blood sampling, and b) an oral dose of glucose would result in a measureable blood glucose response.

\section{B.3. Methods}

Animals: Seven adult white rhinos were used in this study. Four white rhinos (one male, three females) were housed at the Hamilton Zoo (Hamilton, New Zealand). Two male white rhinos, a father and his two sons, kept in a bachelor herd at the Auckland Zoo (Auckland, New Zealand). Their ages ranged from 5 to 20 years. One of the females was lactating.

\section{Blood Collection: Rhinos were trained for blood collection via ear} venipuncture before the study started in order to minimize any stress due to the procedure. The rhino may be in a chute or standing parallel to the bars of an enclosure. If necessary during colder weather, a tourniquet was applied at the base of the ear. Blood was aspirated with a $1 \mathrm{ml}$ syringe and a 23 or 25 gauge needle. Blood glucose concentrations were measured immediately using a handheld glucose meter (Accu-Chek, Roche Diagnostics, New Zealand). Alternately, the skin was pricked 
with a needle and the Accu-Chek test strip held directly to the drop of blood on the rhino's ear.

Five Percent Glucose Tolerance Test: This was a short experiment intended to identify any issues with blood collection, diet palatability, and animal training. The time of the last meal of the day was recorded and the rhino fasted overnight. The following morning the rhino was fed either its normal diet of hay or hay plus glucose powder (5\% dietary energy [DE] of daily diet; Healtheries, Auckland, New Zealand). Blood was collected at the time of first feeding and then 75 minutes later.

B.4. Results

I collected blood from six of the seven rhinos for all tests. One of the young males at the Auckland Zoo would not return to be bled after the initial collection. Average pre-collection blood glucose values for the hay only treatments were $3.4 \pm$ 1.0 s.d. $\mathrm{mmol} / \mathrm{L}$ (range: $2.0-4.4 \mathrm{mmol} / \mathrm{L}$ ), and 75 minutes later the average value was $3.5 \pm 1.0 \mathrm{mmol} / \mathrm{L}$ (range: $3.2-5.44 \mathrm{mmol} / \mathrm{L}$ ). The blood glucose results are shown in Figure B.1. Average pre-collection values for the hay plus glucose powder treatments were $3.2 \pm 0.9 \mathrm{mmol} / \mathrm{L}$ (range: $1.9-4.2 \mathrm{mmol} / \mathrm{L}$ ) and at 75 minutes later the average value was $4.3 \pm 1.4 \mathrm{mmol} / \mathrm{L}$ (range: $2.7-6.2$ ). 


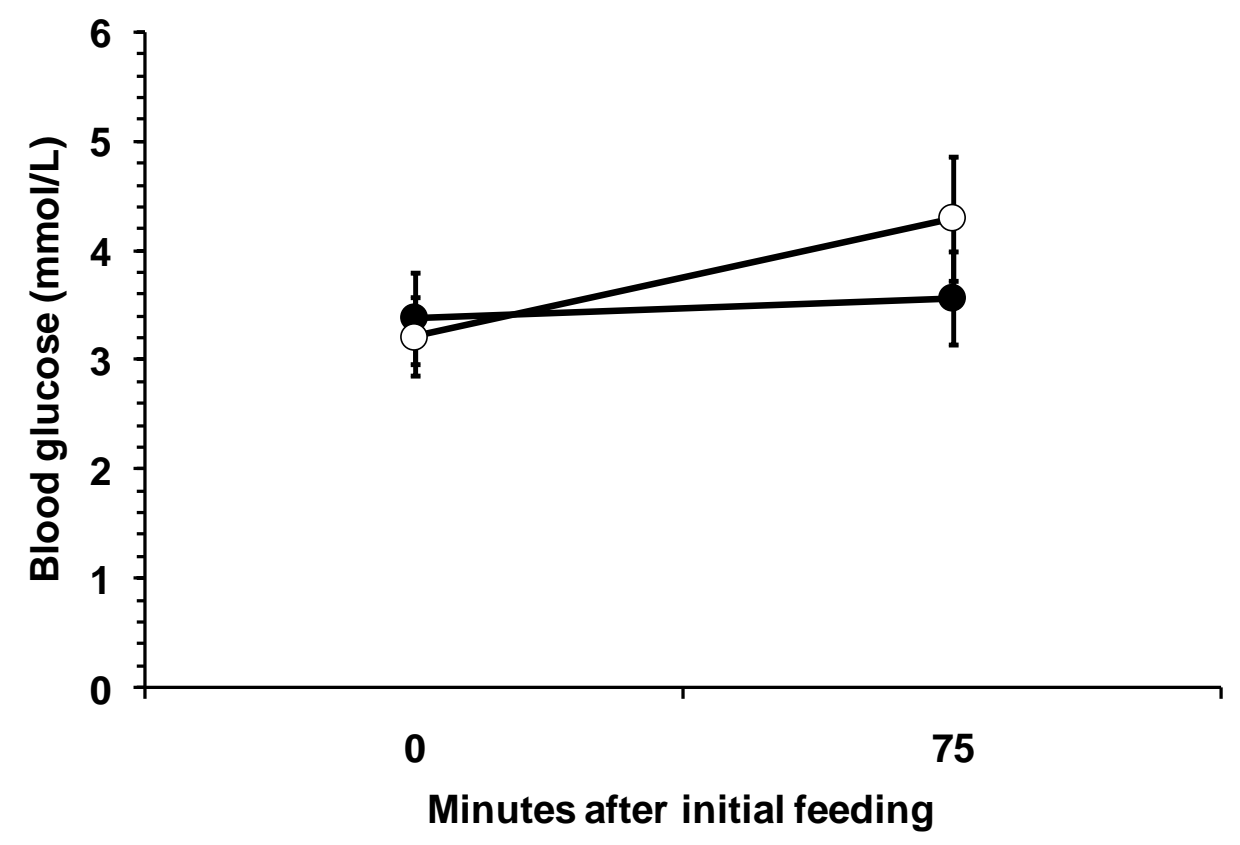

Figure B.4.1. Change in white rhino blood glucose values after eating 5\% glucose (\% of total daily DE intake).

$(\mathrm{o}=$ hay + glucose powder, $\bullet=$ hay only; $\mathrm{n}=6 ;+/$ - s.e.m. $)$.

\section{B.5. Discussion}

With animal cooperation, the handheld glucose meter can provide rapid detection of blood glucose values. The glucose meter values need to be compared to commercial laboratory assays for reliability. 


\section{B.6. References}

Berkeley EV, Kirkpatrick JF, Schaffer NE, Bryant WM, Threlfall WR. 1997. Serum and fecal steroid analysis of ovulation, pregnancy, and parturition in the black rhinoceros (Diceros bicornis). Zoo Biology 16(2):121-132.

Cameron E. 2004. Facultative adjustment of mammalian sex ratios in support of the Trivers-Willard hypothesis: evidence for a mechanism. Proceedings of the Royal Society B-Biological Sciences 271(1549):1723 - 1728.

Cameron EZ, Lemons PR, Bateman PW, Bennett NC. 2008. Experimental alteration of litter sex ratios in a mammal. Proceedings of the Royal Society $B$ Biological Sciences 275(1632):323-327.

Holden MD, Gregory J, Watkins V, Radford L. 2006. Operant-conditioning programme for White rhinoceros, Black rhinoceros and Indian or Greater one-horned Asian rhinoceros Ceratotherium simum, Diceros bicornis and Rhinoceros unicornis at Whipsnade Wild Animal Park, Dunstable, UK. International Zoo Yearbook 40(1):144-149. 


\section{Appendix C. Conference presentations.}

C.1. Berkeley, E.V. and W. L. Linklater: The Effects of Changes in Body Condition on Rhinoceros Birth Sex Ratios: Initiation of a Worldwide Zoo Research Study. In: Proceedings of the 2007 Australasian Regional Association of Zoos and Aquariums, Wellington, New Zealand.

We are inviting zoos to participate in a collaborative study examining the effects of stress and overfeeding on rhinoceros birth sex ratios. Our hypothesis is that increasing levels of stress and nutrition elevate glucose concentrations in female rhinos leading to early female embryo loss resulting in male-biased birth sex ratios. Using non-invasive techniques to monitor serum glucose and faecal corticoids and a slight diet reduction, we will test whether declining body condition will result in more female calves. The intended outcome is to increase the number of female births to help ensure the long-term sustainability of the captive rhinoceros population.

C.2. Berkeley, E.V. and W. L. Linklater: Effects of Diet on Glucose Levels and Subsequent Birth Sex Ratios in Rhino Species, Rhino Keeper Association 5th International Meeting, Melbourne, Australia, May, 2007.

We are inviting zoos to participate in a collaborative study examining the effects of stress and overfeeding on rhinoceros birth sex ratios. Our hypothesis is that increasing levels of stress and nutrition elevate glucose concentrations in female rhinos leading to early female embryo loss resulting in male-biased birth sex ratios. Using non-invasive techniques to monitor serum glucose and faecal corticoids and a slight diet reduction, we will test whether declining body condition will result in more female calves. The intended outcome is to increase the number of female births to help ensure the long-term sustainability of the captive rhinoceros population. 
C.3. Berkeley, E. V. and W. L. Linklater. Assessing Body Condition in Rhinos. Crissey Zoo Nutrition Symposium, Raleigh, North Carolina, December, 2007

Anecdotal evidence suggests that rhinos in captivity are overweight compared to their wild counterparts. Excess weight in captive zoo animals can result in adverse health effects (i.e. inflammatory-mediated diseases) and interfere with captive breeding efforts (Leigh, 1994; Videan, 2007). Regular use of quantitative tools, such as body weight and visual body condition scores, can also provide insight on long-term changes on individual and herd health (Stephenson, et al, 2002). As part of a larger study, rhino health status will be measured using the following parameters: weight, morphometric measurements, A-mode ultrasound of muscle and fat thickness, quantitative body condition, and serum markers.

C.4. Berkeley, E.V. and W. L. Linklater. The Effect of Elevated Body Condition on Birth Sex Ratios in Rhinos. Crissey Zoo Nutrition Symposium, Raleigh, North Carolina, December, 2007.

Male-biased birth sex ratios have been observed for many years in the captive rhino population (Atkinson, 1997). Recent advances in other species, notably mice, domestic cattle and feral horses, led to the theory that sex selection around the time of conception is mediated by glucose (Cameron, 2004, Cameron and Linklater, 2007). As glucose increases due to stress have been hypothesized to affect birth sex ratios in translocated rhinos, it seems reasonable that elevated glucose due to diet could also increase male births (Linklater, 2007). There is additional evidence that 
there are seasonal effects on birth sex ratios in black rhinos (Hrabar and duToit, 2005, Berkeley and Linklater, unpublished). The purpose of the current study is to test whether glucose, through diet, influences birth sex in captive rhinos.

The Trivers-Willard hypothesis states that a female will adjust the sex of their offspring in response to environmental conditions in order to produce the sex that has the greatest potential to reproduce (Trivers and Willard, 1973). This phenomenon has been observed reliably and frequently across taxa for at least 50 years. What has been lacking is an understanding of the mechanism regulating birth sex ratio. Two main theories exist, one pre-conception, one post-conception. The pre-conception theory centers around the idea that steroid hormones (i.e. testosterone) in the developing follicle predispose the maturing egg towards one sex or the other (James, 2004). The post-conception theory proposes that glucose concentrations in the uterus during the time of early embryonic development (preblastocyst stage) differentially effect male and female embryo metabolism with high glucose levels resulting in more male offspring (Gutierrez-Adan, et al. 2006). We can address these conflicting theories by careful experiment design and selection of appropriate serum markers.

C.5. Berkeley, E. V. and W. L. Linklater. Blood glucose profiles in response to different diets in white rhinoceros (Ceratotherium simum). In: Proceedings of the 7th International Conference on Behaviour, Physiology and Genetics of Wildlife, Berlin Germany, September 2009.

Excess dietary glucose may be a factor in several captive rhino diseases and reproductive abnormalities. Glucose limitation or excess around the time of 
conception may also influence selective death of male or female embryos. We may be able to develop dietary strategies to reduce the incidence of reproductive problems in captive rhinos and select the desired offspring sex if we understand the role of glucose in regulating sex at conception. The first step to understanding the role of glucose is to know how dietary glucose changes circulating glucose profiles. The glycemic index has been developed for humans to measure differences in glucose metabolism after eating different foods. This study was undertaken in white rhinos to determine if we could adapt this approach to detect differences in the longevity of a glucose response in the blood, and measure its magnitude in response to different diets. Six white rhinos were fasted overnight then randomly assigned to be fed one of 3 different meals: 1) 10\% DE (daily digestible energy intake, where digestible energy conversion is assumed to be the same as the domestic horse) as lucerne hay, 2) 5\% DE as glucose powder, or 3) $10 \% \mathrm{DE}$ as concentrated horse pellets. Each rhino was fed each of the diets over the course of the study. Before feeding, a resting blood glucose sample was drawn then blood glucose was measured every 45 minutes for three hours using a handheld glucose meter. Area under the curve (AUC) results showed the blood glucose response to the $10 \%$ lucerne diet was $41 \%$ less than the $5 \%$ glucose diet, and $35 \%$ lower than the $10 \%$ pellet diet $(\mathrm{P}<0.05)$. Respectively, AUC values (\% DE +/- s.e.m.) were: 1) 10\% lucerne: 664.5 +/- 14.5; 2) $5 \%$ glucose powder: $1126.5+/-23.6$; 3) $10 \%$ concentrated horse pellets: 1026.8 +/- 66.6. These results indicate that the lucerne in the diet may be insulinotropic, possibly resulting in beneficial health effects for captive rhinos. Further explorations of a) temporal changes in blood glucose in response to captive rhino diets, b) dietary energy variation in wild rhino diets, c) circulating glucose concentrations in free- 
ranging rhinos, and d) the role of glucose in reproductive and pathological processes in all species of rhinos are recommended. 